\title{
Somatization in frequent attenders of general practice : determinants, psychiatric problems, consequences for everyday life and health care utilization
}

Citation for published version (APA):

Portegijs, P. J. M. (1996). Somatization in frequent attenders of general practice : determinants, psychiatric problems, consequences for everyday life and health care utilization. [Doctoral Thesis, Maastricht University]. Universiteit Maastricht. https://doi.org/10.26481/dis.19961218pp

Document status and date:

Published: 01/01/1996

DOI:

10.26481/dis.19961218pp

Document Version:

Publisher's PDF, also known as Version of record

Please check the document version of this publication:

- A submitted manuscript is the version of the article upon submission and before peer-review. There can be important differences between the submitted version and the official published version of record.

People interested in the research are advised to contact the author for the final version of the publication, or visit the DOI to the publisher's website.

- The final author version and the galley proof are versions of the publication after peer review.

- The final published version features the final layout of the paper including the volume, issue and page numbers.

Link to publication

\footnotetext{
General rights rights.

- You may freely distribute the URL identifying the publication in the public portal. please follow below link for the End User Agreement:

www.umlib.nl/taverne-license

Take down policy

If you believe that this document breaches copyright please contact us at:

repository@maastrichtuniversity.nl

providing details and we will investigate your claim.
}

Copyright and moral rights for the publications made accessible in the public portal are retained by the authors and/or other copyright owners and it is a condition of accessing publications that users recognise and abide by the legal requirements associated with these

- Users may download and print one copy of any publication from the public portal for the purpose of private study or research.

- You may not further distribute the material or use it for any profit-making activity or commercial gain

If the publication is distributed under the terms of Article $25 \mathrm{fa}$ of the Dutch Copyright Act, indicated by the "Taverne" license above, 
Somatization in frequent attenders of general practice

Determinants, psychiatric problems, consequences for everyday life and health care utilization

Piet J. M. Portegijs 
The study presented in this thesis was conducted at the Research Institute for Extramural and Transmural Health Care (ExTra), which participates in the Netherlands School of Primary CaRe Research (CaRe), acknowledged in 1995 by the Royal Dutch Academy of Science (KNAW).

ISBN 90-9010076-8

- Bohn Stafleu Van Loghum bv (chapters 2 and 3)

Springer-Verlag (chapter 4)

Oxford University Press (chapter 5)

Piet Portegijs (other chapters)

All rights reserved. No part of this book may be reproduced or transmitted in any form or by any means, electronic or mechanical, including photocopying, recording, or by any information storage and retrieval system without written permission from the publisher, except for the inclusion of brief quotations in a review.

illustration: Chris Voskamp

Cover design: Guus van Rooij (Unigraphic)

graphic advice: Guus van Rooij, Channa Wijnans

printing: Unigraphic 


\section{Somatization in frequent attenders of general practice}

Determinants, psychiatric problems, consequences for everyday life and health care utilization

Proefschrift

ter verkrijging van de graad van doctor

aan de Universiteit Maastricht op gezag van

de Rector Magnificus, Prof. mr. M. J. Cohen,

volgens het besluit van het College van Decanen

in het openbaar te verdedigen

op woensdag 18 december 1996 om 16.00 uur

door

Piet J. M. Portegijs 


\section{Promotor}

Prof. dr. J.A. Knottnerus

Co-promotores:

Dr. H.F. Kraan

Dr. F.G. van der Horst

Beoordelingscommissie:

Prof. dr. F. Sturmans (voorzitter)

Prof. dr. M.W. deVries

Prof. dr. J.Th.M. van Eijk (Vrije Universiteit Amsterdam)

Prof. dr. H. Philipsen

Dr. P.F.M. Verhaak (NIVEL)

The study presented in this thesis was supported by grant no. 920-01-157 from the Netherlands Organization for Scientific Research Council for Medical Research as part of the Incentive Fund Programme for General Practice Research.

Publication of this thesis was made possible by a grant from:

SmithKline Beecham Farma

Oostnederland Zorgverzekeraar 


\section{Preface}

Our western health care system can function only if both patient and physician play their role. Implicitly (sometimes explicitly) it is agreed that the patient should not bother the physician with minor or trivial complaints. The physician should do his (or her) best to find the cause of the symptoms that the patient presents with, and try to take that cause away or at least minimize the consequences. If a patient repeatedly consults his general practitioner with complaints that bother him a lot, and the general practitioner cannot find the cause, both patient and general practitioner may feel guilt as well as anger. The patient may doubt whether he is exaggerating and nevertheless blame the general practitioner; "There has to be something, hasn't it?" The general practitioner may be anxious that he may have overlooked a serious or treatable disorder, while feeling irritated for being bothered for these inconsequential complaints. Thus, illness without (diagnosable) disease, or somatization, is both a health care problem and a strain on the patient - general practitioner relation. Somatization is a rewarding subject for small talk among doctors, and somatizing patients are given many disparaging names ('fat file syndrome', 'crock', 'heart-sink patients'). I doubt if patients, on birthday parties or in the canteen, judge more favourably on their general practitioners.

One might expect that both points of view would be dealt with in an extensive study as presented here. This was hardly possible, however. In most of the analyses presented here we look at the patient from a point of view that is objective in a medical frame of reference (chapter 7 and parts of chapter 8 are exceptions). In the interviews I have done personally, the participating patients have given me some idea on how things look like from their point of view. The stereotypical somatizing patient who denies categorically any relation between psychosocial stressors and his symptoms I have not encountered. I was impressed by the sympathy they had for their general practitioner and the trust they placed in him, while they had received the same explanation for so many complaints they had consulted him for: "Stress". They had to consult their general practitioner because one must do something when complaints interfere too much with daily life. Just like the general practitioner had to see them. They did not expect much good coming out of it and entered the consultation reluctantly, just like the general practitioner. And still they stubbornly tried to make the best of it, together with their general practitioner.

A general practitioner may have the impression that for some of his somatizing patients, the door to his consulting room is a revolving one; no matter what he does to help them out of the consulting room, informed, reassured and optimally treated, they will come back to that room with the same complaint, or a similar one. His efforts just do not make a difference. In the interviews I learned that some somatizing patients had a similar impression. They felt that they never really came in that room, always found themselves outside again 
before they had an explanation for their symptoms, an answer to their worries or a therapy that could put their trust in.

On the cover of this book I could show that the approach chosen in this thesis is only one way to look at the problem. Chris Voskamp drew a cartoon that in my view illustrates beautifully how the patient's view and the general practitioner's view combine to make a vicious circle. My friends and colleagubs seeing all kinds of different meanings in it, I have explained what I meant wit $h$ it here (without pretending that this is the only way to look at it). 


\section{Contents}

1 Introduction

2 What do we call somatization? 1: A search of the international literature for a definition to be used in general practice research

3 What do we call somatization? 2: An answer from the international literature tested against 19 years of 'Huisarts en Wetenschap

4 Somatization in frequent attenders of general practice

5 A troubled youth: Relations with somatization, depression and anxiety in adulthood

6 Somatization and somatic complaints in primary care:

Relations with depression and stress

7 Somatizing patients react very similarly to non-somatizers 103 in everyday life

8 Somatization and health care utilization: A prospective study

9 General discussion

10 Summary

11 Samenvatting

Dankwoord

Curriculum Vitae 


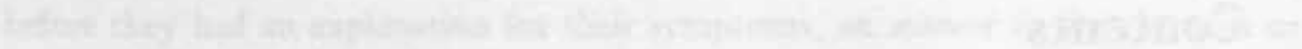

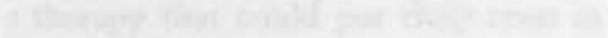

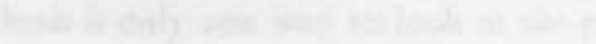

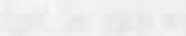

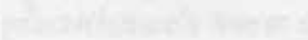

(1)

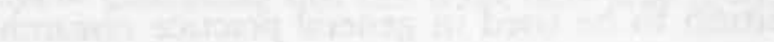

3.

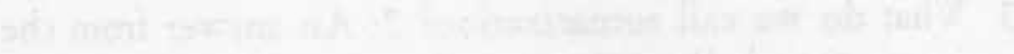

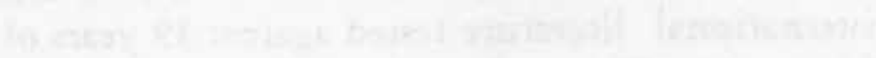

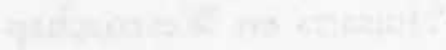

(18)

$4=$

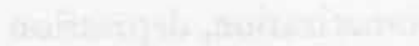

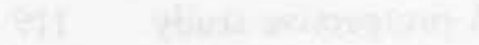

$x^{2}$

(2)

7 


\section{Introduction}

Scientific knowledge on human health, disease and technology to treat disease, grew fast after a shift of paradigm in the $19^{\text {th }}$ century. The humoral pathology with its central metaphor of health as a balance between the four body fluids and of disease as a disruption of that balance, was finally abandoned. The lesion-paradigm of Virchow replaced it: from then on a disease was assumed to be the consequence of a specific defect in a specific body part. The human body became a very sophisticated machine, but with ever better microscopes and medicines, scientific medicine would eventually be able to get to grips with it. The power of this paradigm shift was enormous. How many of the readers were born (or gave birth) with ceasarean section, had bacterial pneumonia, appendicitis, serious trauma and might not have lived to read this thesis without our technological medicine? And how many more were saved from tetanus, malnutrition or tuberculosis through vaccination, environmental sanitation or balanced food? However, this paradigm shift did not apply to the whole field of health and disease; after Descartes an almost unbridgeable gap had come into being between body and mind.

While the lesion-paradigm had been so succesful in explaining disease, in the 1970 s the limits of its domain began to draw attention. It could not explain how one can have complaints without an objective disease: something you can put your fingers on, see through the microscope or see on the monitor. I suppose that, as technological medicine developed, the patients without a diagnosable disorder must have felt more and more abandoned. With many others, they had hoped and waited for a disease to be discovered that would explain their complaints and open the door to effective treatment. That waiting room had emptied fast, and the stigma of malingering (real or perceived) had grown accordingly. Patients and their families might see the link between stress in their life and worsening of complaints, but even that did not provide comfort. What Descartes had split was not easy to rejoin (unlike some non-western cultures, where it is accepted as obvious that conflicts, like a virus, can cause disease. ${ }^{123}$ As a general practitioner I have heard so frequently: "But there's got to be something, doctor?" Psychosomatic disorders, or disease worsened by stress (for instance duodenal ulcer, asthma) are easier to deal with than (subjective) illness without any (objec- 


\section{Chapter 1}

tive) disease. This illness without disease, or somatization, is the subject of this thesis.

In the Netherlands, the general practitioner is in a favourable position to care for somatizing patients: he (or she) can attend to both the somatic and the psychosocial aspects of the patient's problems. He can not refer the patient to either the medical specialist or mental health care. The medical specialist cannot provide much more than a negative conclusion ("no abnormalities within my domain") and symptomatic treatment, with the risk of doctor shopping. The typical somatizing patient resents being referred to a psychiatrist or orher mental health care worker for complaints he (or she) perceives as somatic in origin (which is understandable from his point of view). Psychiatric research is mainly focussed on the small minority of patients whose somatizing behaviour is maladaptive and/or inflexible enough to be called a psychiatric disorder. The scientific discipline of general practice therefore is important for somatization research. Huygen and co-workers at the Nijmegen Universitair Huisartsen Instituut as early as 1974 saw somatic fixation as a core problem in general practice. Their studies have had a large influence on vocational training for general practice, postgraduate education and the medical curriculum.

In the 1980's, it seemed that general practice tried to gain acceptance as a scientific discipline within medicine by concentrating on clearly defined somatic problems. This was a promising approach as far as the specific somatic complaints of somatizing patients were concerned; the clinical guideline Low Back Pain of the Dutch College of General Practitioners can be most helpful to the GP to justify his treatment strategy for chronic low back pain in a somatizing patient and reassure the patient. ${ }^{4}$ However, we doubted whether this approch would add to an understanding of the somatizing patient himself or the process of somatization. Meanwhile, prospects for reseach on somatization were good in 1988. The advent of the DSM-III in 1980 had stimulated psychiatric research on somatization disorder. Findings of these studies raised questions about the much larger group of parients with milder forms of somatization.

\section{The study proposal}

With our study we wanted to gain understanding of the mechanisms that make patients, and somatizing patients in particular, emphasize the somatic aspect of their distress at certain moments or in certain situations. ${ }^{5}$ With the Experience Sampling Method (an adaptation of diary methods) we had a sensitive instrument to measure somatization symptoms and mood in the natural context of everyday life withou interfering too much with daily routine. Having multiple records per parient we would be able to assess how a particular patient reacted (with physical 
complaints and/or bad mood) to certain contexts. Important in its own right and necessary for an interpretation of Experience Sampling results was a detailed description of cross-sectional data. In addition, we wanted to assess the predictive value of cross-sectional and Experience Sampling data for incidence of somatization and prognosis. Thereby we also hoped to validate these findings, and to initiate more detailed studies on prevalence and course of somatization, and through this understanding of mechanisms to studies of specific interventions.

As for the mechanisms mentioned above; we were interested mainly in the relation between somatization and depression and in the relation between somatization and stressors. On a cross-sectional level both relations were wellknown; we hoped to describe them more in detail with our Experience Sampling instrument, and to assess their prognostic significance in the follow-up.

Somatization and depression (that is: DSM-III depressive disorder) are closely related. Somatic symptoms (especially pain) are so frequent in depression that they may be regarded core symptoms. Depression is frequently found in chronic pain patients. Psychiatrists have tended to interpret the depression as the primary disorder: masked or somatized depression. ${ }^{6}$ However, this interpretation is difficult to reconcile with a concept of somatization as a stable trait, while depression typically is an episodic disorder. Is somatization a sequel to a depressive episode, where the depressive mood has cleared but somatic symptoms persist, because of an underlying conflict that has not been solved? If so, more active case-finding of depression by GPs might be worthwhile. And what about the patient who asks "wouldn't you get depressive if you had somatic symptoms everyday like mine?" Elucidating this somatization-depression relation is important; for depression reasonably effective therapies were available.

Most of us have experienced the link between stress and somatic symptoms. Does this imply a link between somatization and stress too? For depression, Brown and Harris had in a series of elegant studies demonstrated that major life events increased risk of depression (onset), especially if in a domain in which the patient already had chronic difficulties. 'With questionnaires developed out of the Brown and Harris interview schedule we were able to assess this relation for somatization without confusing too much stressors with stress symptoms.

Key questions of the study are:

1 What are the relations between somatization and depression, anxiety, unfavourable youth experiences, major life events, chronic difficulties and social support?

2 Do somatizing patients differ from non-somatizers in their reactions (with somatic complaints) to bad mood, daily events (= microstressors) and social support? 


\section{Chapter 1}

3 Do somatizing patients differ from non-somatizers in subjective well-being, health care utilization, specific health problems and quality of physicianpatient communication?

When designing our study, we considered the following: if we would compare somatizing patients to control persons with low medical consumption and no somatic complaints, some results would be pretty obvious. Besides, we wanted our study to yield findings relevant for general practice. With somatic complaints, whether stress-related or caused by self-limiting disease, being an ordinary phenomenon for all of us, the GP is interested in these complaints only if the risk of chronicity, medicalization or iatrogenic harm is high. Therefore the study was performed in a high-risk population: frequent attenders with (a history of) chronic or recurrent abdominal, neck or back complaints. A study in an 'indicated population' like this we judged essential to demonstrate validity and utility of the somatization concept. ${ }^{8}$ In psychiatric research, the use of 'distressed controls' is based on similar grounds. ${ }^{9}$ The second reason for this choice was more practical. Concerning the second question we were most interested whether somatizing patients differed from non-somatizers in their reactions with, or to, somatic complaints. These analyses were possible only if both groups had somatic complaints. The same reason applied for the third question, where analyses of differences in reasons for encounter or physician-patient relation were possible only if both groups attended fairly frequently.

\section{Outline of the thesis}

The thesis has been structured as a series of articles, each with its own introduction, methods, results and discussion. We have tried to make it readable as a whole by having the chapters follow one another as logically as possible, and by avoiding unnecessary repetitions. The research questions introduced above are amplified on in the respective chapters. Methodological aspects are dealt with in the first chapter where they are relevant, with a short summary and reference to this chapter in later ones. Results are discussed in relations to findings of earlier chapters. In the rest of this chapter I will give an outline of the respective chapters.

The most critical (and most likely to be criticized) decision in the design of the study was the choice how to define and operationalize somatization. In chapter 2 and 3 our choice for a definition of somatization as a personality trait and an operationalization virtually identical to Escobars Somatic Symptom Index $4 / 6$ (SSI 4/6) is defended. In chapter 2 we present a semiquantitative analysis of the -then- recent international literature in search of a definition and 
operationalization suitable for research in primary care or open populations. A short inventory of the theoretical models (that is: putative causal mechanisms) of somatization is included. The chapter ends with a plea to clarify the relation between our definiton of somatization and the DSM-III-R somatization disorder by a transfer of the latter from axis I to axis II of DSM-III-R.

Despite the attention for the topic in the Netherlands, a contribution from Dutch general practice was conspicuously absent in the international literature reviewed in chapter 2. Therefore, in chapter 3 we focus on articles published in 19 years of 'Huisarts en Wetenschap' (the scientific journal of the Dutch College of General Practitioners) to see whether this yields any new perspectives on definition of somatization.

Chapter 4 reports on a preliminary study in 80 frequent attenders of general practice on relations between somatization and sociodemographic variables, depressive and anxiety complaints, consultation frequency and health problems as determined by the general practitioner. The reason for this study was that for efficiency reasons we had to be sure that the inclusion criteria would yield a prevalence of about $50 \%$ in the main study. Validating the operationalization of somatization (in a separate study) was incidental.

In chapter 5 and following the main study in 107 patients is reported. Youth experiences are the focus of chapter 5 . First we describe relations of somatization with the two groups of psychiatric disorders most prevalent in general practice (and whose distinction from somatization and from each other is sometimes vague): depressive and anxiety disorders. Then relations between youth experiences (illness experiences, deprivation of parental care, sexual or physical abuse and other life events) and somatization, depressive disorders, anxiety disorders and combinations of the three are reported. Finally analyses are presented on the question whether unfavourable youth experiences in general are related to problems in adult life, or specific youth experiences are related to specific problems later. The chapter ends with a plea that general practitioners pay attention to unfavourable youth experiences; be attentive to their possible presence in children, record them (or their signals) carefully, and invite (and help) adult patients with somatization, depression or anxiety to disclose them.

Chapter 6 deals with the theme of chronicity - lifetime somatization versus somatic complaints in the previous week - in relation to stress. Following Brown and Harris' studies on incidence of depressive episodes, we operationalized stress as major life events, chronic difficulties and (lack of) social support. The association somatization-depression is further explored by analyzing relations of recent and lifetime/chronic manifestations of both (somatic complaints, lifetime somatization, depressive complaints, recent depressive disorder, lifetime depressive disorder and dysthymic disorder). In multivariable analyses we analyzed which youth experience and stress variables were independent predictors of 


\section{Chapter 1}

somatization. The chapter ends with a discussion of the merits of various conceptualizations of the term 'somatization'.

In chapter 7 we go over a single week in the life of the participating patients with the fine-tooth comb of the Experience Sampling Method. In this adaptation of diary methods the patient wears a wristwatch that gives an auditory signal up to ten times a day, at unexpected moments. The patient then fills in a short questionnaire on how he was doing the very moment before he heard the signal (what he thought, how he felt, what he was doing, where he was, etc.). We were interested in differences between somatizing and non-somatizing patients as to complaints (both physical and psychological) and context variables (thoughts, activities, places, etc.). The core of the chapter is the analysis on differences between somatizing and non-somatizing patients in their reactions (with physical and psychological complaints) to these contexts.

In chapter $\mathbf{8}$ results of the prospective part of the study are reported. The patients had filled in postal questionnaires on complaints, life events, chronic difficulties and absenteeism 8 and 16 months after the initial interview. Both patients and general practitioners had filled in short questionnaires after each consultation. And the general practitioners gave summary data from the medical records and their assessment of somatization in the patients. The focus of the chapter is on the impact of somatization: on subjective well-being (over a longer period than in the earlier chapters), illness behaviour (absenteeism, medical consumption) and on the doctor-patient relation. In addition, construct validity of our operationalization of somatization and of the general practitioner's assessment of somatization are compared, and - limited - data on prognosis are presented.

In chapter 9 we join conclusions of earlier chapters together into a more or less coherent picture of 'the' somatizing patient. Some methodological aspects are discussed more fully. We go into the relations between somatization and somatic fixation, and give some recommendations for practice and research.

In The thesis is summarized in chapter 10.

De Nederlandse samenvatting staat in hoofdstuk 11.

\section{References}

1 Kirmayer LJ. Culture, affect and somatization: Part 1. Transcultural Psychiatric Research Review 1984; 21: 159-188

2 Tousignant M. Pena in the Ecuadorian sierra: A psychoanthropological analysis of sadness. Cult Med Psychiatry 1984; 8: 381-389

3 Kleinman AM. Depression, somatization and the 'new cross-cultural psychiatry'. Soc Sci Med 1977; 11: 3-10

4 Faas A, Chavannes AW, Koes BW, Hoogen JMM van den, Mens JMA, Smeele LJM, Romeinders ACM, Laan JR van der. NHG-Standaard Lage-Rugpijn [Clinical 


\section{Introduction}

Guideline Low Back Pain of the Dutch College of General Practitioners]. Huisarts en Wetenschap 1996; 39: 18-31

5 Kraan HF. Somatisatie in het dagelijks leven: Een huisartsgeneeskundig cohortonderzoek [Somatization in daily life: A cohort study in general practice]. Maastricht, Universiteit Maastricht; 1988 [study proposal]

6 Bridges KW, Goldberg DP. Somatic presentation of DSM-III psychiatric disorders in primary care. J Psychosom Res 1985; 29: 563-569

7 Brown GW, Harris TO. Social origins of depression: A study of psychiatric disorder in women. London, Tavistock Publications; 1978

s Dinant GJ, Knottnerus JA, Van Wersch JW. Discriminating ability of the erythrocyte sedimentation rate: A prospective study in general practice. Br J Gen Pract 1991; 41: 365-370

9 Dijkman-Caes CIM. Panic disorder and agoraphobia in daily life [thesis]. Maastricht, University of Limburg; 1993 
Chapter 1 


\section{What do we call somatization?"}

\section{1: A search of the international literature for a definition to be used in general practice research}

\section{Abstract}

A definition of somatization for patient-centred research on somatization in general practice should be more comprehensive than the DSM-III-R definition of somatization disorder. It should be easily operationalized. A survey of the recent international literature was done by searching the Index Medicus. In 80 percent of papers somatisation was defined as DSM-III-R somatization disorder. The remaining papers - mostly related to primary health care - conceptualized somatization as a continuum, from a normal psychologic mechanism (in most persons), to a psychiatric disorder in extreme cases.

These so-called continuum definitions were more suitable for research in general practice. A more comprehensive version of the DSM-III-R somatization disorder definition (the Somatic Symptom Index, or SSI) appeared to be the best for use in general practice. The relation with DSM-III-R somatization disorder could be clarified if the latter were moved from axis I to axis II of DSM-III. Personality traits (not meeting the criterion of 'psychiatric disorder') can be recorded on axis $\Pi$. The structure of the DSM-III-R and empirical data suggest that such a move would be possible.

Published as: Portegijs PJM, Kraan HF, Knottnerus JA, Stoffers HEJH. Wat heet somatisatie? 1: E.en zoektocht in de internationale literatuur naar een definitie voor huisartsgeneeskundig onderzoek. Huisarts en Wetenschap 1992; 35: 18-25,43 


\section{Chapter 2}

\section{Introduction}

Most general practitioners (GPs) are frequently confronted with patients presenting somatic complaints that these patients themselves attribute to somatic disease, but where nonetheless no somatic disease can be demonstrated. Often there are indications that psychological stress or conflict plays a role in development or persistence of these complaints. This phenomenon, called somatization here, poses an important problem in health care. ${ }^{1}$

Because the GP cannot produce a satisfactory somatic explanation nor give an satisfying treatment of these complaints, these patients will request further investigation and treatment by a somatic specialist. Such a referral has several disadvantages: diagnostic procedures can give complications, false positive tests can lead to unnecessary treatment with its associated disadvantages. Furthermore, there is a chance that the patient, instead of being reassured by the investigations, is even more convinced that something is wrong with his/her body. The somatic specialist is powerless against this conviction; the specialist can prove disease, not health. The GP will be more inclined to refer these patients to mental health care. This is often not acceptable to the patients, however, because they are not aware of any psychosocial problem. Therefore somatization is a problem best approached from the general practice point of view.

At the start of the 1970s, workers of the Nijmegen University Department of General Practice developed the concept of 'somatic fixation'. This concept was based on long-term observation of families and on social scientific insights in information processing and communication patterns within relationships. Since then, many studies have been done on the possibilities of GPs to prevent somatic fixation or at least not aggravate it. The results of this research have had a large influence on professional training and post-graduate education in general practice. $^{2}$

Somatic fixation was defined in 1978 as: "... a reduction of more comprehensive problems to merely medical-somatic ones in the interaction between physician and patient." ${ }^{n 3}$ It is a problem that by definition arises in the physicianpatient interaction and that can only be assessed by observation in the consulting room.

In empirical research, this direct observation is often difficult to perform. Maybe this is the reason why, in the past ten years, studies have been done primarily on somatization as a characteristic of the patient instead of the physician-patient interaction. Most of these studies were performed by psychiatrists, and in psychiatric populations. These studies have been encouraged by the introduction of the 'Diagnostic and Statistical Manual of Mental Disorders, third edition' (DSM-III) as the official psychiatric classification in the United States. 
Table 1: Symptom list of DSM-III-R somatization disorder (1987)

\section{Gastrointestinal symptoms:}

1 vomiting (other than during pregnancy)

2 abdominal pain lother than when menstruatingl

3 nausea (other than motion sickness)

4 bloating (gassy)

5 diarrhea

6 intolerance of (gets sick from) several different foods

\section{Pain symptoms:}

7 pain in extremities

8 back pain

9 joint pain

10 pain during urination

11 other pain (excluding headaches)

\section{Cardiopulmonary symptoms:}

12 shortness of breath when not exerting oneself

13 palpitations

14 chest pain

15 dizziness

Conversion or pseudoneurologic symptoms:

16 amnesia

17 difficulty swallowing

\section{8 loss of voice}

19 deafness

20 double vision

21 blurred vision

22 blindness

23 fainting or loss of consciousness

24 seizure or convulsion

25 trouble walking

26 paralysis or muscle weakness

27 urinary retention or difficulty urinating

Sexual symptoms for major part of the person's life after opportunities for sexual activity:

28 burning sensation in sexual organs or rectum (other than during intercourse)

29 sexual difference

30 pain during intercourse

31 impotence

Female reproductive symptoms judged by the person to occur more frequently or severely than in most women:

32 painful menstruation

33 irregular menstrual periods

34 excessive menstrual bleeding

35 vomiting throughout pregnancy

DSM-III gives criteria for the diagnosis 'somatization disorder', which are specified as follows (in the revised version of 1987):

* A history of many physical complaints, a belief that one is sickly, beginning before the age of 30 and persisting for several years.

* At least 13 symptoms from a list of somatization symptoms (see table 1) that cannot (or only partly) be explained by organic pathology or pathophysiologic mechanisms, and have caused the patient take medicine (other than over-the-counter medication), see a physician, or alter his/her life-style. ${ }^{4}$ 


\section{Chapter 2}

Somatization disorder is an empirically defined concept and does not, according to the authors of the DSM-III, imply a specific theory of somatization. ${ }^{5}$

The definition of somatization disorder applies to a small group of patients with an obvious psychiatric problem. Prevalence of this diagnosis in women in the United States is estimated to be $0.3 \%$ in the general population, and $0.6 \%$ in those who visit their GP. ${ }^{6,7}$

The prevalence of milder forms of somatization is unclear. Huygen et al. estimate that 'chronic nervous functional complaints' play a part in $18 \%$ of consultations with the GP. ${ }^{1}$ In other studies, both higher $(70 \%)$ and lower (5\%) rates were found. ${ }^{8}$ Probably prevalence is fairly high.

With the support of the 'NWO Incentive Fund Programme for General Practice Research', we have started a study on relations between these milder forms of somatization on the one hand and depression, anxiety disorders, major life events, social support and alexithymia (inability to express emotions) on the other.

For a study like ours, a definition of somatization that fits within the frame of reference of the GP is indispensable. That definition must meet a minimum of three demands:

* usable within a general practice population;

* comparable with definitions used in relevant (often psychiatric) studies;

* operationalizable for patient-centred research: the definition, formulated on the theoretical level, has to be easily translated in criteria that can be tested in empirical research.

The 'real' DSM-III-definition is not usable, as it applies to extreme cases of somatization only. In a systematic literature study, we have searched for an alternative, using the following study questions:

* Which types of definitions of somatization can be distinguished in the recent literature?

* How often and in what circumstances are these types of definitions used?

* What other characteristics of somatization are mentioned?

* How are these types of definitions operationalized?

\section{Literature}

A search was conducted of the Index Medicus using the keyword 'somatoform disorders' for the period 1983 - August 1988. This produced 548 articles in 220 journals.

In the Maastricht University library 95 journals were available with a total of 327 articles. Of the 125 journals that were not available, one-third was psychiatrically oriented, the rest concerned mainly somatic specialisms. Often 
these were foreign journals with a national readership. For practical reasons, we refrained from requesting these articles from other libraries. Furthermore, 25 less important psychiatric journals and 8 journals that were difficult to classify were removed from the selection. We ended with 62 journals, four of which were GPoriented and 7 general medical journals. These included 258 articles, 144 of which dealt with somatization.

The definitions of somatization in these 144 articles were classified. Unavoidably, information was lost in this process: therefore, we also assessed what other characteristics of somatization were mentioned. Then we recorded how these definitions were operationalized for research. Finally, the type of article (research article, review, letter, etc.), the population involved and the professional orientation of the first author were documented.

\section{Types of definitions}

Definitions of somatization found in the literature could be classified from two angles:

1 Definitions that interpret somatization as a psychiatric disorder ('disorder definitions') versus definitions that presuppose a continuum of somatization, from a normal psychological mechanism to a psychiatric disorder ('continuum definitions'). A continuum definition, therefore, includes, apart from the extremely somatizing patients, somatizing patients who would not be labelled as suffering from a psychiatric disorder, who nevertheless are at risk for superfluous diagnostic procedures and therapies.

2 Definitions that link the complaints with psychosocial problems versus definitions that do not. If such a link is made in a definition, this gives the opportunity to distinguish between patients with a mild form of somatization and patients with not yet recognized somatic disease. A priori, definitions wherein this link is made are the most relevant for research in a general practice, as milder forms of somatization are most prevalent here.

\section{Prevalence of types of definitions}

In $78 \%$ of the articles a disorder definition is used, while a continuum definition is used in the remainder (see Table 2). Remarkably, with the disorder definitions rarely $(18 \%)$ is a link with psychosocial problems mentioned. With the continuum definitions this is more frequent $(63 \%)$.

In $71 \%$ of the articles that present results of quantitative research, it is a disorder definition without a link to psychosocial problems that is used. In 
Chapter 2

Table 2: Types of definitions of somatization (absolute numbers)

disorder continuum total

without relation with

77

10

87

psychosocial problems

with relation with

17

17

34

psychosocial problems

total

94

27

121

23 articles without (classifiable) definitions excluded

scientific reviews and editorials as well as other publications (letters, post-graduate education, article, etc.) other types of definitions are used more frequently (see Table 3).

In secondary and tertiary care populations (both in psychiatry and in somatic specialties) mainly disorder definitions are used $(88 \%)$, while this is less frequent $(59 \%)$ in general populations and primary care populations (see Table 4).

A comparable picture emerges when we look at the professional background of the first author (see Table 5). However, the majority of the articles are written by psychiatrists, not only in psychiatric but also in other populations.

\section{Other characteristics}

In virtually all disorder definitions, characteristics are mentioned that correspond with the description of somatization disorder in the DSM-III. The emphasis is placed on the large number and the diversity of complaints, the dramatic and/or vague presentation and the absence of a somatic explanation. The start of the disorder at an early age, the chronic and/or recurrent course and the relation with psychological factors or conflicts are also fairly often mentioned. Causal factors or therapeutic options are rarely discussed.

Most authors who use a continuum definition argue that somatization can be both a situation-dependent reaction and a stable personality characteristic. Additionally, the absence of an (adequate) somatic explanation for the complaints and the dependent and demanding behaviour of the patient are frequently mentioned. Somatization is fairly often interpreted as an expression of psychosocial distress. ${ }^{10}$ Authors of various theoretical orientations mention that major life 


\section{Definitions of somatization in the international literature}

Table 3: Types of definitions of somatization and types of articles they are mentioned in (percentages)

$\begin{array}{llll}\begin{array}{l}\text { research } \\ \text { article }\end{array} & \begin{array}{l}\text { review or } \\ \text { editorial }\end{array} & \text { other } & \text { total } \\ n=68 & n=19 & n=34 & n=121^{\circ}\end{array}$

disorder without

71

52

55

64

rel. psych. problem

disorder with

10

16

21

14

rel. psych. problem

continuum without

9

16

3

rel. psych. problem

continuum with

10

16

21

14

rel. psych. problem

23 articles without (classifiable) definition excluded

events (serious disease, marriage, change of job, for instance, or stress in general) can provoke somatization."

With the continuum definitions causal mechanisms usually are mentioned, especially cognitive, behavioural or communicative ones. Psychodynamic theories are cited less often.

According to the cognitive model, somatizing patients perceive physical sensations more strongly than the affective component when emotionally upset, are preoccupied with these sensations and interpret them as signs of disease. ${ }^{\text {to }}$

In behavioural models, explanations are proposed from an individual perspective, in which somatization serves to obtain social support to avoid intimacy or frightening situations, for instance. Other behavioural models focus on the community. In this view, somatization is an effective means to manipulate scarce resources of social power and to influence an inequitable distribution of available means. ${ }^{11}$

One step further is the concept of somatization as a language, a form of communication that is meaningful for the community or culture: somatization as

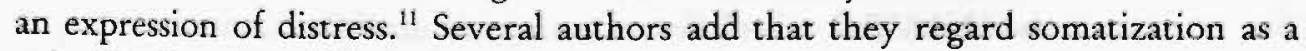
primitive language. ${ }^{12,13}$

This notion resounds through the psychodynamic view that somatization can be the result of alexithymia (inability to express emotions). ${ }^{10}$ The suggestion of 


\section{Chapter 2}

Table 4: Types of definitions of somatization and populations studied (percentages)

\begin{tabular}{llllll} 
& $\begin{array}{l}\text { general } \\
\text { population } \\
n=10\end{array}$ & $\begin{array}{l}\text { primary } \\
\text { care } \\
n=27\end{array}$ & $\begin{array}{l}\text { psychiatry } \\
n=43\end{array}$ & $\begin{array}{l}\text { somatic } \\
\text { specialist } \\
n=31\end{array}$ & $\begin{array}{l}\text { total } \\
n=111^{*}\end{array}$ \\
\hline $\begin{array}{l}\text { disorder without } \\
\text { rel. psych. problem }\end{array}$ & 60 & 40 & 74 & 78 & 66 \\
$\begin{array}{l}\text { disorder with } \\
\text { rel. psych. problem }\end{array}$ & 0 & 19 & 16 & 6 & 13 \\
$\begin{array}{l}\text { continuum without } \\
\text { rel. psych. problem }\end{array}$ & 10 & 15 & 5 & 3 & 7 \\
$\begin{array}{l}\text { continuum with } \\
\text { rel. psych. problem }\end{array}$ & 30 & 26 & 5 & 13 & 14
\end{tabular}

33 articles without (classifiable) definition or population unspecified excluded

somatization as a 'primitive' defense mechanism also originates in psychodynamic quarters. ${ }^{13}$ However, the continuum definitions are a more heterogeneous group than suggested in this overview.

\section{Operationalizations}

For disorder definitions, the DSM-III-R criteria for somatic disorder are the operationalization. These criteria are further elaborated in measuring instruments, of which the Diagnostic Interview Schedule is most frequently used. ${ }^{14}$

The continuum definitions are phrased on a theoretical level: they contain no empirical criteria. It is remarkable that with these definitions usually no operationalization of the theoretical concept is given, while a translation into a measurable criterion is of major importance here. The operationalizations that are given lack a clear common denominator. Only one operationalization is mentioned more than once: Escobar's. ${ }^{15}$ This operationalization is a more comprehensive version of the DSM-III-R criteria for somatization disorder: four (for men) or six (for women) symptoms are required instead of 13 . 


\section{Definitions of somatization in the international literature}

Table 5: Types definition of somatization and professional orientation of the first author (percentages)

$\begin{array}{lllll} & & \text { somatic } & \text { other e } \\ \text { GP } & \text { psychiatrist } & \text { specialist } & \text { lunknown } & \text { total } \\ n=4 & n=91 & n=10 & n=16 & n=121 *\end{array}$

disorder without

50

66

80

44

64

rel. psych. probiem

disordet with

0

15

20

6

14

rel. psych. problem

continuum without

$0 \quad 10$

0

6

8

rel. psych. problem

continuum with

50

9

44

14

rel. psych. problem

\# if not mentioned, department or institute

@ most of them social sciences

* 23 articles without (classifiable) definition excluded

\section{Interim conclusions}

The types of definitions we found in our literature study indicate the most important choices that have to be made in the development of a definition of somatization for general practice research.

The first question is whether somatization should be defined as a psychiatric disorder per se or as a psychological reaction that only in extreme cases indicates psychiatric disorder (continuum definition). The second question is whether a relation of complaints and psychosocial problems should be included in the definition.

If we want to follow the international literature, the choice is obvious: in 80 $\%$ of the articles the DSM-III somatization disorder definition is used, usually without a relation with psychosocial problems (in the definition). If we look for the best definition for GP research the results are less clear, however. The 


\section{Chapter 2}

DSM-III definition without psychosocial problems is noticeably often used in articles on quantitative research. This cannot be attributed to a higher 'scientific quality' of these articles; we think the lack of a generally accepted operationalization of a continuum definition is a more likely cause. In scientific reviews and editorials, that accurately reflect developments in theory, we often found a continuum definition and/or relation with psychosocial problems.

This explanation is supported by the critical comments of several authors who opt for a disorder definition. They see the DSM-III somatization disorder as a valid diagnostic entity, but feel that its criteria are too restrictive; milder forms of somatization cannot be identified. ${ }^{15,16}$ Authors who choose a continuum definition, add that somatizing patients should be treated and looked after principally in primary care. ${ }^{7}$ Somatization, defined according to a continuum definition, in this view should be an important theme for GP research.

Another point of criticism is that somatization disorder is difficult to delineate from other somatoform disorders (for example hypochondriasis), mood and anxiety disorders. ${ }^{15,18}$ So supplementary criteria are required to distinguish between somatization and other psychiatric disorders or somatic disease.

As may be expected, we find a continuum definition with a relation to psychosocial problems more often in articles concerning general populations or primary care populations.

The other characteristics that are mentioned with the two types of definitions differ so much that one may wonder whether these definitions concern the same problem. This discrepancy results from the narrow definition of somatization disorder as a problem that starts early in life and essentially remains unchanged throughout the greater part of adulthood. In the serious forms of somatization that satisfy this definition, original causal factors lie in the distant past (usually it is diagnosed after years of complaining), prognosis is known (chronic/recurrent course), and chances of an intervention influencing prognosis appreciably are meagre. Causal factors or therapeutic possibilities are rarely discussed in disorder definition articles; their study would require a follow-up period of many years. And if therapy is discussed, it is guidance more than treatment. ${ }^{19,20}$

In milder forms of somatization, defined according to a continuum definition, etiological and intervention studies are possible, and we see this in the other characteristics too. However, as yet, these etiological factors cannot be included in a definition. If an etiological factor were included, that factor would always be present (by definition) and subsequent study of its influence would be impossible. The diversity of the causal mechanisms mentioned proves that these mechanisms are not much use at the moment as elements of a definition of somatization.

The relation with psychosocial problems too presents difficulties (at least for empirical studies). Although this relation is often mentioned with continuum 
definitions, the other characteristics show that these psychosocial problems are sometimes taken to mean psychosocial distress, sometimes major life events and sometimes stress in general.

The large differences between the continuum definitions also appear in the operationalization. Only the operationalization of Escobar et al. has been tested empirically and proven useful for research. ${ }^{15}$ A preliminary study of this criterion (not yet published) supported its validity. We found a strong relation between somatization and depression and gender (women somatized more frequently). Somatizing patients had complaints since the age of 14 years (mean); nonsomatizers since they were 23 years old.

Our conclusion is that for general practice research a continuum definition holds more promise than a disorder definition. A relation with psychosocial problems is plausible, but this relation has not been studied thoroughly enough for it to be included in a definition. Knowledge of causal mechanisms too is insufficient for these mechanisms to be included in a definition. So the definition has to be a descriptive one. The more comprehensive version of the DSM-III criterion by Escobar et al. qualifies as an operationalization.

\section{Towards a definition for general practice}

What do these results - based on mainly psychiatric literature - mean for general practice research?

GPs could say that somatization in general practice is something different from somatization as seen in psychiatry, and develop their own definition for use in primary care. If this resulted in two definitions unrelated to each other, this would have some clear disadvantages:

* The many studies on somatization carried out in psychiatry in recent years would not be very useful for hypothesis-generation for GP research.

* Research into etiological factors, prognostic factors and effectiveness of interventions in general practice would not be very useful for hypothesisgeneration for psychiatric research.

* It would be impossible to assess to what extent referral patterns of GPs influence the study population of psychiatric studies - and consequently distort results (selection bias).

* Both in research and in patient care, communication problems might arise between GPs and psychiatrists. The importance of a common language is

"in the meantime it has been published; chapter 4 . 
illustrated by the multidisciplinary character of the topic: most psychiatrists publish on non-psychiatric populations.

A definition of somatization for general practitioners, therefore, should be closely related to the DSM-III on the one hand, but less restrictive on the other. An operationalization for this is available, but there is a problem on the theoretical level of the definition itself: how can a link be made between a GP continuum definition and a psychiatric disorder definition?

In theory, the DSM-III presents a solution with its multiaxial structure. Axis I (see appendix), on which psychiatric disorders in the narrow sense are classified, is the most widely known. On Axis II stable personality characteristics are classified. These personality characteristics can be inflexible or maladaptive enough to be considered psychiatric disorders (personality disorders), but they can also be within the range of normal functioning (personality traits). On Axis II a disorder definition of somatization (personality disorder) and a more comprehensive continuum definition (personality trait or disorder) could be connected with each other.

The present DSM-III somatization disorder, however, is placed on Axis I, the psychiatric disorders in the narrow sense. So this solution is only possible if the somatization disorder is moved to Axis II and designated a personality disorder. The question is: does the somatization disorder fit on Axis II?

To answer this question, we once again studied the literature. The structure of DSM-III, its historical development, and criticisms were studied. Furthermore, we searched for empirical data on the relation between somatization disorder and personality disorder.

\section{Somatization to Axis II: a theoretical argument}

The DSM-III (and its predecesor DSM-II) is the official classification of the American Psychiatric Association (APA) and is designed to be used for thirdparty reimbursement as well. ${ }^{5}$ An a-theoretical approach was necessary to make the classification acceptable for clinicians of various theoretical orientations. Based on empirical research, disorders were defined and grouped in such a way that homogeneous patient groups arose. So the division in Axis I and Axis II disorders is not based on an explicit theoretical model. DSM-III only states that "this separation ensures that consideration is given to the possible presence of disorders that are frequently overlooked when attention is directed to the usually more florid Axis I disorder." The president of the 'task force' that developed the DSMIII further substantiated this division with the comment that in the field tests a 
majority of respondents (clinicians) thought that the division in two axes was useful. ${ }^{21}$

The definitions of personality traits (Axis II) and psychiatric disorders (Axis I or II) included in DSM-III bring more clarity. A personality trait is defined as an "enduring pattern of perceiving, relating to, and thinking about the environment and oneself". A psychiatric disorder is defined as a "clinically significant

behavioral or psychological syndrome or pattern that occurs in an individual and that is typically associated with either a painful symptom (distress) or impairment in one or more important areas of functioning (disability). In addition, there is an inference that there is a behavioral, psychological, or biological dysfunction, and that the disturbance is not only in the relationship between the individual and society." A personality disorder is a personality trait that also satisfies the definition of a psychiatric disorder; "(...) inflexible and maladaptive and cause either significant impairment in social or occupational functioning or subjective distress. ${ }^{55}$ Personality characteristics (and personality disorders) are always classified on Axis II.

Somatization is not necessarily an expression of a dysfunction, but can also be regarded as a biological or psychological adaptive mechanism that falls within the limits of the normal. Moreover, somatization does not necessarily cause subjective distress or impairment in the routine of everyday life. ${ }^{22}$ Translating psychosocial problems into somatic symptoms can make these problems more bearable or can be a way to function reasonably well despite these problems. ${ }^{23}$ Physical complaints, for example can amount to an excuse. If distress or impairment in functioning is not necessarily present in somatization, then somatization no longer fits in the definition of a psychiatric disorder cited above.

Somatization always fits within the definition of a personality trait. Whether it also falls within the definition of a personality disorder then depends on how fixed or maladaptive the somatizing behaviour is.

When DSM-III was introduced in 1980 , it was emphasized that the manual was no more than an intermediate step and an attempt to understand psychiatric disorders better. ${ }^{5}$ The various criticisms of and suggestions for revisions of DSMIII generally support a transfer of somatization to Axis II. A plea has been made for a clearer conceptualization of Axis II in relation to Axis I, with more attention for personality traits of the patient besides personality disorders. ${ }^{24}$ Williams, who was closely involved in the development of the DSM-III, suggests placing episodic disorders, together with progressive chronic disorders such as schizophrenia, on Axis I. ${ }^{25}$ Developmental and personality disorders that make up lifelong and stable handicaps, should be grouped on Axis II. In this classification somatization belongs on Axis II. For gravity of complaints can vary over time, but the underlying psychological mechanism is stable. 


\section{Chapter 2}

\section{Somatization to Axis II: empirical data}

There are a few striking similarities between the description of somatization disorder and personality disorders. ${ }^{5}$ Both start at a young age, mostly before the end of adolescence. The course is chronic, although gravity of complaints can vary over time.

The DSM-III takes for granted a large overlap of the various personality disorders. A relation between somatization disorder and (other) personality disorders can be interpreted as an indication that somatization disorder may be counted as a personality disorder. In a family study, a clear relation between the so-called antisocial personality disorder (previously called 'sociopathy') and somatization disorder was found. ${ }^{26}$ Somatization disorder has even been called the feminine equivalent of antisocial personality disorder. ${ }^{27}$

Hyler and Sussman see somatizing patients' lives with many physical complaints as suggestive of a personality disorder and base their therapy on this view. ${ }^{28}$ In one of the few well designed intervention studies in this field, a therapy was tested, tailored to a conceptualization of somatization disorder as a personality disorder. ${ }^{19}$ This therapy consisted of a once-only psychiatric consultation and further guidance in primary care. Emphasis was placed on a continuous relationship with a single physician, and on avoiding diagnostic procedures if the patient had symptoms, but no signs of disease in the physical examination. This approach - more guidance than treatment - led to a $50 \%$ reduction of medical expenditures for these patients without change in satisfaction with the care received.

Katon et al. assume that somatization is a personality trait; they define somatization as a coping mechanism on a cognitive and behavioural level, not as an Axis I diagnosis. ${ }^{12}$ In their study, in hospitalized patients for whom a psychiatric consultation was requested, somatizing patients had DSM-III personality disorders more frequently than non-somatizers.

There are clear indications that personality disorders affect risk of Axis I disorders and their course. ${ }^{29}$ This model, in which somatization is interpreted as a personality trait, is especially prevalent in review articles. ${ }^{9,10}$ The findings of Katon et al. fit in well with such a model: they found a much stronger relation between somatization and (DSM-III) depression than between somatization and DSM-III somatization disorder. ${ }^{12}$ In other studies a clear relation between somatization and mood and anxiety disorders was found too. ${ }^{15}$ 


\section{Conclusions and recommendations}

This literature study led to the conclusion that a definition for general practice research should be more comprehensive than the DSM-III somatization disorder definition, should be a continuum definition (it should not imply psychiatric disorder) and should be logically connected to the DSM-III definition. Empirical research is required before one can judge whether a relation with psychosocial problems should be included in the definition.

In view of this uncertainty, our conclusion regarding the operationalization of a definition for general practice can only be a provisional one; The more comprehensive version of the DSM-III criterion by Escobar ( 4 or 6 complaints instead of 13) is the most promising. ${ }^{15}$ This operationalization is inherently unreliable to a certain extent; somatic complaints caused by as yet undiagnosed somatic disease are included. For research this unreliability seems to be acceptable as the best attainable solution at present.

For the care of an individual patient, a definition including a relation with psychosocial problems may be better. Although these psychosocial problems are more difficult to operationalize for quantitative research, the GP does have information about them or can ask for it. In a sequel to this article we will return to this issue.

A connection between a GP (continuum) definition and the generally accepted psychiatric definition of DSM-III somatization disorder can only be made if somatization disorder is moved from Axis I to Axis II (personality disorder) of DSM-III. Within the theoretical structure of the DSM-III, somatization disorders fits just as well on Axis II as on Axis I, if not better. Empirical data support this transfer.

With this a solution is given for the problem of defining somatization for general practice research. Strikingly, we did not find a Dutch contribution. In our database of the international literature we found only three Dutch articles. These articles were meant for post-graduate education, not for development of scientific theory. In a sequel to this article we will investigate whether the articles written in Huisarts en Wetenschap over the last 19 years present an alternative for this definition. 


\section{References}

Huygen FJA, Hoogen HJM van den, Logt AT van de, Smits AJA. Nerveus-functionele klachten in de huisartsenpraktijk. I. Een epidemiologisch onderzoek [Nervousfunctional complaints in general practice 1: An epidemiological study]. Ned Tijdschr Geneeskd 1984; 128: 1321-1327

2 Grol RPTM (ed.). Huisarts en somatische fixatie: Theorie en praktijk van de preventie van somatische fixatie [General practitioner and somatic fixation: Theory and practice of the prevention of somatic fixation]. Utrecht/Antwerpen: Bohn, Scheltema \& Holkema, 1983.

3 Huygen FJA. Preventie van somatische fixatie I: Geschiedenis van een onderzoeksproject [Prevention of somatic fixation 1: The history of a research project]. Huisarts en Wetenschap 1978; 21: 363-365.

4 Koster van Groos GAS. Beknopte handleiding bij de diagnostische criteria van DSMIII-R (vertaling) [Concise manual for the diagnostic criteria of DSM-III-R]. Amsterdam/Lisse; Swets en Zeitlinger 1989 ( $2^{\mathrm{e}}$ druk).

American Psychiatric Association. Diagnostic and Statistical Manual of Mental Disorders, Third Edition. Washington DC, American Psychiatric Association; 1980

6 Robins LN, Helzer JE, Weissman MM, et al. Lifetime prevalence of specific psychiatric disorders in three sites. Arch Gen Psychiatry 1984; 41: 949-958.

deGruy F, Columbia L, Dickinson P. Somatization disorder in a family practice. J Fam Practice 1987; 25: 45-51

8 Verhaak P. Psychische problemen in de huisartspraktijk [Psychological problems in general practice]. Maandblad Geestelijke Volksgezondheid 1981; 1: 31-46

9 Lipovski ZJ. Somatization: Medicine's unsolved problem. Psychosomatics 1987; 28: 296-297

${ }^{10}$ Lloyd GG. Psychiatric syndromes with a somatic presentation. J Psychosom Res 1986; 30: $113-120$

"Katon W, Ries RK, Kleinman A. The prevalence of somatization in primary care. Compr Psychiatry 1984; 25: 208-215

${ }^{12}$ Katon W, Ries RK, Kleinman A. The prevalence of somatization in primary care: Part II: A Prospective DSM-III study of 100 consecutive somatization patients. Compr Psychiatry $1984 ; 25: 305-314$

13 Escobar JI, Randolph ET, Hill M. symptoms of schizofrenia in hispanic and anglo veterans. Cult Med Psychiatry 1986; 10: 259-276

${ }^{14}$ Robins LN, Helzer JE, Croughan J, Ratcliff KS. The NIMH Diagnostic Interview Schedule: Its history, characteristics, and validity. Arch Gen Psychiatry 1981; 38: 381-389

${ }^{15}$ Escobar JI, Burnam MA, Karno M, Forsythe A, Golding JM. Somatization in the community. Arch Gen Psychiatry 1987; 44: 713-718

${ }^{16}$ Bridges KW, Goldberg DP. Somatic presentation of DSM-III psychiatric disorders in primary care. J Psychosm Res 1985; 29: 563-569

17 de Leon J, Saiz-Ruiz J, Chinchilla A, Morales P. Why do some psychiatric patients somatize? Act Psychiatr Scand 1987; 76: 203-209

18 Weintraub MI. Hypochondriasis and somatization. JAMA 1988; 259: 1809-1810 
${ }^{19}$ Smith GR, Monson RA, Ray DC. Psychiatric consultation in somatization disorder: A randomized controlled study. N Engl J Med 1986; 314: 1407-1413.

20 Quill TE. Somatization disorder: One of medicine's blind spots. JAMA 1985; 254: 3075-3079

21 Spitzer RL, Forman JBW. DSM-III field trials: II. Initial experience with the multiaxial system. Am J Psychiatry 1979; 136: 818-820

22 Lipowski ZJ. Somatization: The concept and its clinical application. Am J Psychiatry 1988; $145: 1358-1368$

23 Eijk JTM van. Levensgebeurtenissen en ziekte: Een verkennend onderzoek naar het effect van enkele levensgebeurtenissen op het ontstaan van ziekte bij personen met een sterk en zwak probleemoplossend vermogen [Life events and illness: An exploratory study into the effect of some life events on occurrence of illness in persons with strong and weak problem-solving abilities]. Utrecht; Huisartsenpers, 1979 (proefschrift Nijmegen).

24 Klerman GL, Vaillant GE, Spitzer RL, Michels R. A debate on DSM-III. Am J Psychiatry 1984; 141: 539-553

25 Williams JBW. The multiaxial system of DSM-III: Where did it come from and where should it go? II. Empirical studies, innovations and recommendations. Arch Gen Psychiatry 1985; 42: 181-186

26 Cloninger CR, Reich T, Guze SB. The multifactorial model of disease transmission: III. Familial relationship between sociopathy and hysteria. Br J Psychiatry 1975; 127: 23-32

27 Murphy GE. The clinical management of hysteria. JAMA 1982; 247: 2559-2564

28 Hyler SE, Sussman N. Somatoform disorders: Before and after DSM-III. Hospital and Community Psychiatry 1984; 35: 469-478

29 Frances A. The DSM-III personality disorders section: A commentary. Am J Psychiatry 1980; 137: 1050-1054 


\section{Appendix: DSM-III}

DSM-III stands for 'Diagnostic and Statistical Manual of Mental Disorders, third edition'. The DSM-III is the official psychiatric classification in the United States, published by the American Psychiatric Association in 1980. By now a revised version has appeared (1987)." Differences between the original and the revised version are small and hardly relevant for patient care (except for the anxiety disorders). DSM-III has quickly become the internationally accepted psychiatric classification, both for patient care and for research.

DSM-III describes psychiatric disorders and organizes them in chapters. Moreover, it provides operational criteria to reach a diagnosis - unlike earlier editions and other classification systems. These operational criteria concern, as far as possible, concrete and observable behaviour. Judgement on hypothetical causal mechanisms is not necessary to reach diagnosis. On the one hand this was done to improve reliability, on the other it was necessary to make the classification acceptable for clinicians of various theoretical orientations. To ensure that all information relevant for diagnosis and therapy is elicited, DSM-III is designed as a multi-axial classification;

- Syndromes with an episodic character and clearly evident symptoms or behavioural dysfunctions are placed on Axis I.

Chronic non-remitting psychological states, primarily personality disorders, personality traits and developmental disorders, are placed on Axis II. Together these axes make up a further specification of the psychiatric disorders part of the International Classification of Diseases, ninth edition, Clinical Modification (ICD-9-CM)

The most important chapters that Axis I is organized in are the organic mental disorders, substance abuse disorders, schizophrenic disorders, other psychotic disorders, affective disorders," anxiety disorders, somatoform disorders, adjustment disorder, psychological factors influencing physical condition and finally problems not attributable to a mental disorder that are a focus of attention or threatment.

The distinction between Axis I and Axis II seems to be inspired by a theoretical model in which a personality trait, personality disorder or developmental disorder (Axis II) affects the risk of a psychiatric disorder in the narrow sense (Axis I), or its course. However, this is not said so explicitly. The official text states that on Axis II those disorders (or characteristics) are placed that usually start in childhood or adolescence and that remain stable (that is: without exacerbations or remissions) throughout adult life. On both Axis I and Axis II multiple diagnoses can be recorded. On Axis III all somatic diseases or handicaps (physical disorders and

and a new edition: American Psychiatric Association. Diagnostic and statistical manual of mental disorders, $4^{\text {th }}$ edn. Washington DC: American Psychiatric Association, 1994. 
conditions') are recorded that - potentially - are relevant for an understanding or the treatment of the patient's problem. It is coded according to ICD-9-CM. The Axes IV (severity of psychological stressors) and V (highest level of functioning in past year) are meant for use in research - or special clinical setting. These Axes are scored on an ordinal scale.

For the GP the significance of the DSM-III is in its practical and objectifying approach of psychiatric manifestations. The diagnostic system can be learned fairly easily, without in-depth theoretical knowledge of psychiatric disorders or personality. It yields a clear diagnosis, especially for the frequently occurring anxiety disorders and mood disorders, that are probably underdiagnosed in general practice. Axis III ensures that somatic diseases are given attention too. For the GP this has always been self-evident; in psychiatry this is an important innovation. Axis IV invites further exploration of psychosocial stressors that have caused the problem or disorder, or affect its course. Axis V directs attention to the healthy part of the patient: the social roles in work, family, relationship or society, that especially in chronic disorders can become strongly restricted. 
Chapter 2 
Chapter 3

\section{What do we call somatization? "}

\section{2: An answer from the international literature tested against 19 years of 'Huisarts en Wetenschap'}

\section{Abstract}

In chapter 2 we concluded that for research on somatization in general practice a more comprehensive version of the psychiatric (DSM-III) definition of somatization disorder is to be preferred. In this chapter we analyse 19 volumes of 'Huisarts en Wetenschap' to explore whether Dutch general practice research offers an alternative for this definition. We found the concepts 'nervous-functional complaints' (and, connected to this 'somatization'), 'somatic fixation' and 'problem behaviour'.

The 'somatic fixation' concept was difficult to apply in patient-centred research, while 'problem behaviour' appeared to be too broad a concept. The concepts 'nervous-functional complaints' and 'somatization' (as used in Huisarts en Wetenschap) offers the best possibilities for formulating a definition. This result agrees with our earlier conclusions.

Published as: Portegijs PJM, Kraan HF, Knotnerus JA, Stoffers HEJH. Wat heet somatisatie? 2: Een antwoord uit de internationale literatuur getoetst aan 19 jaar Huisarts en Wetenschap. Huisarts en Wetenschap 1992: 35: 65-69' 


\section{Chapter 3}

\section{Introduction}

For patient-centred research on somatization in general practice, a definition is required that is easily operationalized. This definition has to be less restrictive than the somatization disorder definition in the Diagnostic and Statistical Manual of Mental Disorders, Third Edition (DSM-III), the generally accepted psychiatric classification system. ${ }^{1}$ This definition should be clearly related to the DSM-III definition, however, to facilitate use of the many psychiatric studies of recent years for hypothesis generation, and to prevent communication problems between researchers. In patient care too, good communication between psychiatrists and general practitioners (hence a common language) is important.

By means of a literature study we found a definition that satisfies our requirements reasonably well: a more comprehensive version of the somatization disorder definition. ${ }^{2,3}$ This definition specifies: four (for men) or six (for women) symptoms from a list of somatic symptoms for which no (adequate) somatic cause can be discovered. However, this definition has not yet been used extensively in empirical research.

Remarkably, in our database of the recent international literature we found almost no contributions from Dutch general practice to theory development on somatization. Nevertheless, a concept such as somatic fixation has had a large influence on the training and post-graduate education of Dutch general practitioners (GPs). Linking up with the international literature, therefore, is important for Dutch general practice research. Whether Escobar's definition will be generally accepted for patient-centred research in primary care is not clear, however.

We have searched recent volumes of 'Huisarts en Wetenschap' for an alternative for, or confirmation of, Escobar's definition.

\section{Methods}

We started with the registration of all articles in 'Huisarts en Wetenschap' in the cumulative register 1972-1986 and the annual registers from 1987 to 1990 indexed under the keyword 'somatization'. This keyword is the only one that explicitly concerns the general problem somatization (the term 'somatic fixation is covered too). Further, we searched for the keywords 'problem patients' and 'psychosocial problem'. Finally, we looked for 'classification', because the more general problem of classification and delineation of general practice problems is covered by this keyword.

Based on the title, we evaluated which articles dealt with somatization. If the title was not informative, the article itself was read. Articles with the keyword 


\section{Definitions of somatization in 'Huisarts en Wetenschap'}

'classification' were used only if they concerned a general classification of problems.

Of the 88 articles with the keyword 'psychosocial problem', many were excluded because no relation with somatic complaints was mentioned. Further, articles were excluded because they dealt with a possible specific manifestation, for example irritable bowel syndrome, not the issue of somatization as such. Finally, we excluded a few case studies about specific treatment modalities (hypnotherapy, behavioural therapy).

The final selection consisted of 20 articles. In these articles, all concepts possibly related to somatization were studied, together with the definitions used and the operationalizations, if given.

\section{Results}

The keywords 'somatization', 'problem patients' and 'psychosocial problem' often referred to the same articles. Therefore, they are discussed as a group. In 11 articles selected on these keywords, seven concepts related to somatization were found (see Table 1). Usually a description of the concept was given, albeit sometimes a brief one.

The term 'nervous-functional complaints' was used most frequently, defined as "physical complaints for which no organic basis can be found that can explain their gravity". ${ }^{4}$ Sometimes a relation with psychosocial problems was mentioned: "We call such complaints nervous-functional, because there are well-founded suspicions that psychosocial problems are at the root of the problem". In other articles, this relation was not directly mentioned, but as appears from the context assumed to be present. ${ }^{5}$ According to Stam, the concept "nervous-functional complaints' is synonymous to 'psychosomatic complaints'. ${ }^{6}$ Verhaak mentioned that for the term 'functional complaints' terms like 'hysteria', 'psychosomatics', 'neurosis', 'neurotic complaints' and 'psychosocial complaints' are used, but did not state whether he considered these terms synonymous.'

Postma pointed out that the term 'somatization' may refer to the level of the physician (diagnosis), the level of the patient (a supposedly aetiological descrip. tion) and to the communication between physician and patient (for example 'somatic fixation'). ${ }^{8}$ He preferred a descriptive rather than aetiologic definition to avoid losing sight of the physician's contribution: "The somatizing patient is a patient who very frequently consults with the GP. This patient comes with complaints, both physical ones (that then cannot be medically explained satisfactorily) and complaints in the sphere of the family, relationships, work or environment." He added: "The practising GP recognizes these patients by their full 
Chapter 3

table 1: Concepts of 'somatization', by keyword of the article."

\begin{tabular}{|c|c|c|c|c|}
\hline & \multicolumn{2}{|c|}{$\begin{array}{l}\text { Somatization } \\
\text { Psychosocial problem } \\
\text { Problem Patient } \\
\text { (n }=11)^{\circ}\end{array}$} & \multicolumn{2}{|c|}{$\begin{array}{l}\text { Classification } \\
(n=10)^{\text {. }}\end{array}$} \\
\hline & mentioned & defined & mentioned & defined \\
\hline $\begin{array}{l}\text { Nervous-functional complaints } \\
\text { (and psychosomatic compl.) }\end{array}$ & 7 & 4 & 2 & \\
\hline chronic complaining / somatization & 5 & 3 & 1 & 0 \\
\hline somatic fixation & 2 & 1 & 1 & 0 \\
\hline problem behaviour & 2 & 2 & 4 & 2 \\
\hline psychosomatic illness & 2 & 2 & 1 & 0 \\
\hline vague complaints & 2 & 1 & 0 & 0 \\
\hline neurasthenia & 1 & 1 & 0 & 0 \\
\hline illness behaviour & 0 & 0 & 2 & 1 \\
\hline $\begin{array}{l}\text { hysterical and hypochondriacal } \\
\text { neurosis }\end{array}$ & 0 & 0 & 1 & 0 \\
\hline psychological symptoms & 0 & 0 & 1 & 0 \\
\hline
\end{tabular}

One article with the keywords 'psychosocial problem' and 'classification' was counted twice, the total number of articles was 20.

green cards, fat medical records and many specialist letters, the receptionist knowing their names and the doctor's own irritation."

Van Mierlo based himself on a model in which an incidental psychosocial problem is transformed into a somatic (= nervous-functional) complaint by a process of somatization on the patient level. ${ }^{4}$ If the GP pays attention to the somatic complaints only, there is a high risk of this somatizing behaviour becoming a habit, and of the initially incidental nervous-functional complaint growing into habitual complaining.

The above fits into a model of somatization (more or less synonymous to 'chronic complaining') as the presentation of many nervous-functional complaints over a long period of time.

The concept 'somatic fixation' too was related to the concept 'nervous-functional complaints', but here the emphasis lay on the physician-patient communication. It has been defined as follows: "Somatic fixation means a reduction of more compre- 


\section{Definitions of somatization in 'Huisarts en Wetenschap'}

hensive problems to merely medical-somatic ones in the interaction between physician and patient."

The concept was developed in the 'Prevention Project' of the Nijmegen University Department of General Practice, in which was investigated how families predisposed for high medical consumption could be identified. It was assumed that these families could be recognized by specific signals: the presentation of complaints that primarily indicate psychosocial or behavioural problems rather than organic disease. The class of nervous-functional complaints would be the most important subgroup of these complaints. Registration of these nervousfunctional complaints proved to be too unreliable for the prediction of future morbidity. As a consequence, the theoretical model of somatic fixation was developed. The attention was shifted from nervous-functional complaints to the total morbidity presented to the GP, and to the interaction between physician and patient.

The model of somatic fixation is a circular theoretical model, based on the theory of 'biosocial resonance'. Three cycles (vicious circles) are distinguished that each may lead to continuation or deterioration of physical complaints. These cycles take place within the individual, in the interaction of the individual with his/her social environment, and in the interaction between the individual (and the social environment) and the physician.

The model provided a theoretical explanation for a symptom (predisposition of some families for high medical consumption), not a definition of an observable symptom (= a diagnosis). A more elaborate description is given too: "Somatic fixation designates the phenomenon that persons receive or demand exclusively somatic attention for problems that are not primarily or only partly somatically determined. As a result, important psychosocial aspects are pushed into the background, rendering them inaccessible and unsolvable. The authors themselves stated, regarding the status of the concept: "The study was not aimed at testing the theory as a whole or parts of it. The aim of the study was to find risk factors associated with the process of somatic fixation. The theoretical model served to choose the data to be collected and to interpret the findings." ${ }^{10}$ So, somatic fixation is a theory as well as a phenomenon (problem, process, diagnosis).

Subsequently, the authors emphasized the interpretation of somatic fixation as a phenomenon. In this they made a connection with the concept somatization, defined here as "the phenomenon that people direct attention primarily to the somatic component of their tension". ${ }^{10}$ The context indicated that somatic fixation is interpreted as a process in which the mechanism of somatization develops into a habitual way to avoid a source of tension. In addition, somatic fixation was interpreted as the end point of this process: a chronic pattern of complaints. ${ }^{11}$ "The writers also mentioned another two points of view: somatic fixation as a way for the patient to deal with his environment, and somatic fixation as a problem in the 
physician-patient relationship. They emphasized the relationship characteristic; it is not a characteristic of specific patients, but a characteristic of the relationships that particular patients have with their environment and with particular general practitioners. The emphasis on somatic fixation as a characteristic of the relationship rendered the end point a provisional one: if the patient, his/her environment and/or the physician change their communication patterns, the interaction also changes and thus the relationship. The authors regarded the physician "at least as responsible for starting this process [somatic fixation, PP] as the patient". This too had to do with the interpretation of somatic fixation as a characteristic of the relationship.

These results on somatic fixation stem from a series of articles (counted here as one) published in 1978, aimed at translating results of the first part of the Prevention Project for daily patient care. In this study, medical consumption was measured rather than somatic fixation."

In the ten articles found with the keyword 'classification', the concept 'problem behaviour' was used most frequently (see Table 1). In these articles another six concepts were mentioned, although only once or twice.

Problem behaviour was defined as "the discussion of life's problems [as opposed to medical-somatic ones, PP] in the encounter between patient and GP. It was assumed that this was clear to both GP and patient, and that it concerned an important problem (...), in the GP's judgement (...". ${ }^{12}$ It was emphasized that it had to concern an explicitly mentioned problem. The definition was supplemented by some examples; manifest relational problems, work problems, and crises were mentioned as important problems; being shy of a driving test, a minor quarrel with a neighbour, temporary worries about possible serious disease (carcinophobia, cardiophobia) were problems of minor importance, that could not lead to problem behaviour.

The concept was developed as part of a classification of problems for general practice, meant to describe fully the problems presented to the GP. Apart from diagnoses and complaints, the opinion of the patient (definition of the problem, request for help) should be made explicit. Because the developers felt that explicit discussion of life's problems is part of the GP's job, psychosocial problems formed an important part of this classification. The classification was developed from the International Classification of Diseases by removing infrequently occurring specific diagnoses, and adding codes for problem behaviour and codes at the complaint level. Psychosocial problems should coded twice: one code for the way in which the person experiences his/her problems (specific symptom or psychiatric diagnosis) and one for the substance of the problem (problem behaviour). So a psychosocial problem was coded for example as 'depressive reaction' and 'relational problem between husband and wife'. In this view (it was not 


\section{Definitions of somatization in 'Huisarts en Wetenschap'}

explicitly stated) somatization could be conceived as 'low back pain' and 'relational problem between husband and wife'.

The definition of problem behaviour was the operationalization: the rules for deciding whether or not there is problem behaviour in a particular case were given. None of the other concepts discussed in this article were operationalized in such a way.

Nearly all definitions refrain from stating whether somatization is a psychiatric disorder; all of them were continuum definitions. ${ }^{3}$ Only the terms 'neurasthenia' and 'hysterical and hypochondriacal neurosis' had a 'disorder character', but they were rarely used. The concept 'psychosomatic illness' too did not indicate a disorder according to the DSM-III. The illness here indicated physical disease (for example stomach ulcer) that results from psychological mechanisms that in themselves are not necessarily pathological.

\section{Discussion}

What have we learned from taking stock of the Dutch contributions? Quite a few concepts are used that are rarely related to each other or operationalized. It is not clear to what extent these concepts overlap empirically (labelling the same problems as somatization). In our discussion of the most important concepts we found, we will try to bring some clarity. The most important concepts are: 'somatic fixation', 'problem behaviour' and 'nervous-functional complaints' (in relation to 'somatization').

The concept 'somatic fixation' is not defined as a characteristic of the patient but as a characteristic of the GP-patient communication. The more elaborate descriptions indicate that somatic fixation is not always stable. An operationalization for patient-centred research that does justice to this definition should be suitable for observations of unselected physician-patient contacts in a certain period. Moreover, it should entail stock to be taken of the 'more comprehensive problems', which are reduced to medical-somatic problems. The various other characteristics of somatic fixation (process, end-point of process, the relation patient-environment, the relation patient-physician) make the concept even more complex, and thus more difficult to operationalize.

The concept 'problem behaviour' has the great advantage that it fits within the accepted medical classifications, for example the International Classification of Primary Care (ICPC). However, it does not differentiate between patients who consult their physician with physical reasons for encounter and those who come with an explicitly psychosocial request. Furthermore, patients whose life problems are not explicitly discussed, or patients who name these life problems 
differently, do not satisfy the definition. This implies that both somatizing patients and non-somatizers can have problem behaviour, while the 'real' somatizing patients (who do not or not sufficiently appreciate the relevance of psychosocial problems as causal factors for their somatic symptoms) fall outside the definition. Problem behaviour therefore is not a workable concept for our goal.

Anyway, the general concept of somatization (by whatever definition) does not fit within a classification such as ICPC. Somatizing patients may have problems in component 1 (complaint level) of nearly every chapter. Somatization may also be an expression of a psychiatric disorder (component 7 , diagnosis level, of chapter P), or of social problems (component 1, chapter Z). The solution proposed - coding both the form of reaction and the problem content - is satisfactory only for a problem such as depression, where the reaction form is specific. In somatization, many different symptoms count as reaction form, and things become even more difficult if somatizing patients have multiple complaints. Should all of these be coded? We think that somatization, if relevant for a specific study, is better coded on a separate axis, independent of apart from the ICPC classification.

The morbidity analysis 1972 of the Ommoord group practice, in which the problems the GPs were consulted for were related to demographic variables, confirms this conclusion: the first factor from the canonical correlation analysis (a kind of factor analysis) described a group of patients with high medical consumption, psychosocial problems and a long list of vague complaints. ${ }^{13}$ Somatization here is not evident as a specific problem (= code on diagnosis list), but a specific pattern of problems.

The definition of 'nervous-functional complaints' refers to a diagnosis based on exclusion ('... no organic basis can be found ...') and is therefore always provisional: an organic cause may yet be found. The relation with psychological problems does not bring us much further, as there are too many somatic diseases in which this relation is likely or proven. Moreover, one of the first questions to be answered in somatization research is: What is the relation between nervousfunctional complaints and psychosocial stress? For this question, the relation cannot be included in the definition.

However, for the time being, we do not need to know whether a specific complaint is nervous-functional; what we need to know is whether the patient somatizes, and that is defined as the presentation of many nervous-functional complaints over a longer period. ${ }^{4}$ Even if the criterion for nervous-functional complaints leads to a certain 'noise' level, the criterion for somatization derived from it may be reliable and valid. 
So the concept of somatic fixation is difficult to operationalize in patient-centred research, while the concept of problem behaviour is too broad on the one hand, and too restricted on the other. For the time being, the concepts of nervousfunctional complaints and somatization, as defined by van Mierlo et al. and Postma, offer the best prospects for a practicable criterion for somatization for patient-centred research. ${ }^{4.8}$ A definition of somatization as having many nervousfunctional complaints over a longer period of time fits well with Escobar's definition. ${ }^{2}$ This definition fits in too with the definition Huygen et al. had originally chosen for their Prevention Project.

We conclude that the Dutch general practice literature does not yield a better definition for mild forms of somatization than Escobar's criterion, if one wants to operationalize this concept for patient-centred research in primary care. Rather there is support for this criterion, althought it has not been explicitly mentioned in the articles we read. Further, a continuum definition of somatization (that does not label somatization as necessarily pathological) agrees more with the opinions of Dutch authors than a disorder definition.

The choice of Escobar's definition is a provisional one. Once the relation with psychosocial problems has been elucidated, a definition that includes this relation is more promising. In a clarifying review Lipowski has proposed such a definition: "a tendency to experience and express somatic complaints and symptoms that are not explained by patbologic findings, to attribute these complaints to somatic disease and to seek medical attention for them. It is usually assumed that this tendency becomes manifest in response to psychosocial stress brought about by life events and situations that are personally stressful to the individual." ${ }^{14}$ The overlap between Escobar's definition and a provisional operationalization of Lipowski's definition is included in our study.

Furthermore, the choice of Escobar's definition applies to patient-centred research only. In a study on the consultation process, for example, somatic fixation can be operationalized, we think, if the consultation is observed and the patient is interviewed afterwards. And in patient care too, the concept of somatic fixation or Lipowski's definition might be more useful than Escobar's definition, which remains a diagnosis based on exclusion.

\section{References}

1 American Psychiatric Association. Diagnostic and Statistical Manual of Mental Disorders, Third Edition. Washington DC, American Psychiatric Association; 1980

2 Escobar JI, Burnam MA, Karno M, Forsythe A, Golding JM. Somatization in the community. Arch Gen Psychiatry 1987; 44: 713-718 


\section{Chapter 3}

3 Portegijs PJM, Kraan HF, Knottnerus JA, Stoffers HEJ. Wat heet somatisatie? I: Een zoektocht in de internationale literatuur naar een definitie voor huisartsgeneeskundig onderzoek. Huisarts en Wetenschap 1992; 35: 18-25,45

${ }_{4}$ Mierlo G van, Smits A. Nerveus-functionele klachten: De huisarts en het gezinsgesprek: De klacht en de huisarts [Nervous-functional complaints: The general pratitioner and the family disscussion: The complaint and the general practitioner]. Huisarts en Wetenschap 1974; 17: 52-55

5 Lamberts H. Probleemgedrag in de eerste lijn [Problem behaviour in primary care]. Huisarts en Wetenschap 1975: 18: 492-502

6 Stam J. Psychosomatische klachten: Over moeilijkheden en mogelijkheden bij de hulpverlening [Psychosomatic complaints: On difficulties and opportunities in patient care]. Huisarts en Wetenschap 1976; 19: 140-144

7 Verhaak PFM. Functionele klachten: De nieuwe kleren van de keizer? [Functional complaints: The emperor's new clorhes?]. Huisarts en Wetenschap 1988; 31 (suppl H\&P12): 25-31

8 Postma TNM. Somatiserende patiënten in de huisartspraktijk [Somatizing patients in general practice]. Huisarts en Wetenschap 1981; 24: 169-176

9 Huygen FJA. Preventie van somatische fixatie I: Geschiedenis van een onderzoeksproject [Prevention of somatic fixation 1: The history of a research project]. Huisarts en Wetenschap 1978; 21: 363-365.

${ }^{10}$ Smits A, Eijk J van, Grol R, Huygen F, Mierlo G van, Mokkink H. Preventie van somatische fixatie II: Een theoretisch model en onderzoekgegevens [Prevention of somatic fixation 2: A theoretical model and results of the study]. Huisarts en Wetenschap 1978; 21: 366-369

"Grol R, Eijk J van, Huygen F, Mierlo G van, Mokkink H, Smits A. Preventie van somatische fixatie III: Somatische fixatie in de huisarts-patiëntrelatie [Prevention of somatic fixation 3: Somatic fixation in the general practitioner-patient relation]. Huisarts en Wetenschap 1978; 21: 402-405

${ }_{12}$ Lamberts H. De morbiditeitsanalyse - 1972 door de groepspraktijk Ommoord: Een nieuwe ordening van ziekte- en probleemgedrag voor de huisartsgeneeskunde (I) [The morbidity analysis 1972 by the group practice Ommoord: A new classification of illness and problem behaviour for general practice 1]. Huisarts en Wetenschap 1974: $17: 455-473$

${ }^{13}$ Lambers H. De morbiditeitsanalyse - 1972 door de groepspraktijk Ommoord: Een nieuwe ordening van ziekte- en probleemgedrag voor de huisartsgeneeskunde (III) [The morbidity analysis 1972 by the group practice Ommoord: A new classification of illness and problem behaviour for general practice 3]. Huisarts en Wetenschap $1975 ; 18: 61-73$

${ }^{14}$ Lipowski ZJ. Somatization: The concept and its clinical application. Am J Psychiatry 1988; $145: 1358-1368$ 


\section{Somatization in frequent attenders of general practice *}

\section{Abstract}

The DSM-III-(R) definition of somatization disorder is too restrictive for use in general practice. A more comprehensive definition, the 'somatic symptom index' (SSI) has shown good validity in open populations. However, a definition has to differentiate validly within a population of frequent attenders to be a useful diagnostic instrument in general practice. We studied a threshold of five complaints (nearly identical to the SSI) in 80 Dutch general practice patients. Patients were selected on age (20-44 years), history of back, neck or abdominal complaints, and on frequency of consultation - at least 12 consultations in the previous three years, corrected for consultations with compelling somatic reason for encounter. Prevalence of somatization in this group was $45 \%$. Women had a two times higher risk of somatization. A relation with age was not found. Somatization was related to depressive complaints (relative risk 2.5 ) and probably also to anxiety. Somatizing patients consulted their general practitioner more often and had more health problems (especially psychic problems) than non-somatizers. These results support the validity of this definition. The distinction between our definition of somatization and somatization defined as a symptom of psychiatric (e.g. depressive or anxiety) disorder is emphasized.

Published as: Portegijs PJM, Horst FG van der, Proot IM, Kraan HF, Gunther NCHF, Knottnerus JA. Somatization in frequent attenders of general practice. Soc Psychiatry Psychiatr Epid 1996; 31: 29-37

A Dutch adaptation will be published as: Portegijs PJM, Horst FG van der, Proot IM, Kraan HF, Gunther NCHF, Knottnerus JA. Somatisatie bij patiënten met hoge consultfrequentie. Huisarts en Wetenschap (accepted for publication) 


\section{Chapter 4}

\section{Introduction}

The general practitioner has a special responsibility for patients with chronic or recurrent somatic complaints that cannot be adequately explained by somatic disease. It is not the medical specialists' task to deal with the presumptive psychosocial origins of the complaints, and these patients may resent referral to a psychiatrist. This problem is usually called 'somatization'. Although doctors have a vivid image of their somatizing patients (these patients are given many disparaging diagnoses such as 'fat file syndrome' or 'crock') defining somatization for research purposes has proved to be difficult.

The introduction of DSM-III in 1980 has more or less solved this problem for those interested in somatization as a psychiatric disorder in itself. ${ }^{1}$ The DSMIII somatization disorder applies to a small group of seriously disabled patients with long-standing multiple or recurrent complaints. ${ }^{2}$ Although somatization disorder is placed on axis I of DSM-III, its description better fits a personality disorder (axis II). ${ }^{3}$

For the general practitioner or consultation/liaison psychiatrist, somatization normally is not a psychiatric problem in itself. It may be a symptom of a depressive or anxiety disorder. ${ }^{4}$ It has also been described as a kind of personality trait, a "tendency to experience and communicate distress in a somatic rather than a psychological mode". Within the social context of the patient this tendency is not necessarily dysfunctional, but within the health care system it has a risk of iatrogenic harm.

Bridges and collaborators have studied the presentation with somatic complaints of patients with an episode of depressive or anxiety disorder in general practice. ${ }^{4,6}$ The Escobar group has concentrated more on patient characteristics than on the episode of complaints. Escobar has introduced an operationalization for somatization that is a more comprehensive version of the DSM-III somatization disorder.' The criterion for this somatic symptom index (SSI) or 'abridged somatization' is four complaints for men and six for women, instead of 12 and 14, respectively. Both Bridges and Escobar have chosen the name 'somatization' for these clearly distinct constructs.

After an extensive literature search we have argued that the SSI is the best operationalization of somatization for research in general practice or open populations. ${ }^{3}$ Somatization so defined has been shown to be related to female gender, older age and lower socioeconomic status. ${ }^{7}$ It is related to current or lifetime depressive disorder, and to symptoms of anxiety. ${ }^{8.9}$ For somatoform 


\section{Somatization in frequent attenders}

disorders the relation with dysthymia has been emphasized. ${ }^{10}$ Somatizing (SSI) patients have a higher medical consumption. ${ }^{711}$ Whether or not somatization itself and psychic and/or social problems are diagnosed more frequently by the general practitioner in somatizing (SSI) patients is unclear. Most studies on the SSI have been done in the United States. As the health care system must influence the consequences of somatization (and maybe the process of somatization too), validation in a country with a different health care system is important.

Somatization is related to consultation frequency, almost by definition. A general practitioner knows which patients are frequent attenders, and is familiar with their risk of psychopathology and other diagnoses. Therefore, knowing whether a patient somatizes is especially relevant for the general practitioner if this knowledge adds to what he already knows based on consultation frequency. Therefore, we studied frequent attenders.

The aim of the study was to examine, in frequently attending general practice patients, the relation of somatization with:

- Gender, age and level of education (as an indicator of socioeconomic status)

- Depressive and dysthymic disorder, anxiety and agoraphobia

- Consultation rate and general practitioner's diagnoses of psychic, social and vague somatic problems.

\section{Methods}

\section{Subjects}

The study was carried out in 7 out of 18 general practices participating in the Registration Network of Family Practices of the University of Limburg (RNH: 'RegistratieNet Huisartspraktijken'). ${ }^{12}$ The data of the RNH consist of health problems defined as: "anything that has required or does or may require health care management and has affected or could significantly affect a person's physical or emotional well-being". ${ }^{13}$ Health problems are included if they are permanent, chronic (longer than six months) or recurrent. ${ }^{12}$ Once included, problems are never deleted from the database; if a problem does not need the attention of the general practitioner any more, its status is changed from 'active' into 'blind'.

With a two-stage selection procedure we selected a group of frequent attenders with a more or less comparable medical history and a low prevalence of interfering serious somatic problems or psychiatric problems. First, we selected 


\section{Chapter 4}

from the RNH database (anonymous for privacy reasons) records on the following criteria:

* Age 20-44 years.

* Back, neck and/or abdominal complaints, whether an active or a blind problem. ${ }^{14}$

* No serious somatic disease as an active problem. This was operationalized in 51 codes on the diagnosis level of the International Classification of Primary Care (ICPC, see also instruments paragraph). ${ }^{14}$

* No psychiatric disorders, either active or blind. This was operationalized in 10 ICPC codes (most on diagnosis level). Problems that might be related to somatization, such as 'hysterical/hypochondriacal disorder' (P75), depressive or anxiety disorders were not used as exclusion criteria.

The receptionist and the general practitioner then identified the patients and selected those who had consulted at least 12 times in the previous three years without compelling somatic reason for encounter..$^{15 *}$ A compelling somatic reason for encounter was defined as "a complaint, symptom or problem that would be a reason to consult the general practitioner for every right-minded person". Interpretation of this criterion was discussed with all participating general practitioners, some examples were given ("a flu is not a compelling somatic indication for a healthy person, it is for someone with chronic bronchitis. A cervical smear is a compelling somatic indication if the last one was more than three years ago"), and the first few patients were coded with the first author present. The general practitioner alone judged what was a compelling somatic

This was operationalized in the ICPC-codes:

D01 generalized abdominal pain/crampsD12 constipation

D02 stomach ache / stomach pain LO1 neck sympt./complaints, excl. headache

D03 heartburn

LO2 back symptoms/complaints

D06 other localized abdominal pain L03 low back complaints without radiation

D08 flatulence / gas pain/belching L08 shoulder symptoms/complaints

D09 nausea

L83 syndromes of the cervical spine

D10 vomiting

D11 diarrhea

L.84 osteoarthritis of the spine

L86 lumbar disc, lesion, radiation

The codes L83, L.84, L.86 are defined on the level of diagnosis, but are so often used as an indicator for chronic complaints that we included them.

* The average number of consultations with Dutch general practitioners (for all reasons for encounter) with patients in the age group 25-44 years is about 3.5 per year. 
reason for encounter, however, as he/she is the only one who can weigh his/her own notes. With this criterion we aimed to correct the consultation frequency for obvious and serious somatic problems. This corrected consultation frequency should not be seen as a measure of needless use of services or somatization (it is related to somatization, of course).

The general practitioner excluded a patient if he/she thought that participation would seriously harm the patient or his/her relation with the patient. The general pracitioner invited the selected patients to participate by letter. The names and addresses of patients who consented were passed on to the researchers who then visited the patients for further information about the study and data collection.

\section{Instruments}

Somatization, depressive and dysthymic disorder were assessed with the relevant sections of the Diagnostic Interview Schedule (DIS). ${ }^{16,17}$ The following criteria were used for somatization:

1 The patient has had at least five complaints from the list of complaints for the DSM-III-R somatization disorder. These complaints:

(a) were so serious, that the patient consulted a physician for them, took drugs (excluding over-the-counter drugs) and/or changed his habits and (b) could not adequately be accounted for by somatic disease or alcohol, substance or drug (ab)use.

2 Complaints started before the age of 30 years.

In only the number of complaints required (5 instead of 13) did these criteria differ from the DSM-III-R criteria for somatization disorder. ${ }^{18}$ Unlike Escobar's SSI (where analogous to the original DSM-III, a higher threshold was used for women) the criteria were identical for men and women., Depressive (current) and dysthymic disorder were operationalized according to the DSM-III-R criteria.

Complaints of anxiety and agoraphobia (not diagnoses) were assessed with the respective subscales of the Symptom Checklist-90 (SCL-90). ${ }^{19}$ The SCL-90 assesses 90 'psychoneurotic' complaints over the previous seven days. In the analyses the standardized scores (corrected for sex) for the normal Dutch population were used. ${ }^{20}$

Level of education is recorded in the RNH database as 'low' (lower vocational education or less), 'medium' (intermediate vocational education or general secondary education) or 'high' (higher vocational education or university). In The Netherlands, educational level is a valid measure for socioeconomic status. ${ }^{21}$ 


\section{Chapter 4}

In the ICPC, problems are organized in chapters: $\mathrm{D}=$ digestive, $\mathrm{L}=$ musculoskeletal, $\mathrm{P}=$ psychic, $\mathrm{Z}=$ social problems, etcetera. $\mathrm{W}$ ithin these chapters a distinction is made between complaints and diagnoses. If a diagnosis can be made according to specified criteria, the problem is coded on the diagnosis level, otherwise it is coded on the complaint level. Complaints typical of somatization, such as nausea (D09), are coded on the complaint level, as are complaints that almost always have a somatic cause such as jaundice (D13) or rectal blood loss (D16). So the number of complaint-level problems could not be taken as an indicator of a general practitioner's diagnosis of somatization. Therefore, we translated the DSM-III-R list of somatization complaints into ICPC problem codes (independently, with consensus judgment for discrepancies, J. Metsemakers, IP, PP). Inclusion codes for the study were removed from this list of 'vague somatic problems'.

\section{Analysis}

The relation of somatization with dichotomous variables was reported as the relative risk of somatization for the group at risk. For statistical tests we used the Chi-square test or the Fisher exact test, where indicated. For variables on ordinal or interval levels, somatizing patients were compared with non-somatizers using the Mann-Whitney $U$ test. All tests were two-sided. Analyses were done with SPSS/PC+ version 4.0 .

\section{Results}

\section{Patient selection}

On 1 March 1990, data of 25357 patients were listed in the RNH database. ${ }^{22}$ There were 2659 patients registered with participating general practitioners and aged 20-44 years. In this 'base population', 460 patients had back, neck or abdominal complaints. Forty-one of them were excluded because of serious somatic disease or psychiatric disorders. Of the remaining 419 patients, 105 had had at least 12 consultations with the general practitioner in the previous three years without compelling somatic reason for encounter (consultation frequency missing in 54 patients). Four patients were excluded by the general practitioner. Of the remaining 101 patients, 80 (79\%) participated in the study.

Participating patients were representative of the base population with regard to sex, while older patients and patients with a low level of education were 
overrepresented (mean age 37 years versus 34 years, low education $62 \%$ versus $44 \%$ ). Only four participating patients had a high level of education. For further analyses they were added to the group with a medium level of education. The mean number of consultations per year was 7.5 and the mean number of consultations per year without compelling somatic reason for encounter was 5.9 (79\%).

\section{Prevalence of somatization}

Forty-five patients had or had had at least five complaints on the DSM-III-R list of somatization complaints. In 36 of these patients, the first complaint had started before age 30 , so the prevalence of somatization was $45 \%$ in this group of frequent attenders (95\% confidence interval $35 \%$ - $56 \%$ ). Five patients $(6 \%)$ had a DSM-III-R somatization disorder.

\section{Demographic variables and somatization}

Women somatized twice as often as men (see Table 1). This was not a consequence of sex-related DIS-items such as menstrual complaints or impotence; if these were excluded, the relative risk was 1.9. According to the SSI (four items for men, six for women) men somatized as often as women (relative risk 1.0).

Table 1: Demographic variables and somatization $(\mathbf{N}=80)$

'Risk group'

(dichotomous variable)

Female sex

Low level of education

$49(62)$

37

Frequency

Somatizing in

Somatizing in Relative

risk group (\%) other group (\%) risk (CI)

$2.0(1.1 \cdot 3.6) \quad 0.009 *$

$0.65(0.4-1.1) \quad 0.083^{\wedge}$
Significance

(Chi ${ }^{2}$ test)

\section{Significance}

Ordinal variable

Somatizers

Non-somatizers

(Mann.Whitney U)

Mean age (years)

37

37

0.724

Mean age at first complaint (years)

17

23

$0.001 \cdots$

This table consists of two subtables, for dichotomous (upper part), and for ordinal (lower part) independent variables. ${ }^{\wedge}: p<0.10, \quad *: p<0.05, \quad *: p<0.01$ 
Table 2: Somatization in relation to depression and anxiety $(\mathbf{N}=\mathbf{8 0})$

$\begin{array}{llllll}\text { 'Risk group' } & \text { Frequency } & \text { Somatizing in } & \text { Somatizing in } & \text { Relative } & \text { Significance } \\ \text { (dichotomous variable) } & \cap(\%) & \text { risk group }(\%) & \text { other group (\%) } & \text { risk (CI) } & \text { (Chi }^{2} \text { test) }\end{array}$

$\begin{array}{llllll}\text { Depressive/dysthym. dis. } & 12(15) & 75 & 40 & 1.9(1.2 .2 .9) & 0.030 * \text { * } \\ \text { Dysphoria or loss of } & 50(63) & 58 & 23 & 2.5(1.2 .5 .0) & 0.003 * *\end{array}$
interest (ever)

\section{Somatizers Non-somatizers}

Significance

Ordinal variable

mean score ${ }^{b}$

(Mann-Whitney U)

\begin{tabular}{llll}
\hline Anxiety (SCL-90) & 4.6 & 4.0 & $0.075^{\wedge}$ \\
Agoraphobia (SCL.90) & 4.2 & 4.1 & 0.753 \\
Depression (SCL.90) & 4.3 & 3.6 & $0.085^{\wedge}$ \\
\hline
\end{tabular}

This table consists of two subtables, for dichotomous (upper part), and for ordinal (lower part) independent variables. $\uparrow: p<0.10, *: p<0.05, \quad * *: p<0.01$

- Fisher exact test.

- Standardized score, scaled as: 1 - very low (in relation to the normal Dutch population of the same sex),

2 - low, 3 = below average, 4 - average, 5 - above average, 6 - high, 7 - very high.

A relation with age was not found, but complaints had started at an earlier age in somatizing patients than in non-somatizers. Had the criterion of a start before age 30 not been part of the operationalization of somatization, the mean age of 'somatizing' patients would have been 38 years versus 35 years for 'non-somatizers' $(p=.043)$ and the age at which the first complaint had started would have been 20 years in both groups.

The prevalence of somatization tended to be higher in patients with a medium or high level of education. Differences in marital status or composition of household were not found.

\section{Depression, anxiety and somatization}

There were four patients with current depressive disorder and eight with dysthymic disorder. The relative risk for somatization in patients with an 
affective disorder (depressive or dysthymic) was 1.9 (see Table 2). Depressive episodes in the past had not been ascertained, but we did know about the core symptoms: depressed, dysphoric mood and/or loss of interest of at least two weeks duration. Many patients had experienced these symptoms, and they were strongly related to somatization.

Somatizing patients appeared to have higher scores on the SCL-90 subscale 'anxiety'. A relation with agoraphobia was not found.

Figure 1: Consultation frequency and somatization

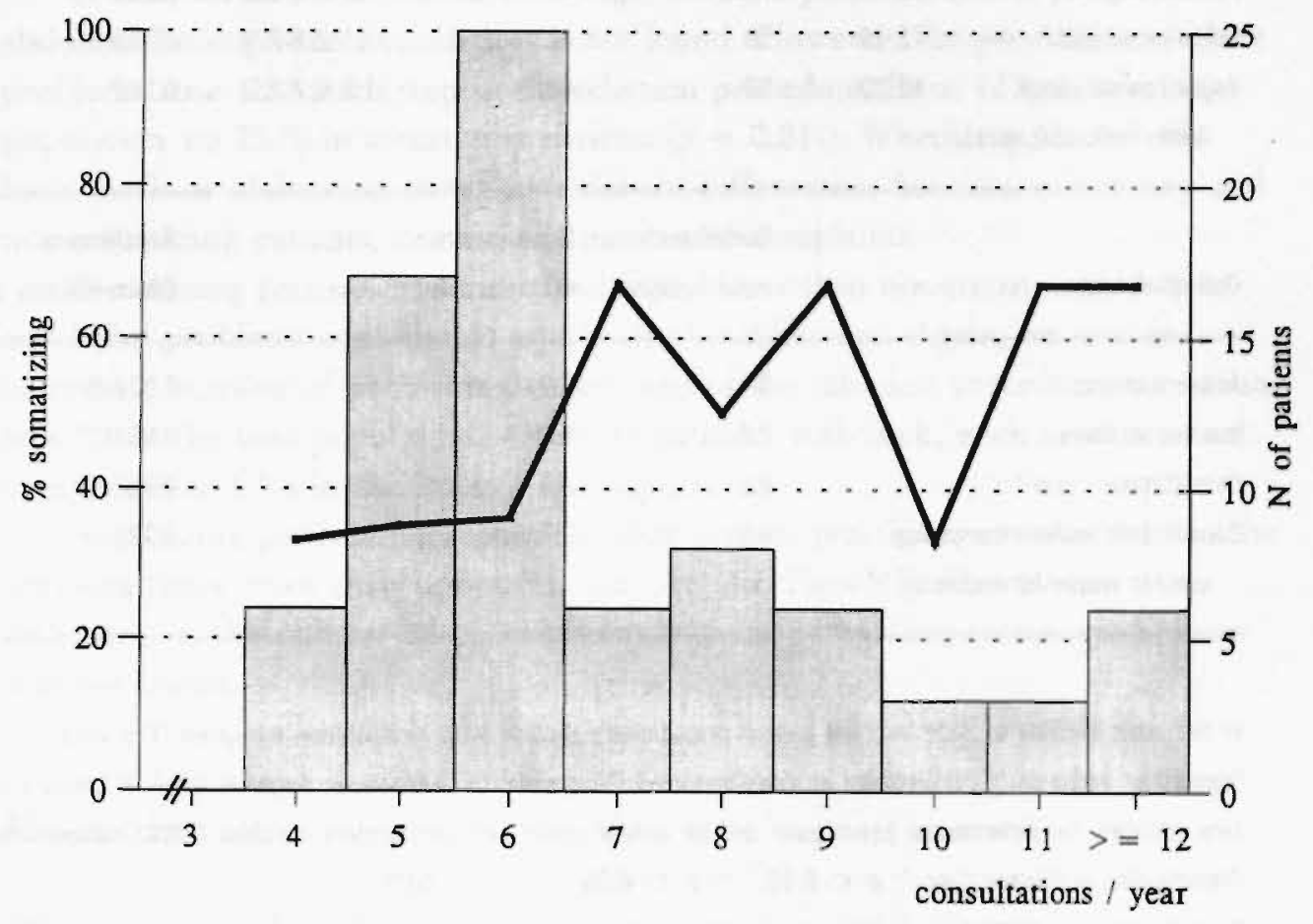

In this figure the proportion of patients somatizing is depicted as a function of the consultation frequency (line, left vertical axis). As an aid to interpretation, a histogram of the consultation frequencies is given too (averaged over three years, right vertical axis). 


\section{Chapter 4}

Table 3: Somatization in relation to health problems and consultation frequency $(\mathbf{N}=\mathbf{8 0}$ )

$\begin{array}{lcllll}\text { 'Risk group' } & \text { Frequency } & \text { Somatizing in } & \text { Somatizing in } & \text { Relative } & \text { Significance } \\ \text { (dichotomous variable) } & n(\%) & \text { risk group (\%) } & \text { other group (\%) } & \text { risk (Cl) } & \text { (Chi }{ }^{2} \text { test) }\end{array}$

In this table relations of data from the general practitioner's records with somatization are given. The tem 'complaints' refers to (ICPC.)problems on complaint level, 'diagnoses' to problems on diagnosis level. It consists of two subtables, for dichotomous (upper part), and for ordinal (lower part) independent variables. ICPC: International Classification of Primary Care ${ }^{\wedge}: \mathrm{p}<0.10, \quad \because \mathrm{p}<0.05, \quad \cdots: \mathrm{p}<0.01$

- Fisher exact test.

b In the ICPC social problems are defined on complaint level.

c This is counted over the previous three years, then averaged.

d Data from one practice were lost, so 19 patients are missing here. 


\section{Health problems, consultation frequency and somatization}

Thirty-one patients had a psychic (chapter P of the ICPC) and/or social (chapter Z) problem (see Table 3). A relation with somatization was not found. A distinction between psychic and social problems showed a strong relation with the former and no relation at all with the latter. A further differentiation of psychic problems into psychic complaints (ICPC code P01-P29) and psychic diagnoses (code P70-P99) yielded about the same relative risk. The relation of psychic problems with somatization was not be accounted for by specific problems; most problems were more prevalent in the somatizing group, but only for code P02 ('acute stress or situational disturbance') was the relation significant.

A relation of somatization with vague somatic problems (back, neck and abdominal complaints excluded) was not found. However, the prevalence of these problems rose with each step in the selection procedure, from $12 \%$ in the base population to $25 \%$ in somatizing patients $(p=0.011)$. Whether patients had back, neck or abdominal complaints did not differentiate between somatizing and non-somatizing patients, nor did the number of complaints.

Somatizing patients had more health problems than non-somatizers. Active and blind problems contributed equally to this difference. Again, we saw an increasing number of problems in every step of the selection procedure; the mean was 3.1 in the base population, 4.4 in the patients with back, neck or abdominal complaints and 5.5 in the interviewed patients.

Somatizing patients had consulted their general practitioner more often in the previous three years than non-somatizers (see also Figure 1). However, a difference in the number of consultations without compelling somatic indication was not found.

\section{Discussion}

Whether or not (our definition of) somatization is a useful diagnostic concept in general practice is subject to debate. Relations of the SSI with gender, socioeconomic status, depression and anxiety in the general population have been well established. ' However, frequency of consultations - inherently related to somatization - is also related to gender, socioeconomic status, depression and anxiety. If these relations are present within a group of frequent attenders, that is a strong indication for the validity of the definition; this would prove that it distinguishes meaningfully even within this more homogeneous population. Only 
then could it eventually be developed into a valuable diagnostic tool; a general practitioner cannot but notice which patients consult frequently, and is only interested in the somatization concept if it provides additional predictive power. Our definition (virtually identical to the SSI) passed this test.

As a consequence of this restriction to frequent attenders this study cannot be compared directly with other studies on the SSI. If we had interviewed a (large) unselected general practice population or had compared our frequently consulting, somatizing patients with a group of rarely consulting non-somatizers, we would in all probability have found larger differences. This is illustrated by our findings on number of problems and prevalence of vague somatic complaints (here we did have data for the whole practice population). However, we did not have the opportunity to do this. Therefore, the positive findings of this study are fairly strong, while the negative ones have little value as evidence.

\section{Demographic variables and somatization}

The influence of necessarily arbitrary decisions is painfully demonstrated in our data on gender differences. Having decided to use one threshold for both men and women, we reported here that women somatize twice as often as men. If we had followed Escobar's SSI 4/6 criterion, we would have said that in The Netherlands, as in Puerto Rico, men somatize as often as women.? We propose that one threshold for both sexes be used for the time being; the conceptual relation with the DSM-III-R somatization disorder is more clear this way (identical criteria for men and women have remained in the new DSM-IV, although there has been a major change in operationalization). ${ }^{23}$ Eventually, gender-specific thresholds will probably be necessary to adjust for gender bias in answering the questions; there probably is a stronger taboo for men to complain or show weakness. However, currently there are no data on which to base the size of an adjustment: do men with five complaints have impairments that are as serious in daily life as women with six have? Do they have the same risk of iatrogenic harm? Escobar's motivation for different thresholds does not help in this; the discrepancy is not due to sex-related items such as menstrual complaints, but to gender differences in response tendencies on the other iterns. ${ }^{24}$ Despite these uncertainties one can conclude that the relative risk for women to somatize increases with the threshold of the definition used; studies on somatization disorder or 'persistent somatization' have yielded more extreme gender differences than studies with the SSI or Bridges' definition of somatization. ${ }^{7.2528}$ This was to be expected; if the somatization disorder definition 'sees' only the tip of the iceberg, then a less restrictive 


\section{Somatization in frequent attenders}

definition will apply to a broader, that is more heterogeneous group. In general this implies that if the general practitioner or consultation/liaison psychiatrist wants to detect somatization in its milder forms, he/she cannot rely on the rather stereotyped description (female, chaotic life, etc.) of patients with somatization disorder as diagnostic clues.

A higher prevalence of (SSI) somatization has been reported in older patients. ${ }^{7,29}$ This should be interpreted with caution, however. The theoretical construct of somatization that the SSI claims to measure is best described as a personality trait, that is, it is more or less stable in time. ${ }^{3,5,24}$ However, the operationalization is not a measure of the strength of this trait, but a lifetime count of the different complaints this trait has manifested itself in. So if a patient at age 15 years starts having a new complaint every two years, the diagnosis of somatization will depend on whether he/she is interviewed before age 25 years or after. A rising prevalence of somatization with age might be interpreted as an artefact rather than as a true relation. Our finding of a fairly small age difference on just the complaint count (without the start before age 30 criterion) is then seen as an indication that this artefact plays a minor role, and the start before age 30 years criterion as effectively neutralizing the effect. This explanation is a tentative one, however; all patients were aged $20-44$ years, which must have led to some underestimation of the relation with age. Our findings were consistent with those of Escobar; he does not mention a start before age 30 criterion and has found a rising prevalence with age. ${ }^{7}$

The explanation of the relation with age as an artefact is supported by Fink's findings. ${ }^{27}$ He used a count (of hospital admissions) over eight years instead of a lifetime one, and found no relation with age. However, his 'persistent somatizers' are more seriously disabled than our patients. We do not see how a fixed-period criterion could be developed for mild somatization.

The iceberg analogy is also applicable to the age of onset. Fink has found that persistent somatizers start their hospital career at an earlier age than other patients. ${ }^{27}$ This is also the case for the DSM-III-R somatization disorder. ${ }^{18}$ In our study the age at which the first complaint started did not differentiate between 'somatizers' and 'non-somatizers' at all (unless age of onset was part of the definition).

Somatization seemed to be less frequent in patients with a low educational level, whereas we expected it to be the other way round. The overrepresentation of poorly educated patients might explain this: level of education may be related more strongly to consultation frequency than to somatization. This would mean 
that the higher consultation frequency of poorly educated patients is largely dependend on (sub-)cultural standards of their social group, and that a disposition to somatize is more individual or runs in the family.

\section{Depression, anxiety and somatization}

Prevalence of (current) depressive disorder in patients consulting their general practitioner has been reported to be as high as $10 \%{ }^{30}$ Our finding of a lower prevalence, even in this selected group, reflects a difference in perspective. If one is interested in episodes of disease or in the general practitioner's workload, waiting room patients are preferably studied, in which case a high prevalence of current depressive disorder may be expected, related to somatization. ${ }^{9.31}$ As we were interested in the health of patients in their everyday life, we interviewed our patients at a time unrelated to the last consultation. Dysthymic disorder seemed to be more important in our patients, which supports Howland's conclusion that dysthymia in its consequences for public health is as important as major depression. ${ }^{10}$ We now regret that we did not interview the patients for lifetime depressive disorder. Having defined somatization as a more or less stable trait, we would expect lifetime depressive disorder to be a stronger predictor of somatization than current depressive disorder. Ever having experienced dysphoria or loss of interest for at least two weeks was the strongest predictor of somatization in our study. About half of these patients would probably meet criteria for lifetime depressive disorder. It is likely that subsyndromal forms must have contributed to this strong relation with somatization too. This supports Howland's plea for more attention to be paid to subsyndromal depressive conditions. $^{10}$

A relation between somatization and anxiety has often been described. ${ }^{5}$ However, the term somatization is often used for the somatic complaints associated with anxiety states, in line with Bridges' definition. If these studies are excluded, only a few remain; a relation with anxiety (symptoms and/or disorders) has been found for both mild somatization and somatization disorder. ${ }^{9.25}$ We can neither confirm nor refute this relation, finding only weak indications for a relation with the SCL-90 anxiety subscale. However, the indications for a relation with the depression subscale were also weak (although depression is clearly related to somatization). We doubt whether this is a result of limitations of the SCL-90 itself: the subdivision of anxiety into specific disorders seems to be more or less artificial, and anxiety in general is strongly related to SCL-90 scores. ${ }^{32}$ More likely 
is that a stable trait (somatization) is only weakly related to one's experiences in a particular week (the SCL-90 refers to the previous week).

Our data on psychiatric problems serve to illustrate the difference between our trait operationalization of somatization and Bridges' definition of somatization as a symptom pattern in a psychiatric disorder. ${ }^{6}$ It is highly unlikely that more than half of the patients somatizing according to our operationalization would meet the criteria for a (current) psychiatric disorder.

\section{Health problems, consultation frequency and somatization}

One would expect somatization to be apparent somehow in the list of health problems, in view of the definition of a problem (see Methods) and the importance of prevention of somatization as a topic in general practice.

We found a relation with psychic problems. However, further specification of this relation is impossible. A relation with vague somatic complaints on the problem list (back, neck and abdominal complaints excluded) was not demonstrated, although the rising prevalence of these problems with each step in the selection procedure was indirect evidence. Somatizing patients had more problems than non-somatizers. They also consulted their general practitioner more frequently. After correction for consultations with a compelling somatic reason for encounter this difference disappeared, indicating that they probably consulted their general practitioner for complaints suggesting serious somatic problems too, and not just for trivial or vague complaints. Huygen et al. have found this in their studies on somatic fixation. ${ }^{33}$ On the other hand, maybe there is a subtle difference in (presentation of) complaints, too subtle to show up in the general practitioner's notes.

We consider that our results indicate a problem in using general practitioners' records in somatization research; somatization is a valuable concept, it can be operationalized satisfactorily and its relations with other variables show reasonable construct validity, but the concept as such seems not to get written down in the patient records. This invisibility of somatization should not be surprising; earlier we have argued that somatization does not fit into a classification such as the ICPC, because both presumed causal factors (social problems or psychiatric disorders) and response (vague somatic complaints) are non-specific within the framework of this classificaion. ${ }^{34}$ This invisibility interferes with the care for somatizing patients; at each consultation the patient's problem list confronts the general practitioner with a somatic complaint implicitly asking for a (medical) diagnosis, while a diagnosis of somatization, which may have been 
made, is lost. This stimulates the repeated ruling out of organic pathology that was unlikely to be the cause of the complaints in the first place. ${ }^{35}$ It also hinders the long-term structured guidance these patients need. ${ }^{5,36,37}$ For research purposes, we propose that a separate ordinal axis 'somatization' be added to the ICPC, for an evaluation of the effect on well-being and medical consumption.

\section{Impact of somatization in general practice}

About half of the interviewed patients met our criterion for somatization, which illustrates its importance in frequent attenders with vague somatic complaints on their problem lists (we found no indication that some of these complaints have higher risks than others). Does this figure tell us anything about the prevalence of somatization in the open population in The Netherlands or in the general practitioner's waiting room? Simple arithmetic yielded a minimum prevalence of $2.2 \%$ in the open population aged $20-44$ years (assuming that patients with low consultation frequency and patients without back, neck or abdominal complaints never somatize, corrected for exclusion criteria and non-response). As these assumptions are a bit unreasonable, we would guess that somatization in The Netherlands is as frequent as in the United States: about $5 \% .{ }^{2}$ If so, it would be one of the most common problems in this age group: it would rank about fifth in the $\mathrm{RNH}$ problem top ten. Considering the higher consultation frequency of somatizing patients, the prevalence in the waiting room would be more than 10 $\%$. Somatization, as defined in this study, is an important problem in Dutch general practice: it is common and has consequences for well-being, risk of iatrogenic harm and use of scarce health care resources.

This concept of somatization cannot be seen as a characteristic of an isolated patient; the health care system must play a role too, as it offers certain opportunities of getting help or relief from duties, and precludes others. Our data were insufficient for a conclusion on this point, but it seems that, despite the differences between the health care systems in the United States and The Netherlands, results are fairly similar. If confirmed in other studies, this would give the concept a kind of 'cross-system' validity. The differences between the United States and Dutch health care systems are especially relevant for somatization. Almost everyone in The Netherlands is registered with a general practitioner, which facilitates a long-term relation and should diminish doctor-shopping within primary care. The general practitioner explicitly has a gatekeeper function for access to medical specialists, which should diminish doctor-shopping in secondary care. Moreover, doctors in The Netherlands do not (yet) have to be as afraid of a 
malpractice lawsuit, which should give them more options to resist excessive patient demands.

\section{Conclusion}

The operationalization of somatization as a more comprehensive version (5 instead of 13 items) of the DSM-III-R operationalization of somatization disorder can be implemented in research in general practice. Relations with demographic variables, depression, health problems and consultation frequency support its validity. The relation with anxiety is less clear.

\section{References}

1 American Psychiatric Association. Diagnostic and statistical manual of mental disorders, 3rd edn. Washington DC: American Psychiatric Association, 1980.

2 Escobar JI, Burnam MA, Karno M, Forsythe A, Golding JM. Somatization in the community. Arch Gen Psychiatry 1987; 44: 713-718

3 Portegijs PJM, Kraan HF, Knottnerus JA, Stoffers HEJH. Wat heet somatisatie? 1. Een zoektocht in de internationale literatuur naar een definitie voor huisartsgeneeskundig onderzoek. [What so we call somatization? 1. A search of the international literature for a definition to be used in general practice research.] Huisarts en Wetenschap 1992; 35: 18-25,43

4 Goldberg DP, Bridges K. Somatic presentations of psychiatric illness in primary care setting. J Psychosom Res 1988; 32: 137-144

5 Lipowski ZJ. Somatization: The concept and its clinical application. Am J Psychiatry 1988; 145: 1358-1368

6 Bridges KW, Goldberg DP. Somatic presentation of DSM-III psychiatric disorders in primary care. J Psychosom Res 1985; 29: 563-569

7 Escobar JI, Rubio-Stipec M, Canino G, Karno M. Somatic symptom index (SSI): A new and abridged somatization construct: Prevalence and epidemiological correlates in two large community samples. J Nerv Ment Dis 1989; 177: 140-146

8 Simon GE, VonKorff M. Somatization and psychiatric disorder in the NIMH Epidemiologic Catchment Area Study. Am J Psychiatry 1991; 148: 1494-1500

9 Katon W, Russo J. Somatic symptoms and depression. J Fam Pract 1989; 29: 65-69

${ }^{10}$ Howland RH. General health, health care utilization, and medical comorbidity in dysthymia. Int J Psychiatry Med 1993; 23: 211-238 


\section{Chapter 4}

14 Escobar JI, Golding JM, Hough RL, Karno M, Burnam MA, Wells KB. Somatization in the community: Relationship to disability and use of services. Am J Public Health 1987; 77: 837-840

12 Metsemakers JFM, Höppener P, Knottnerus JA, Kocken RJJ, Limonard CBG. Computerized health information in the Netherlands: A registration network of family practices. Br J Gen Pract 1992; 42: 102-106

13 Sandlow LJ, Bashook PG. Problem oriented medical records: Self instruction for practitioners. Chicago: Michael Reese Hospital and Medical Center, 1978.

is Lamberts H, Wood M. The International Classification of Primary Care. Oxford: Oxford University Press, 1987.

15 Centraal Bureau voor de Statistiek. Statistisch jaarboek 1991. [Statistical yearbook 1991] 's-Gravenhage: SDU/uitgeverij, 1991.

16 Robins L.N, Helzer JE, Croughan J, Ratcliff KS. National Institute of Mental Health Diagnostic Interview Schedule: Its history, characteristics, and validity. Arch Gen Psychiatry 1981; 38: 381-389

17 Dingemans $P$, Engeland $H$ van, Dijkhuis JH, Bleeker J. De 'diagnostic interview schedule' (DIS). [The 'diagnostic interview schedule' (DIS).] Tijdschrift voor Psychiatrie 1985; 27: 341-359

18 American Psychiatric Association. Diagnostic and statistical manual of mental disorders, 3rd edn. revised. Washington DC: American Psychiatric Association, 1987.

19 Derogatis LR, Cleary PA. Confirmation of the dimensional structure of the SCL-90:A study in construct validation. J Clin Psychol 1977; 33: 981-989

20 Arrindel WA, Ettema JHM. SCL-90: Handleiding bij een multidimensionele psychopathologie-indicator. [SCL-90: Manual for a multidimensional psychopathology-indicator.] Lisse: Swets \& Zeitlinger, 1986.

21 Berkel-van Schaik AB van, Tax B. Naar een standaardoperationalisatie van sociaaleconomische status voor epidemiologisch en sociaal-medisch onderzoek. [To a standardized operationalisation of socioeconomic status for epidemiological and socio-medical research.] Rijswijk: Programmacommissie Sociaal-economische gezondheidsverschillen, Ministry of Welfare, Public Health and Cultural Affairs, 1990.

22 Metsemakers JFM, Höppener P, Knottnerus JA, Limonard CBG. Health problems and diagnoses in family practice: Report 3, march 1990. Maastricht: Registration Network of Family Practices, University of Limburg, 1990.

23 American Psychiatric Association. Diagnostic and statistical manual of mental disorders, 4th edn. Washington DC: American Psychiatric Association, 1994.

24 Escobar JI. Cross-cultural aspects of the somatization trait. Hosp Community Psychiatry 1987; $38: 174-180$

25 Swartz M, Blazer D, George L, Landerman R. Somatization disorder in a community population. Am J Psychiatry 1986; 143: 1403-1408 
26 Golding JM, Smith GR Jr, Kashner TM. Does somatization disorder occur in men? Clinical characteristics of women and men with multiple unexplained somatic symptoms. Arch Gen Psychiatry 1991; 48: 231-235

27 Fink P. The use of hospitalizations by persistent somatizing patients. Psychol Med 1992; 22: $173-180$

28 deGruy F, Crider J, Hashimi DK, Dickinson P, Mullins HC, Troncale J. Somatization disorder in a university hospital. J Fam Pract 1987; 25: 579-584

29 Swartz M, Landerman R, Blazer D, George L. Somatization symptoms in the community: A rural/urban comparison. Psychosomatics 1989; 30: 44-53

${ }^{30}$ Schulberg HC, Saul M, McClelland M, Ganguli M, Christy W, Frank R. Assessing depression in primary medical and psychiatric practices. Arch Gen Psychiatry 1985; 42: $1164-1170$

31 Smith GR. The epidemiology and treatment of depression when it coexists with somatoform disorders, somatization, or pain. Gen Hosp Psychiatry 1992; 14: 265-272

32 Angst J, Dobler Mikola A. The Zurich Study: V. Anxiety and phobia in young adults. Eur Arch Psychiatry Neurol Sci 1985; 235: 171-178

33 Huygen FJA. Preventie van somatische fixatie: I. De geschiedenis van een onderzoekproject. [Prevention of somatic fixation: I. The history of a research project] Huisarts en Wetenschap 1978; 21: 363-365

34 Pontegis PJM, Kraan HF, Knottnerus JA, Stoffers HEJH. Wat heet somatisatie? 2. Een antwoord uit de internationale literatuur getoetst an 19 jaar Huisarts en Wetenschap. [What do we call somatization? 2. An answer from the international literature tested against 19 years of 'Huisarts en Wetenschap'] Huisarts en Wetenschap 1992; 35:65-69

35 Fink P. Adnission patterns of persistent somatization patients. Gen Hosp Psychiatry 1993; 15: 211-218

${ }^{36}$ Quill TE. Somatization disorder: One of medicine's blind spots. JAMA 1985; 254: 3075-3079

37 Smith GR, Monson RA, Ray DC. Psychiatric consultation in somatization disorder: A randomized controlled study. N Engl J Med 1986; 314: 1407-1413 
Chapter 4 


\section{A troubled youth *}

\section{Relations with somatization, depression and anxiety in adulthood}

\section{Abstract}

Background: Childhood experiences profoundly influence later functioning as an adult. Family practitioners are well-placed to discover the links between childhood troubles and later somatization, depression or anxiety.

Objectives: We aimed to study the interrelation of somatization, depressive and anxiety disorders in frequently attending patients in general practice; to investigate whether these problems are related to a childhood history of illness experiences, deprivation, life events and abuse; and to determine the independent contributions of these childhood factors to the prediction of adult somatization, depressive and anxiety disorders.

Methods: One hundred and six adult general practice patients with high consultation frequency were studied. Somatization was operationalized as a more comprehensive version of DSM-III-R somatization disorder ( 5 complaints; SSI 5/5). For depression (ever depressive and/or dysthymic) and anxiety (panic, phobias and/or generalized anxiety) DSM-III-R criteria were used. Using a structured questionnaire we assessed illness experiences, deprivation of parental care, abuse (sexual/physical) and orher life events before age 19.

Results: The overlap between somatizaton, depression and anxiety was largely accounted for by 16 patients with a triple problem: somatization and depression and anxiety. Somatization was specifically related to deprivation, depression to

Published as: Portegijs PJM, Jeuken FMH, Horst FG van der, Kraan HF,

Knottnerus JA. A troubled youth: Relations with somatization, depression and anxiety in adulthood. Fam Pract 1996; 13: 1-11 
other life events. Abuse (prevalence $16 \%$ ) independently predicted psychiatric problems in general. Youth experiences before age 12 were most important. Conclusions: The high prevalence of triple problems suggests a need to reconsider concepts like somatic anxiety and anxious depression. The specificity of the relation between deprivation and somatization and of the relation between other life events and depression indicates that distinct causal mechanisms (in youth) contribute to these problems.

\section{Introduction}

Childhood experiences profoundly influence later functioning as an adult. This thesis was proposed nearly a century ago and is widely accepted in western societies. Scientific debate continues, though.' Family medicine as a scientific discipline, however, is not an active participant in this debate. Child psychologists and educationalists concentrate on influence of 'normal' childhood experiences on personality and academic achievement. Psychiatrists analyse the childhood experiences of patients with psychiatric disorders within the mental health care system, and study the prognosis in severely troubled children. Severe trouble such as sexual abuse is, however, more frequent and less visible than formerly thought. ${ }^{2}$ Moreover, a high proportion of psychiatric morbidity is never seen within the mental health care system. General practitioners, on the other hand, often have long-lasting relationships with their patients, see them fairly regularly for many reasons, and see members of their families too. Within the health care system, therefore, the general practitioner is well placed to detect both trouble in youth and its possible consequences in adulthood.

Psychiatric knowledge about the long-term consequences of childhood trouble is fragmentary, for practical reasons. Prognosis in institutionalized children, or the childhood history of depressed adults who are referred is easier to study than the combined effects of several - possibly less severe - types of trouble in a primary care population. Somatization (as defined by Lipowski) is most important for the general practitioner because it is a field where he has more expertise than either medical specialists or psychiatrists. ${ }^{3}$ Depressive and anxiety disorders are important too because they are the most prevalent psychiatric disorders in general practice, are frequently not diagnosed as such, and probably have presenting symptoms different from those in referred patients (somatized anxiety, masked depression, for instance). 
This article presents a survey of the relationship between several types of trouble in youth and somatization, depressive and anxiety disorders in adulthood. It was part of a larger study assessing the validity of the somatization concept in a risk group important for general practice: patients with recurrent or chronic abdominal, neck or back complaints and high consultation frequency.

Serious disease and prolonged pain in childhood are related to somatization in adulthood. ${ }^{45}$ Serious handicap through disease of a parent has been reported as a risk factor too. This has been illustrated by Huygen in his prospective analysis of case histories spanning generations. ${ }^{6}$ Katon emphasized the significance of subjective complaints: if children grow up in families where "care is provided for somatic ills, but not for emotional ills", they may later somatize as a strategy to cope with depression and elicit nurturance.?

Many studies have investigated parental separation and parental death as risk factors for later depression, most of them confirmative. ${ }^{8910}$ Lack of care resulting from the loss of a parent or the emotional climate of a family as such may be more important than the loss itself, though. ${ }^{11}{ }^{12}$ Loss or death of a parent is reported as a risk factor for panic disorder. ${ }^{913}$ Lack of parental care too has been implicated as a risk factor for somatization. ${ }^{14}$

Traumatic life events in childhood are related to later depression and panic disorder. ${ }^{15}{ }^{16}$ However, most life events in these studies were related to illness experiences or deprivation of parental care. Whether the stress of having to adapt to changes in situation as such has any influence remains to be established.

About $15 \%$ of adult women in the general population have been abused before age 16, and in psychiatric hospitals even more. ${ }^{217}{ }^{18}$ Sexual abuse has been reported as a risk factor for somatization, for depression and for anxiety. ${ }^{14} 1 / 192021$ Physical abuse is probably similar to sexual abuse in its consequences. ${ }^{14} 22$

The present study was therefore designed to answer the following questions:

1 What is the interrelation of somatization, depressive and anxiety disorders in patients who frequently present in general practice?

2 Are somatization, depressive and anxiety disorders (and psychiatric problems in general) in adulthood related to a childhood history of illness experiences, deprivation, life events and abuse?

3 What is the independent contribution of illness experiences, deprivation, life events and abuse in childhood to the prediction of somatization, depressive and anxiety disorders? 


\section{Methods}

\section{Subjects}

A study group of frequent attenders with a more or less comparable medical history of somatic complaints was selected in two steps. Potential candidates were selected in the Registration Network of Family Practices (RNH) database of the University of Limburg. ${ }^{23}$ Health problems are recorded as ICPC codes in the RNH if permanent, chronic or recurrent. ${ }^{23}$ Criteria were: history of back, neck or abdominal complaints, age 20 - 44 years, absence of active serious somatic diseases and no history of psychiatric disorders other than depression and anxiety. The participating general practitioners, using medical records, then selected on frequency of consultation, with a correction for obvious and serious somatic problems: at least 15 consultations without compelling somatic reason for encounter ("that would be a reason for consultation for any right-minded person") in the previous three years. The general practitioners excluded a patient if they thought that participating would seriously harm the patient or their relationship with the patient. The general practitioners invited the selected patients to participate by letter. Patients who agreed were visited by a trained interviewer for further information about the study and data collection. The protocol for subject selection and recruitment has been described in detail elsewhere. ${ }^{25}$

\section{Instruments}

For demographic data we used a standardized Dutch questionnaire. ${ }^{26}$

Somatization, depressive disorder, dysthymic disorder, panic disorder, agoraphobia, social phobia and other phobias were assessed with the relevant sections of the Diagnostic Interview Schedule (DIS). ${ }^{228}$ For generalized anxiety disorder (not included in the DIS) we used a specially designed questionnaire in DIS format, and DSM-III-R criteria. Somatization was defined as a more comprehensive version of DSM-III-R somatization disorder, with a threshold of 5 complaints instead of $13 . .^{25}{ }^{30}$ For other diagnoses DSM-III-R-criteria were used.

In the absence of standardized questionnaires for retrospective evaluation of unfavourable youth experiences, we designed our own (see appendix). We concentrated on events that were easy to recall. Questions were phrased neutrally. If a patient had experienced abuse, specific follow-up questions were asked, as disclosure, though upsetting, may have a beneficial effect on the patient (and shrinking away from the subject may strengthen the taboo of abuse as something unmentionable). ${ }^{2}$ In these cases patients were also phoned the next day to provide an 
opportunity to express their feelings, as advised by Draijer. ${ }^{2}$ The questionnaire concerned the period up to and including age 18. It comprised four sections: 1 Illness experiences: subjective illness and disease of the patient, disease of family members (reliable recall of subjective illness of family members was thought impossible).

2 Deprivation: situations that indicated a lack of, or a high risk of a lack of, parental care during a lengthy period, or events resulting in such situations.

3 Life events: major disruptions of daily routine that forced the patient to adapt to a new situation (not necessarily negative events). As this scale overlapped considerably with other scales, results are also presented for other life events (overlapping items excluded).

4 Abuse: sexual abuse: any unwanted sexual experience before age 16, indecent assault thereafter. Gravity of sexual abuse was scored in an ordinal scale according to Draijer (page 141). ${ }^{2}$ Physical abuse: beating that was subjectively threatening or necessitated a visit to the doctor. It was coded as abuse only if the situation had been experienced as serious at the time.

\section{Analysis}

In bivariate analyses we stratified for gender; the Mantel-Haenszel Chi ${ }^{2}$ test for linear trend was used for ordinal scales, the Mantel-Haenszel Chi ${ }^{2}$ for dichotomous ones.

Youth experiences that in bivariate analyses were related to a dependent variable (somatization, depression or anxiety) were entered in logistic regression analysis to assess whether they were independent predictors of that dependent variable (forward stepwise, likelihood ratio probability-to-enter 0.10 , probabilityto-remove 0.20 ). We forced variables into the model in additional analyses to test our interpretation of results.

Significance levels for bivariate analyses are one-sided (except where indicated). In logistic regression analyses we present two-sided significance levels. For stratified analysis EPI INFO (dichotomous scales) and TRUE EPISTAT (ordinal scales) were used. ${ }^{31}{ }^{32}$ All other analyses were done with SPSS-PC+ 4.0. 


\section{Results}

\section{Patient selection}

The RNH database contained 1378 patients aged 20 - 44 years with back, neck or abdominal problems and without serious somatic or psychiatric problems. Of these, 185 had had at least 15 consultations without a compelling somatic reason for encounter in the previous three years. The general practitioners excluded 19 patients, 55 refused and five were excluded because of missing data, which left 106 patients for the analyses. Thirty of them had also participated in an earlier study. ${ }^{25}$

\section{Sociodemographic variables}

There were 41 men and 65 women. Median age was 37 years. Most patients were living with a partner (88) and/or children (75). Level of education was comparable to that of the population registered with the participating practices: 43 patients with at least intermediate vocational or general secondary education. About half of the patients ( 26 men, 28 women) had a paid job or studied, a quarter ( 1 man, 27 women) looked after the household, and the rest worked in a sheltered workshop (5), were on long-term sick leave (10), unemployed (4), or unclassifiable for work situation (5).

\section{Somatization, depression and anxiety}

Somatization (at least 5 complaints, start of first complaint before age 30) was present in 51 patients ( $48 \%, 18$ men and 33 women). Four of them had the full DSM-III-R somatization disorder (at least 13 complaints). There were 39 patients ( $37 \%$ ) with 'depression': 33 had a lifetime diagnosis of depressive disorder (five of whom currently depressive) and six of dysthymic disorder. 'Anxiety' was diagnosed in 40 patients ( $38 \%$ ): panic disorder (current or lifetime) 16 patients, agoraphobia 20 , social phobia 8 , other phobias 16 and generalized anxiety disorder 4.

Depression was related to both somatization (odds ratio $3.6,95 \%$ confidence interval 1.5 - 7.7, $\mathrm{p}=0.002$ ) and anxiety $(\mathrm{OR} 2.9, \mathrm{CI} 1.3-6.7, \mathrm{p}=0.005)$. There was a non-significant relation between somatization and anxiety $(\mathrm{OR} 1.8, \mathrm{CI} 0.8$ $4.1, \mathrm{p}=0.066$ ). The picture was more complicated than the crude odds ratios suggest, however (see figure 1). Sixteen patients had all three problems (somatization and depression and anxiety) against an expected number of 7.1 (null hypothesis of no interrelations: $51 / 106$ times $39 / 106$ times $40=7.1$ ). Patients 
Figure 1: Overlap of somatization, depression and anxiety

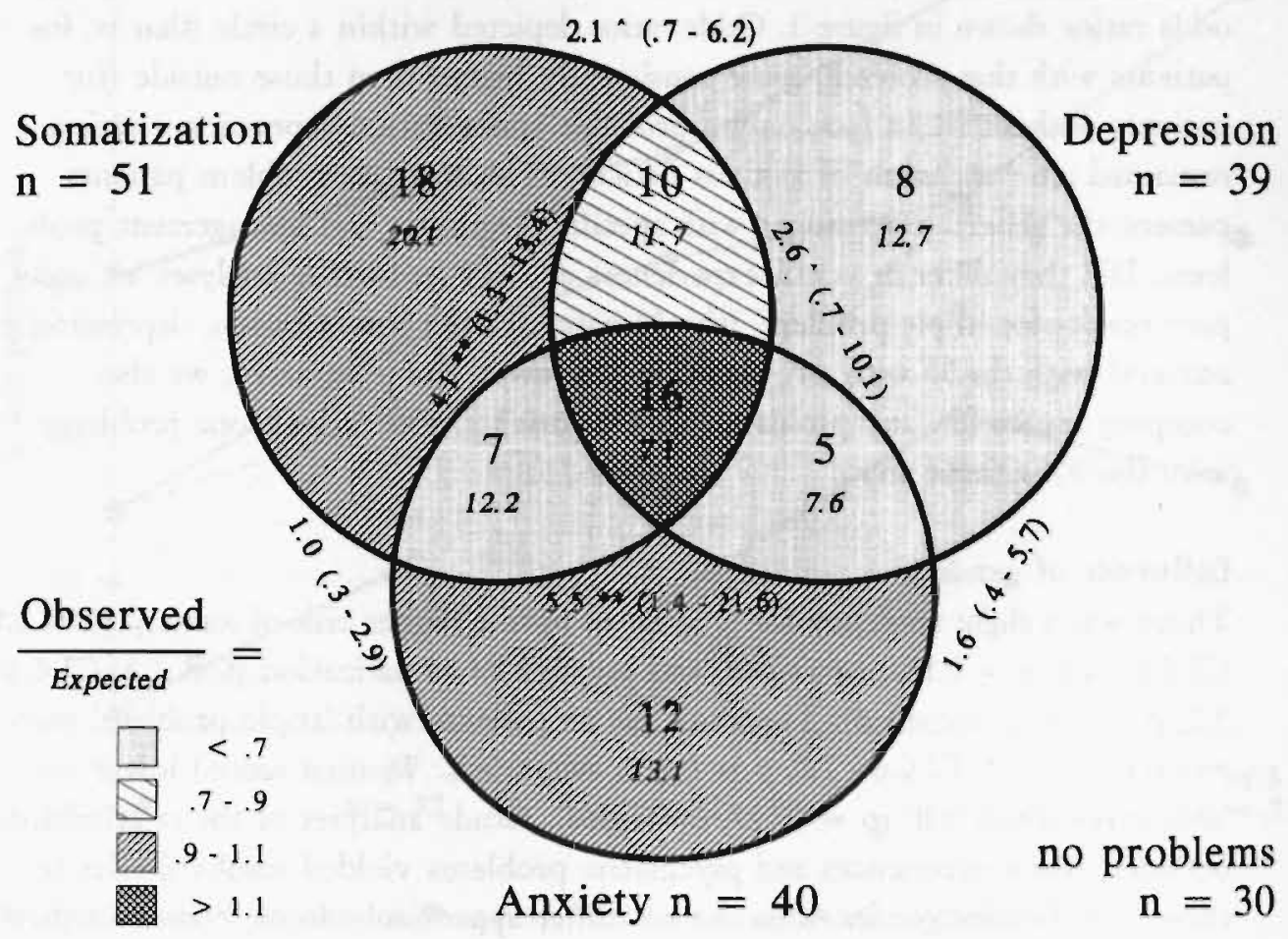

In this Venn-diagram the number of patients observed is given for each area (above), and the number of patients expected under the null hypothesis of no relationships holding between somatization, depression and anxiety (below). The ratio observed/expected is also indicated by the shading. Stratum-specific odds ratios (with $95 \%$ confidence intervals) for relations between two problems are given too, with the third problem as stratification variable: present (inside circle) and absent (outside). 
with two of the three problems were comparatively few. In other words, the relations between somatization, depression and anxiety were largely due to the patients with a triple problem. This finding is quantified in the stratum-specific odds ratios shown in figure 1 . Odds ratios depicted within a circle (that is, for patients with that problem) were consistently higher than those outside (for patients without ic). In fact, only a probable somatization-depression relation remained after exclusion of anxious patients. The 16 triple-problem patients present the general practitioner with specific diagnostic and management problems. Did they differ in youth experiences as well? In further analyses we compare results for 'triple problem' (the 16 patients with somatization, depression and anxiety) with the 90 with two problems or fewer. For symmetry, we also compare results for 'any problem' (the 76 patients with at least one problem) with the 30 without any.

\section{Influence of gender}

There was a slight tendency for women to have a higher risk of anxiety (OR 1.8, CI $0.8-4.2, \mathrm{P}=0.153$, two-sided) and possibly of somatization (OR 1.3, CI 0.6 $3.0, p=0.491$, two-sided). Twelve of the 16 patients with 'triple problem' were women (OR 2.1, $\mathrm{CI} 0.6-7.0, \mathrm{p}=0.222$, two-sided). Women scored lower on 'subjective illness self' ( $p=0.027$, two-sided). Crude analyses of the relationships between youth experiences and psychiatric problems yielded results similar to those stratified for gender. Men did not differ appreciably from women in these relationships. For simplicity we present here results stratified for gender only. Other sociodemographic variables were not significantly related to psychiatric problems or youth experiences.

\section{Illness experiences}

Frequency of serious disease (before age 19) was related to depression (see table 1). A relation with somatization or anxiety was not found. Confrontation with serious disease in parents or siblings was not related with any of the dependent variables, nor was subjective illness.

\section{Deprivation}

Deprivation was strongly related to somatization and related to depression and anxiety as well (see table 1, figure 2). If the analysis was restricted to deprivation before age 13 , relations with somatization and anxiety did not change, but the 
Figure 2: Deprivation and psychiatric problems

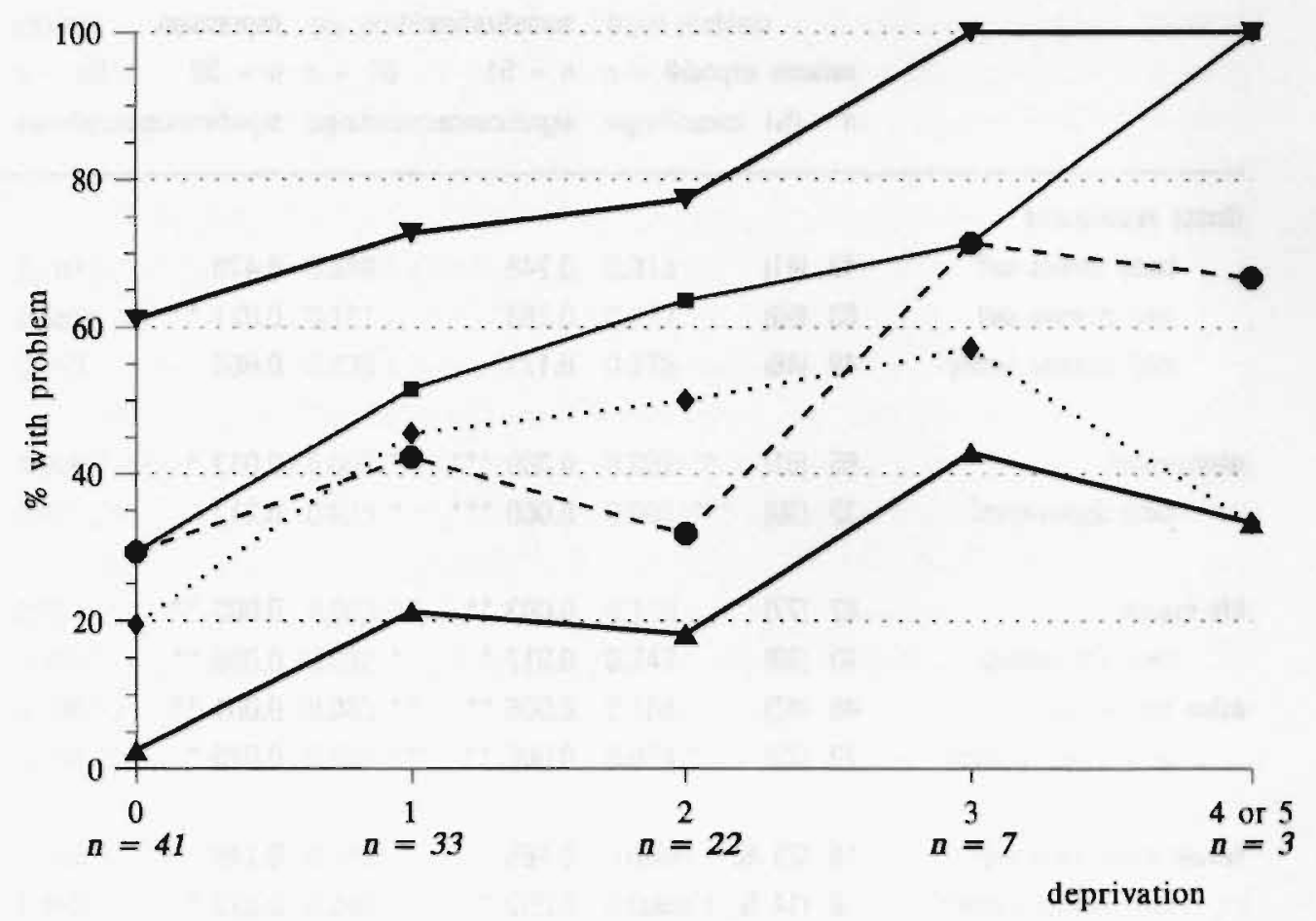

$\star$ somatization $\bullet$ depression $\bullet$ anxiety $\boldsymbol{\nabla}$ any problem $\star$ all problems

In this figure the proportion of patients with somatization, depression, etc. is given as a function of deprivation. As an aid to interpretation, the frequency distribution of deprivation is given too (horizontal axis, italic type).

relation with depression disappeared. As might be expected from the above, deprivation was related to 'any problem'. It was also related to 'triple problem'.

Loss of a parent (also included in the deprivation scale) was related to somatization and depression, but not to anxiety (see table 2).

\section{Life events}

The number of life events in youth was related to depression (particularly strongly), to somatization and thereby to 'any problem' as well (see table 1). Removal of overlapping items ('other life events') did not influence results 


\section{Chapter 5}

Table 1: troubled youth (ordinal variables) in relation to psychiatric problems $(\mathbb{N}=106)$

$\begin{array}{lll} & \text { somatization } & \text { depression } \\ \text { patients exposed } & n=51 & n=39 \\ n \quad(\%) & \text { significance } & \text { significance }\end{array}$

illness experiences

(subj) illness self

43 (41)

0.248

0.478

(obj) disease self

$63 \quad(59)$

0.263

0.021 *

(obj) disease family

49 (46)

0.171

0.664

deprivation'

early deprivation ${ }^{2}$

life events

early life events ${ }^{2}$

other life events ${ }^{3}$

early other events ${ }^{2}$

sexual abuse (women) ${ }^{4}$

early sexual abuse ${ }^{2.4}$
$65 \quad(61)$

32 (30)

82 (77)

$63 \quad(59)$

45 (42)

$23(22)$

16 (25\%, 1 miss.)

0.165

0.003 **

$0.017^{*}$

$0.006^{* *}$

$0.005 *$

0.013 *

0.217

$9(14 \%, 1$ miss.)

$0.057^{\wedge}$

0.146

0.027 *

As far as youth experiences could be expressed on ordinal scales, relations with psychiatric problems are presented in this table. Number of patients with somatization, depression etc. are given on top, some indication of the frequency distributions of the independent variables Inumber of patients scoring 1 or higher) in the left column. Strength of relations is indicated with the significance value of the Mantel-Haenszel Chi ${ }^{2}$ test for trend, stratified for gender. Significant and near-significant relations are marked: *: $p<0.10, \quad * p<0.05, \quad *$ * $p<.01, \quad * *: p<0.001$.

appreciably (see also figure 3). If the analysis was restricted to other events before age 13 , a relation with anxiety was found 100 , while the relation with depression was somewhat weaker. 
Table 1: (continued)

anxiety

$n=40$

significance any problem

$\mathrm{n}=76$

significance triple problem

$n=16$

significance

$\begin{array}{lll}0.707 & 0.389 & 0.313 \\ 0.863 & 0.191 & 0.377 \\ 0.919 & 0.435 & 0.278\end{array}$

$\begin{array}{lll}0.026^{*} & 0.007^{* *} & 0.002^{* *} \\ 0.011^{*} & 0.025^{*} & 0.001 * *\end{array}$

0.551

0.003 ** $\quad 0.110$

0.753

0.032 *

0.247

0.336

$0.003 * *$

0.108

0.037 *

$0.003 *$

$0.074^{\wedge}$
0.105
0.149
0.400
0.445
0.249
$0.060^{\wedge}$

\section{See also figure 2.}

2 Up to and including age 12.

3 See also figure 3.

4 Analysis restricted to women, as only two men reported sexual abuse. One woman declined to answer this question.

\section{Abuse}

Sixteen women $(25 \%)$ and two men (5\%) reported sexual abuse in youth (see table 1). In at least half of the cases a family member or person in a comparable position was the perpetrator. In women, sexual abuse before age 13 was related to depression, and showed a tendency to be related to somatization and 'triple problem' too. To enable comparisons with physical abuse, a dichotomized version (discounting minor forms of abuse as advised by Draijer) is also presented (see table 2). ${ }^{2}$ 


\section{Chapter 5}

Table 2: Abuse and loss in relation to psychiatric problems $(\mathbf{N}=106)$

\begin{tabular}{|c|c|c|c|c|c|}
\hline \multirow{2}{*}{ problem } & \multirow[b]{2}{*}{ abuse / loss } & \multicolumn{2}{|l|}{ age $\leq 18$} & age $\leq 12$ & \multirow[b]{2}{*}{ sign. } \\
\hline & & $\mathrm{OR}(\mathrm{Cl})$ & sign. & $\mathrm{OR}(\mathrm{Cl})$ & \\
\hline somatization & sexual (women) & $2.8(0.7-12)$ & $0.076^{\wedge}$ & $6.4(0.7-57)$ & $0.068 \wedge 1$ \\
\hline \multirow[t]{3}{*}{$51(48 \%)$} & physical & lalways age & $12)$ & $1.7(0.6-5.4)$ & 0.217 \\
\hline & sexual and/or physical & $2.0(0.8-5.6)$ & $0.094^{\wedge}$ & $2.0(0.7-5.8)$ & 0.109 \\
\hline & loss & $2.8(1.0-8.6)$ & 0.027 * & $4.5(0.8-35)$ & $0.057^{\wedge}$ \\
\hline \multirow{4}{*}{$\begin{array}{l}\text { depression } \\
39(37 \%)\end{array}$} & sexual (women) & $2.4(0.6-9.0)$ & $0.164^{\prime}$ & $5.3(0.9-30)$ & $0.055^{\wedge} 1$ \\
\hline & physical & & & $3.9(1.2 \cdot 13)$ & $0.009 * *$ \\
\hline & sexual and/or physical & $2.8(1.1-7.7)$ & $0.021^{*}$ & $4.1(1.4-12)$ & $0.003 * *$ \\
\hline & loss & $2.6(0.9-7.4)$ & 0.039 * & $1.4(0.3-6.8)$ & 0.445 \\
\hline \multirow{4}{*}{$\begin{array}{l}\text { anxiety } \\
40(38 \%)\end{array}$} & sexual (women) & $1.2(0.3-4.4)$ & $0.525^{\prime}$ & $1.0(0.2-5.0)$ & $0.660^{\prime}$ \\
\hline & physical & & & $3.3(1.0-11)$ & $0.025 *$ \\
\hline & sexual and/or physical & $2.3(0.8-6.2)$ & $0.060^{\wedge}$ & $2.5(0.9-7.2)$ & 0.046 * \\
\hline & loss & $0.9(0.3-2.5)$ & 0.535 & $1.5(0.3-7.5)$ & 0.409 \\
\hline \multirow{3}{*}{$\begin{array}{l}\text { any problem } \\
76(72 \%)\end{array}$} & sexual (women) & $1.7(0.3-13)$ & $0.415^{\prime}$ & $2.2(0.2 .53)$ & $0.424^{\prime}$ \\
\hline & physical & & & $>>100$ & $0.002^{* *}$ \\
\hline & sexual and/or physical & $6.4(1.4-44)$ & $0.007^{* *}$ & $11.3(1.6-255)$ & 0.004 ** \\
\hline \multirow{3}{*}{$\begin{array}{l}\text { triple problem } \\
16(15 \%)\end{array}$} & sexual (women) & $1.8(0.4-7.9)$ & $0.359^{\prime}$ & $3.9(0.7-21)$ & $0.120^{\prime}$ \\
\hline & physical & & & $2.9(0.7-12)$ & $0.086^{\wedge}$ \\
\hline & sexual and/or physical & $2.5(0.7-8.9)$ & $0.087^{\wedge}$ & $3.4(0.9-12)$ & $0.034 *$ \\
\hline
\end{tabular}

\begin{tabular}{|c|c|c|c|c|c|c|}
\hline \multirow[b]{2}{*}{$\mathrm{N}$ of patients exposed } & \multicolumn{3}{|c|}{ age $\leq 18$} & \multicolumn{3}{|c|}{ age $\leq 12$} \\
\hline & $N$ & $\%$ & missing & $\mathbf{N}$ & $\%$ & missing \\
\hline sexual (women) & 11 & 18 & 3 & 7 & 11 & 2 \\
\hline physical & & & & 19 & 18 & 0 \\
\hline sexual and/or physical & 27 & 26 & 4 & 24 & 23 & 3 \\
\hline loss & 24 & 23 & 0 & 9 & 9 & 0 \\
\hline
\end{tabular}




\section{(Legend table 2)}

Relations of dichotomous youth experience variables with psychiatric problems are presented here as odds ratios, $95 \%$ confidence intervals and significance values (subtable for each problem). Prevalences of psychiatric problems are given in the left-hand column, frequencies of abuse and loss are in a separate subtable below. Results are stratified for gender lexcept sexual abuse, as this was rarely reported by men). Significant and near- significant relations are marked:

^: $p<0.10, \quad *: p<0.05, \quad * *: p<0.01, \quad * * *: p<0.001$.

1 Fisher exact test (one-sided).

Physical abuse was more evenly distributed over the genders $(10$ men $=25 \%$, 9 women $=14 \%$ ) and had always started before age 13 . It was related to depression, to anxiety, and strongly related to 'any problem'. Among women, there were suggestions of a relation to sexual abuse (OR 2.8, CI 0.6 - 13.6, Fisher exact: $\mathrm{p}=$ 0.191).

The influence of abuse in general (physical abuse for men, physical and/or serious sexual abuse for women) was especially strong if it had started before age 13: early abuse was strongly related to depression and 'any problem'. Relations with anxiety and 'triple problem' were found too.

\section{Multivariable analyses}

Logistic regression analysis was used to assess the independent contribution of specific youth experiences to the prediction of psychiatric problems. These analyses could not establish whether the experiences we assessed are important in their own right; they might be more or less coincidental indications of a more general risk factor 'troubled youth'. As a check, we therefore combined several youth experiences in a 'trouble' scale, and then tested whether the component variables predicted better than this trouble scale.

Deprivation, other life events and abuse (sexual and/or physical) were clearly related to each other (Spearman rank correlation: deprivation - other events 0.23 , deprivation - abuse 0.45 , other events - abuse 0.26 , all significant at $p<0.01$ ). Illness, disease (self) and disease (others) could not be combined with these variables (correlations lower than 0.10 ), nor did they form a scale on their own (correlations 0.10 to 0.20 ). So deprivation, other events and abuse were combined in the 'trouble' scale (alpha $=0.53$ ). 


\section{Chapter 5}

Table 3: Independent contribution of youth experiences to prediction of psychiatric problems ( $N=102$ )

psychiatric probl. youth experience

$\mathrm{Chi}^{2}$

significance

\begin{tabular}{|c|c|c|c|}
\hline \multirow[t]{2}{*}{ somatization } & deprivation & 12.8 & 0.000 \\
\hline & predictive power & 128.6 & 0.029 \\
\hline \multirow[t]{3}{*}{ or: } & trouble & 9.3 & 0.002 \\
\hline & deprivation (given other events) & 8.5 & 0.004 \\
\hline & other events (given deprivation) & 1.4 & 0.230 \\
\hline \multirow[t]{4}{*}{ depression } & other events & 9.7 & 0.002 \\
\hline & disease (given other events) & 3.0 & 0.083 \\
\hline & other events and disease & 12.7 & 0.002 \\
\hline & predictive power & 122.0 & 0.058 \\
\hline \multirow[t]{5}{*}{ or: } & trouble & 11.2 & 0.001 \\
\hline & disease (given trouble) & 2.7 & 0.103 \\
\hline & trouble and disease & 13.9 & 0.001 \\
\hline & other events (given depriv. and disease) & 5.4 & 0.020 \\
\hline & deprivation (given other ev. and disease) & 1.1 & 0.289 \\
\hline \multirow[t]{5}{*}{ anxiety } & deprivation & 4.0 & 0.045 \\
\hline & predictive power & 130.7 & 0.021 \\
\hline & trouble & 2.2 & 0.135 \\
\hline & gender & 1.5 & 0.220 \\
\hline & deprivation (given gender) & 4.4 & 0.037 \\
\hline \multirow[t]{4}{*}{ any problem } & abuse & 8.8 & 0.003 \\
\hline & other events (given abuse) & 6.9 & 0.009 \\
\hline & abuse and other events & 15.7 & 0.000 \\
\hline & predictive power & 104.2 & 0.341 \\
\hline \multirow[t]{4}{*}{ or: } & trouble & 17.1 & 0.000 \\
\hline & predictive power & 102.8 & 0.403 \\
\hline & deprivation Igiven abuse and other events & 1.9 & 0.170 \\
\hline & predictive power & 102.3 & 0.363 \\
\hline
\end{tabular}

(Continued next page) 
(Table 3, continued)

psychiatric probl. youth experience

$\mathrm{Chi}^{2}$

significance

\begin{tabular}{|c|c|c|c|}
\hline triple problem & deprivation & 6.9 & 0.009 \\
\hline & predictive power & 81.7 & 0.908 \\
\hline or: & trouble & 3.8 & 0.051 \\
\hline & gender & 1.7 & 0.193 \\
\hline & deprivation (given gender) & 7.6 & 0.006 \\
\hline & predictive power & 97.3 & 0.928 \\
\hline
\end{tabular}

Main results of logistic regression analyses are presented in this table. For each psychiatric problem, results of forward stepwise analyses are given above, additional analyses Itrouble scale, variables forced in the model) below. For each model, the improvement $\mathrm{Chi}^{2}$ (difference in $\cdot 2 \log$ likelihood of the model with and the one without the independent variable(s) specified) and its significance value are given. The final model is printed in bold type, with its predictive power $1.2 \log$ likelihood, significance value) in italic type below (a significant value here means a weakly predicting model). As the number of patients was 102 in all analyses, degrees of freedom can be deducted from the models themselves. Regression coefficients were not essential for our goal and have been omitted. Significance values in this table are two-sided.

Deprivation was the only significant predictor of somatization (see table 3). Predictive power of this model was relatively low, indicating that other circumstances (not included in this study) must be important too. In this model gender was not a predictor, nor have interactions with gender been observed. The single variable deprivation predicted better than the 'trouble' scale it was part of, with the difference approaching significance. Deprivation also was a much stronger predictor than other life events; deprivation improved prediction significantly in a model containing other events, whereas other events did not improve prediction in a model containing deprivation.

Depression was best predicted by a model containing other life events and disease. Predictive power was low, however. Substituting trouble for other events improved the model slightly but not significantly. Here other events was a stronger predictor than deprivation, improving prediction significantly in a model containing deprivation and disease, while deprivation did not improve prediction in a model containing other events and disease. 
Figure 3: Other life events and psychiatric problems

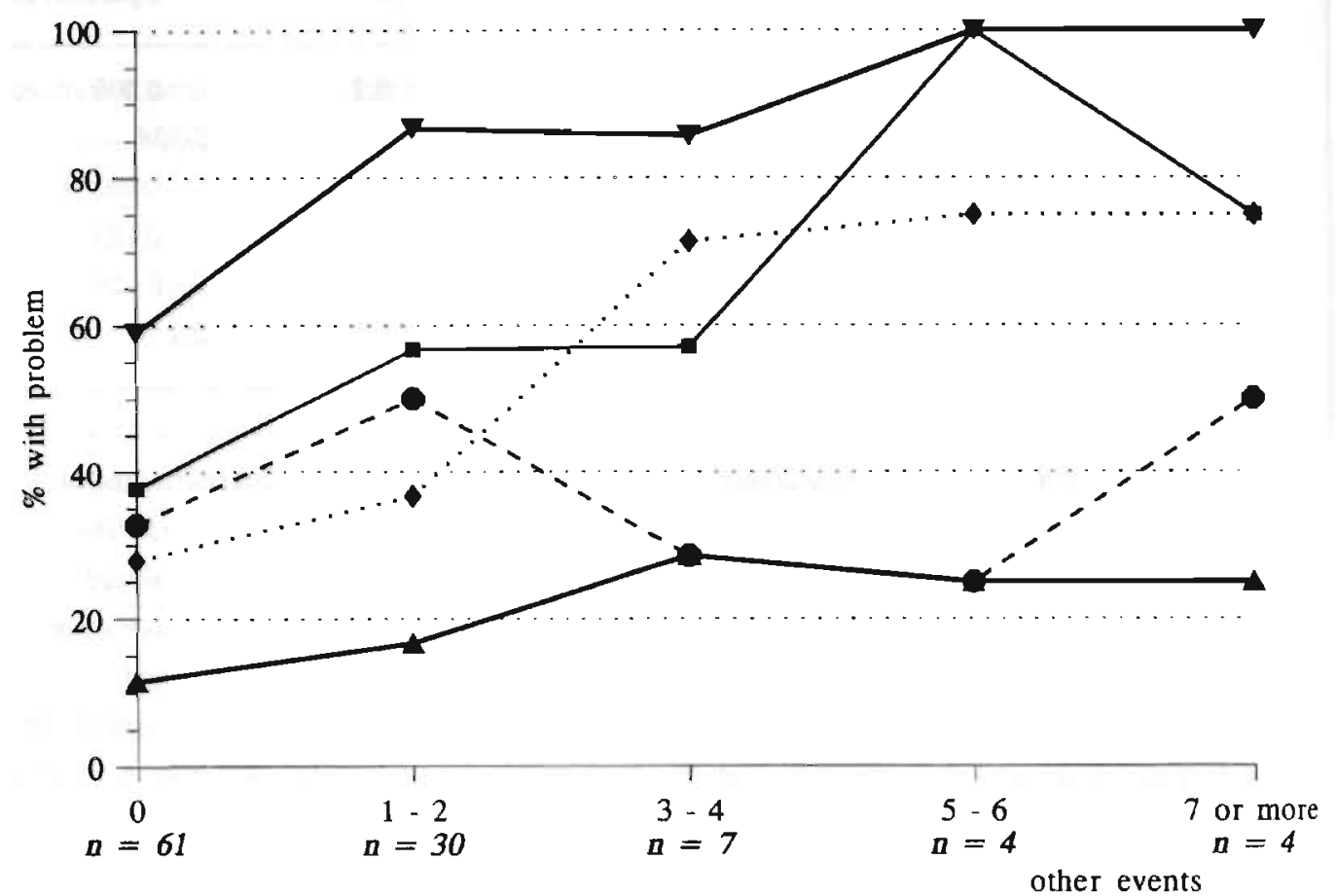

$\star$ somatization $\bullet$ depression $\bullet$ anxiety $₹$ any problem $\star$ all problems

In this figure the proportion of patients with somatization, depression, etc. is given as a function of other life events. As an aid to interpretation, the frequency distribution of other events is given too (horizontal axis, italic type).

The best model for anxiety contained only deprivation, and it was a weak one. Adding gender (probably related to anxiety in bivariate analysis) to the model made little change. Trouble was not a significant predictor.

The stepwise analysis for 'any problem' resulted in a model with abuse and other life events. This model was much stronger than the models for specific problems. With abuse and other events already included, deprivation did not improve prediction significantly. This model could be simplified; a model with only the trouble scale predicted as well as the two- or three-variable ones. 
Deprivation was the only predictor of 'triple problem'. The model appeared to predict very well, but this should be interpreted cautiously because of small numbers. Controlling for gender did not change the model significantly. 'Trouble' was a much weaker predictor than deprivation.

\section{Discussion}

Our findings confirm that common psychiatric problems are related to troubled youth. This holds for somatization and depression, and to a lesser extent for anxiety. Together these problems account for most psychiatric problems in the general population, and consequently of general practitioners' workloads. The population studied is an important risk group well known to the general practitioner: frequent attenders with unexplained somatic complaints. The results of this study indicate which patients might benefit from the active attention of the general practitioner. While the general practitioner's opportunities for prevention of a troubled youth may be few, he can offer extra support or guidance to a patient he knows as vulnerable because of it. Troubled childhood and adolescence may also be an explanation for somatization, depression or anxiety that patient and general practitioner can agree upon. This alone may help the patient by easing feelings of guilt or doubt.

Finding relations between troubled youth and later psychiatric problems is not surprising. What is new is that we found them using a survey design in a fairly small study group that was neither specifically selected on troubled youth, nor on psychiatric problems. Studies on prognosis of severely troubled (for example institutionalized) children are hardly applicable to a general practice population. The same goes for case control studies in institutional care populations, that besides may suffer from selection bias. ${ }^{33}$

\section{Methodological considerations}

Negative results in this study have little value as evidence, because of the relatively small number of patients included (see confidence intervals in table 2). On the other hand this guards against conclusions about relations that are statistically significant, but too weak to be theoretically meaningful.

Data on youth experiences were gathered retrospectively, with an inherent risk of information bias; psychiatric problems might make one reconstruct one's memories in search of meaning. To a certain extent, this was circumvented by 


\section{Chapter 5}

asking for discrete, easy-to-remember situations or events (see appendix). Our survey design and study population make serious bias unlikely anyhow; inclusion criteria were the same for all patients, and few had a history of chronic psychiatric disability or long-term care.

Our study adresses patients that have increased risk of becoming chronically disabled, losing their job and social contacts as a result. To some extent our findings can also be extrapolated to the general practitioner's waiting room population, as this kind of patients is overrepresented there. They cannot be extrapolated to the general population.

\section{Relations between somatization, depression and anxiety}

Prevalence of somatization in the general population is estimated to be about $5 \%$, of (lifetime) depression about $8 \% .^{29}$ If we lump anxiety disorders together, estimated prevalence is about $15 \% .^{34} 35$ Prevalences in this study were much higher, as a result of our inclusion criteria. The inclusion criteria, however, do not explain the high frequency of 'triple problem' (somatization and depression and anxiety) compared to frequencies of two of the three. Orenstein found this pattern of relations for somatization disorder patients. ${ }^{37}$ He hypothesized a diathesis for 'comorbidity' in some patients to explain this. Results of a large-scale study in the general population are consistent with this explanation. ${ }^{36}$ For a description of our results, concepts like 'somatic anxiety' or 'anxious depression' are unnecessary; they might be dropped in favour of a term emphasizing the multiple and diverse symptoms of patients with a combination of somatization, depression and anxiety. We suspect that many difficult patients in general practice belong to this group, as they have two problems that may interfere with the treatment strategy for the third. In their youth experiences, though, these patients are hardly distinguishable from the other patients; deprivation is the most important predictor. The concept of 'somatized' or 'masked' depression is, tentatively, validated in our results. It applies to a small group of patients, however.

\section{Influence of illness experiences}

Our results do not prove that confrontation with illness or disease in youth is unrelated to later somatization. They do suggest that other factors are more important in a general practice population. The discrepancy with the literature (for somatization disorder stronger relations were found) is probably a result of a difference in threshold. ${ }^{45}$ Disease (and confrontation with disease or illness 
behaviour in parents or siblings) might be an all-or-nothing risk factor, either causing serious somatization in youth that progresses into somatization disorder, or not having much influence in the long run. This explanation implies a qualitative difference between somatization disorder and our more comprehensive definition of somatization. However, the literature has suggested differences in degree, not kind. ${ }^{32}$ Relations with illness experiences found can also be explained as early symptoms of, rather than causal factors for somatization disorder.

In our population, disease in youth seems to be more important as a life event (see below) than because of its health-related connotations.

\section{Influence of deprivation}

Bowlby's attachment theory, often the implicit theoretical foundation of many studies on deprivation, emphasizes the quality and continuity of care: who the primary caregiver is, is irrelevant.' In many studies, though, deprivation was operationalized narrowly as loss of a parent, with somewhat conflicting results. ${ }^{8}$. ${ }^{10}$ Our broader operationalization was an independent risk factor for both somatization and anxiety. This strengthens Katon's hypothesis of somatization as a learned response; a child learning by differential reinforcement "bow to elicit nurturance from a caregiver: complaining about a beadache rather than about being sad ..." and learning to attribute symptoms to somatic causes.' In this view, other circumstances (life events) might lead to later problems too, but not to this translation of primarily psychosocial needs into somatic symptoms.

\section{Influence of life events}

With life events related to illness experiences, deprivation or abuse excluded, what remains is the frequency of disruptive changes, like moving house frequently. These other events are the primary risk factor for later depression. Specificity of deprivation-somatization and other events-depression relations suggests distinct causal mechanisms: other life events and disease generally are unexpected, unavoidable and impossible to cope with actively; their influence is relatively shortlived. Apparently they predispose to a passive/depressive coping style, and thereby to later depression. In many deprived situations, on the other hand, the child can understand why things happen (or at least think he does) and do something. This interpretation is supported by the finding that helplessness and perceived vulnerability to loss following loss of a parent have been shown to predict later depression better than the loss itself. ${ }^{38}{ }^{39}$ 


\section{Influence of abuse}

A lower prevalence of sexual abuse was found than we expected on the basis of the literature. ${ }^{218}$ Sexual abuse may have been underreported; patients frequently disclose abuse gradually after experiencing that the interviewer believes them and reacts with empathy. ${ }^{2}$ In this study women could not deny abuse and come back to the topic later. This explanation is supported by the low prevalence of sexual abuse reported in a study with a comparable procedure. ${ }^{40}$ As a result, we may have underestimated relations between sexual abuse and psychiatric problems. The general practitioner does have the opportunity to use a question about sexual abuse as an invitation to return to the topic when and if the patient wishes. Our experiences with the patients have convinced us that he should do so. Some of the women in this study indicated that we were the first people they had ever told about it. Some thanked us for causing them to rethink past events and the way they lived with them now.

Physical abuse may be less of a taboo, distinguishing it from the well-deserved spanking most of us have had is, however, difficult. Our operationalization led us to find a fairly high prevalence (in men) and a doubled risk of depression and anxiety. Physical abuse probably is as important as sexual abuse.

The effect of abuse is clearer if serious sexual abuse and physical abuse are combined: a general practitioner may expect that among his frequent attenders, every fourth patient, man or woman, has been abused before age 13. Abuse in these patients doubles the risk of depression, and increases that of anxiety as well.

\section{Influence of trouble in general}

Deprivation, other life events and abuse: are they causes of later psychiatric problems? Or are they more or less coincidental manifestations of an underlying cause or causes? The question is important: if they are manifestations, not causes themselves, preventive efforts aimed at them may be useless. The data available cannot give an answer directly, but the specificity of the deprivation-somatization and other events-depression relations found provides a clue. If not causes themselves, deprivation and other events are at least manifestations of separate causes. Our comparison of specific youth experiences with the overall trouble scale was based on the same reasoning; the more specific a relation, the less likely an interpretation was to be as the result of some confounder not measured in this study. These comparisons supported a causal interpretation. Combining deprivation with other events and abuse did not improve prediction of somatization beyond deprivation alone; it probably worsened it. For 'triple problem' we found 


\section{Troubled youth and psychiatric problems}

the same. Differences were small for depression and anxiety, which implies a choice for the specific model; the broad trouble scale was not a (significantly) better predictor than deprivation and other events, respectively. Besides, a specific relation of other events with depression was not to be expected: deprivation and abuse contained events too.

\section{Recommendations}

The key findings of this study, such as the high number of patients with a 'triple problem' and the specificity of the deprivation-somatization and other life eventsdepression relations, had not been hypothesized beforehand. A replication study would therefore be valuable, with different inclusion criteria (patients with tiredness, for instance) and ideally in a population more resembling the general population.

Too little is known about therapeutic possibilities for parients with a troubled youth for experiments to be designed. Some insight could be gained with a study on general practitioners' working style and knowledge about their patients' youth experiences in relation to outcome in these patients.

Troubled childhood and adolescence is probably disclosed gradually by the patient more often than diagnosed through specific questioning by the general practitioner. Empathy and preventing hurried surgery hours are therefore as important as diagnostic acumen. The general practitioner may prefer not to record sensitive information like indications of trouble in youth. The lasting effects of trouble are a strong argument for careful recording, if only for the general practitioner's successor.

\section{References}

1 Bowlby J. Developmental psychiatry comes of age. Am J Psychiatry 1988; 145: 1-10

2 Draijer N. Seksueel misbruik van meisjes door verwanten: Een landelijk onderzoek naar de omvang, de aard, de gezinsachtergronden, de emotionele betekenis en de psychische en psychosomatische gevolgen [Sexual abuse of girls by relatives: A national study of prevalence, nature, family backgrounds, emotional significance and psychic and psychosomatic consequences]. Den Haag: Ministerie van Sociale Zaken en Werkgelegenheid, 1988

3 Lipowski ZJ. Somatization: The concept and its clinical application. Am J Psychiatry 1988; 145: 1358-1368

4 Hartvig P, Sterner G. Childhood psychological environmental exposure in women 


\section{Chapter 5}

with diagnosed somatoform disorders: A case-control study. Scand J Soc Med 1985; 13: 153-157

Bass C, Murphy M. Medical problems of adults who were sexually abused in childhood. BMJ 1990; 300: 1197

6 Huygen FJA. Family medicine: The medical life history of families. Nijmegen: Dekker \& van de Vegt, 1978

Katon W, Kleinman A, Rosen G. Depression and somatization: A review: Part I. Am J Med 1982; 72: 127-135

8 Patten SB. The loss of a parent during childhood as a risk factor for depression. Can J Psychiatry 1991; 36: 706-711

2 Kendler KS, Neale MC, Kessler RC, Heath AC, Eaves LJ. Childhood parental loss and adult psychopathology in women: A twin study perspective. Arch Gen Psychiatry 1992; 49: 109-116

${ }^{10}$ Hallstrom T. The relationships of childhood socio-demographic factors and early parental loss to major depression in adult life. Acta Psychiatr Scand 1987; 75: 212-216

$"$ Bifulco AT, Brown GW, Harris TO. Childhood loss of parent, lack of adequate parental care and adult depression: A replication. J Affect Disord 1987; 12: 115-128

12 Kendler KS, Kessler RC, Neale MC, Heath AC, Eaves LJ. The prediction of major depression in women: Toward an integrated etiologic model. Am J Psychiatry. 1993; 150: 1139-1148

13 Tweed JL, Schoenbach VJ, George LK, Blazer DG. The effects of childhood parental death and divorce on six-month history of anxiety disorders. Br J Psychiatry 1989; 154: 823-828

${ }^{14}$ Fry R. Adult physical illness and childhood sexual abuse. J Psychosom Res 1993; 37: 89-103

${ }^{15}$ Faravelli C, Sacchetti E, Ambonetti A, Conte G, Pallanti S, Vita A. Early life events and affective disorder revisited. Br J Psychiatry 1986; 148: 288-295

${ }^{16}$ Faravelli C, Webb T, Ambonetti A, Fonnesu F, Sessarego A. Prevalence of traumatic early life events in 31 agoraphobic patients with panic attacks. Am J Psychiatry 1985; 142: 1493-1494

17 Bushnell JA, Wells JE, Oakley Browne MA. Long-term effects of intrafamilial sexual abuse in childhood. Acta Psychiatr Scand 1992; 85: 136-142

1s Craine LS, Henson CE, Colliver JA, MacLean DG. Prevalence of a history of sexual abuse among female psychiatric patients in a state hospital system. Hosp Community Psychiatry 1988; 39: 300-304

19 Walker EA, Katon WJ, Hansom J, Harrop Griffiths J, Holm L, Jones ML, Hickok L, Jemelka RP. Medical and psychiatric symptoms in women with childhood sexual abuse. Psychosom Med 1992; 54: 658-664

${ }^{20}$ Arnold RP, Rogers D, Cook DA. Medical problems of adults who were sexually abused in childhood. BMJ 1990; 300: 705-708

${ }^{21}$ Mullen PE, Romans Clarkson SE, Walton VA, Herbison GP. Impact of sexual and physical abuse on women's mental health. Lancet 1988; 1(8590): 841-845

22 Andrews B, Brown GW, Creasey L. Intergenerational links between psychiatric disorder in mothers and daughters: The role of parenting experiences. J Child Psychol Psychiatry 1990; 31: 1115-1129 


\section{Troubled youth and psychiatric problems}

23 Metsemakers JFM, Höppener P, Knottnerus JA, Kocken RJJ, Limonard CBG. Computerized health information in the Netherlands: A registration network of family practices. Br J Gen Pract 1992; 42: 102-106

24 Sandlow LJ, Bashook PG. Problem oriented medical records: Self instruction for practitioners. Chicago: Michael Reese Hospital and Medical Center, 1978

25 Portegijs PJM, Horst FG van der, Proot IM, Kraan HF, Gunther NCHF, Knottnerus JA. Somatization in frequent attenders of general practice. Soc Psychiatry Psychiatr Epidemiol 1996; 31: 29-37

${ }^{26}$ Bie SE de. Standaardvragen 1987: Voorstellen voor uniformering van vraagstellingen naar achtergrondkenmerken in interviews [Standard questions 1987: Proposals for uniformization of interview questions about background characteristics]. Leiden: VOI, Vereniging van Onderzoek Instituten, Stuurgroep Dataverzameling, 1987

27 Robins LN, Helzer JE, Croughan J, Ratcliff KS. The NIMH Diagnostic Interview Schedule: Its history, characteristics, and validity. Arch Gen Psychiatry 1981; 38: 381-389

28 Dingemans P, Engeland $\mathrm{H}$ van, Dijkhuis JH, Bleeker J. De 'diagnostic interview schedule' (DIS). Tijdschrift voor Psychiatrie 1985; 27: 341-359

29 Escobar JI, Rubio-Stipec M, Canino G, Karno M. Somatic symptom index (SSI): A new and abridged somatization construct: Prevalence and epidemiological correlates in two large community samples. J Nerv Ment Dis 1989; 177: 140-146

${ }^{30}$ Portegijs PJM, Kraan HF, Knottnerus JA, Stoffers HEJH. Wat heet somatisatie? 1. Een zoektocht in de internationale literatuur naar een definitie voor huisartsgeneeskundig onderzoek [What do we call somatization? 1. A search of the international literature for a definition to be used in general practice research]. [abstract in English] Huisarts en Wetenschap 1992; 35: 18-25,43

31 Epi Info: Version 3 [computer program]. Atlanta: Epidemiology Program Office, Centers for Disease Control, 1988

32 Gustafson TL. True Epistat [computer program]. Richardson, Texas: Epistat Services, 1987

${ }^{33}$ Knottnerus JA. The effects of disease verification and referral on the relationship between symptoms and diseases. Med Decis Making 1987; 7: 139-148

${ }^{34}$ Robins IN, Helzer JE, Weissman MM, Orvaschel H, Gruenberg E, Burke JD, Regier DA. Lifetime prevalence of specific psychiatric disorders in three sites. Arch Gen Psychiatry 1984; 41: 949-958

35 Angst J, Dobler Mikola A. The Zurich Study: V. Anxiety and phobia in young adults. Eur Arch Psychiatry Neurol Sci 1985; 235: 171-178

${ }^{36}$ Vollrath M, Koch R, Angst J. The Zurich Study: IX. Panic disorder and sporadic panic: Symptoms, diagnosis, prevalence, and overlap with depression. Eur Arch Psychiatry Neurol Sci 1990; 239: 221-230

37 Orenstein H. Briquet's syndrome in association with depression and panic: A reconceptualization of Briquet's syndrome. Am J Psychiatry 1989; 146: 334-338

35. Harris TO, Brown GW, Bifulco AT. Depression and situational helplessness /mastery in a sample selected to study childhood parental loss. J Affect Disord 1990; 20: 27-41

39 Mireault GC, Bond I.A. Parental death in childhood: Perceived vulnerability, and adult depression and anxiety. Am J Orthopsychiatry 1992; 62: 517-524 
Chapter 5

${ }^{40}$ Ernst C, Angst J, Foldenyi M. The Zurich Study. XVII. Sexual abuse in childhood. Frequency and relevance for adult morbidity data of a longitudinal epidemiological study. Eur Arch Psychiatry Clin Neurosci 1993; 242: 293-300 


\section{Appendix: Youth experiences questionnaire}

Introduction: I now want to ask you some questions about your youth, and about the family you grew up in. All questions concern events or situations before your $19^{\text {th }}$ birthday.

Illness of the patient

scale

Did you have more frequent illnesses than your classmates or collegues? yes/no Did you sometimes feel ill (or pretend to feel ill) just before a test at school, and stay at home?

yes/no

Did you ever have to repeat a class because of frequent illness?

yes/no

Did you often see the general practitioner in primary school years?

if more than seldom

\section{Disease of the patient}

Did you ever have episodes of serious disease?* $\quad 0,1, \geq 2$ times

Were you ever admitted to hospital?*

$0,1, \geq 2$ times

\section{Disease of family members}

Were your parents always in good health?*

$0,1,2$ parents

Were your sisters, brothers (other household members) always in

good health?*

$0,1, \geq 2$ members

\section{Deprivation}

Have your ever lived in a foster home, boarding school or institution?** yes/no Did your father or mother die?

0, 1, 2 parents

Were your parents divorced? yes/no

Did your father or mother ever have a nervous breakdown?

$0,1,2$ parents

Did you have heavy duties to perform in the family? (if necessary the interviewer elucidates: Did you do work or have responsibilities that would not have been asked of other children of the same age? $) * 2 \%$ yes/no Did your mother or father involve you with their own problems? ? $^{2 *} \quad$ yes/no

\section{Other life events}

Did a sister or brother die?

yes/no

Did you move house frequently? (other neighbourbood, after age four)

count

Were you ever cared for outside your own family for a period of

three or more months before age six?

Did you experience other very major life events before your $19^{\text {th }}$ birthday? count 


\section{Chapter 5}

\section{Abuse}

Introduction: I now want to ask a few questions about subjects that are difficult to discuss for many persons: traumatic experiences you may have had in your youth. For our study these are important questions. If, however, you find it difficult to answer these questions, I 'd rather you kept silent than be upset about it afterwards.

\section{Physical abuse} scale

Were you ever beaten in your youth?

\section{a Did you feel threatened then?}

b Did you ever see a doctor or social worker in connection with beatings or punishment?

c What did these beatings mean for you then? (positive if $a$ or b positive, and $c$ indicates gravity)

\section{Sexual abuse}

Did you as a child (before your $15^{\text {th }}$ birthday) ever have sexual experiences that you did not want?

a Would you tell me what happened then?

b - j: age, person involved, frequency, threats, feeling threatened, violence, meaning for the patient, support then, support later.

\section{(scoring following Draijer)}

Have you ever been sexually assaulted since your $15^{\text {th }}$ birthday?

$\mathrm{a}-\mathrm{i}$ : follow-up questions comparable to previous a - j.

(scoring following Draijer)

* Answers written down, later coded according to the ICPC, positive if diagnosis of serious (life threatening, disabling or chronic) disease.

w. Having lived in a boarding school in the Netherlands indicates family problems more often than good education.

*n*t Answers discussed by the interviewer to ascertain that it really concerned a serious burden in relation to the age of the patient. 


\section{Somatization and somatic complaints in primary care "}

\section{Relations with depression and stress}

\section{Abstract}

Objective: A common terminology across disciplines is necessary for somatization. However, somatization has been defined as a psychiatric disorder, personality trait, symptom of psychiatric disorder, and as somatic complaints. In this article we have tried to clarify relations of these concepts with each other, with depression and with stress. Method: 106 Dutch family practice patients aged 20-44 years with a history of back, neck or abdominal complaints and high medical consumption were interviewed. Instruments were the Diagnostic Interview Schedule, the SCL-90 and questionnaires for social support, chronic difficulties and major life events.

Results: Somatization trait (more comprehensive version of DSM-III-Rsomatization disorder definition, threshold 5 complaints: Somatic Symptom Index 5/5) was associated with somatic complaints in the previous week. However, relations between somatization trait and lifetime depression/dysthymia, as well as relations between somatic complaints and recent depressive complaints/episode, were stronger. Somatization trait was related to chronic difficulties and to lack of support from the parents. While support was an independent predictor of somatization trait, difficulties were not; deprivation in youth explained the bivariate relation. Patients with mild somatization (5-9 complaints) were distinct

Portegijs PJM, Kraan HF, Horst FG van der, Meertens HMHJ, Knottnerus JA. Somatization and somatic complaints in primary care: Relations with depression and stress. Submitted 


\section{Chapter 6}

from both patients without, and patients with serious $(\geq 10)$ somatization. Somatic complaints generally were unrelated to support, difficulties and events. Conclusions: Somatization trait is a stable characteristic with origins in youth that is relevant for present well-being. It is neither a psychiatric disorder, nor a symptom of one, nor can it be equated with somatic complaints. In its mild form it needs attention because of risks of dysthymia and medicalization. Serious somatization is related to frequent depressive episodes.

\section{Introduction}

The problem of somatization transgresses disciplinary boundaries. Most studies in this field have been performed from a psychiatric or psychological viewpoint. This has led to the advice that the general practitioner or other primary care physician is in the best position for longterm guidance of these patients. ${ }^{1}{ }^{2}$ The patients themselves, however, generally put their faith in medical specialists. Therefore, some knowledge about somatization is necessary for almost any physician. A common language across disciplines is necessary too, which means both an unambiguous (and broadly accepted) definition, and clearly described characteristics.

Lipowski has provided a general definition that most authors agree on: " $a$ tendency to experience and communicate somatic distress and symptoms unaccounted for by pathological findings, to attribute them to physical illness, and to seek medical help for them. "3 For research purposes, however, this definition had to be sharpened, which has led to four separate concepts of somatization, each with its own clinical characteristics, prognosis and treatment options. Somatization has been defined as:

* A primary psychiatric disorder, characterized by a long-lasting pattern of chronic or recurrent somatic complaints starting early in life; DSM-III-R somatization disorder. This definition is valid, but too restrictive for general use. $^{34}$

* A milder form of the above, that is not necessarily maladaptive within the social context of the patient and therefore should not be called a psychiatric disorder; the Somatic Symptom Index (SSI). ${ }^{4}$ Somatization could be seen as a personality trait (axis II). ${ }^{6}$

* A symptom of psychiatric disorder, for instance depression (according to Bridges). ${ }^{79}$ 
* Somatic complaints themselves, as in the SCL-90 somatization subscale. ${ }^{10}$ 11 12 There is an implicit assumption here that these complaints are (almost) unrelated to somatic disease.

Henceforth we will refer to these notions as 'somatization disorder', 'somatization trait', 'Bridges' concept of somatization' and 'somatic complaints', respectively. By 'somatization' we will denote somatization in general. Escobar and Lipowski have described these concepts theoretically. ${ }^{3}{ }^{4}$ However, to date, only one study has explicitly aimed at construct-validating their distinction, that is: showing that these concepts have different characteristics. ${ }^{13}$

If somatization is conceptualized as related to or a symptom of psychiatric disorder, mood and anxiety disorders are the most important ones to study. Evidence for a relation with mood disorders is stronger than for anxiety disorders. ${ }^{14}{ }^{15} 16{ }^{17}$ Most relevant here is a specification of the element of time. If a strong somatization trait - recent depressive complaints/disorder relation were found and a much weaker relation between lifetime depressive episode (or dysthymia) and recent somatic complaints, this would suggest that somatization trait is the primary problem.

Most of the proposed theoretical mechanisms of somatization implicate stress as a causal factor. ${ }^{6}$ Lipowski almost included it in his definition of somatization: "It is usually assumed that this tendency becomes manifest in response to psychosocial stress brought about by life events and situations that are personally stressful to the individual. ${ }^{n 3}$ Measuring subjective stress is hardly informative, since cause (stressor) and effect (response, for instance somatic complaints) are inextricably linked. Following Brown and Harris, we divided stressors in major life events, chronic difficulties and (lack of) social support. This division avoided bias by the somatic complaints themselves, closely followed Lipowski's description, and offered an opportunity for comparison with depression. ${ }^{18}$ i9

Studies in psychiatric or somatic specialist populations give biased knowledge about somatization in the population, as somatization itself and its associated characteristics influence whether a patient is referred, and to whom. The central position of the general practitioner in the Dutch health care system offered an opportunity to select a fairly representative, high-risk sample for the study of somatization. We studied patients with high medical consumption and a history of back, neck or abdominal complaints. 


\section{Chapter 6}

In the following we will concentrate on somatization trait and somatic complaints, and present data on a criterion close to that of somatization disorder ('serious somatization') too. Bridges' concept of somatization, being based on the presenting complaint in a specific consultation, could not be assessed in our study.

Earlier we have reported a relation between somatization trait and deprivation of parental care in youth. ${ }^{17}$ Relevant here is whether this relation is mediated by support, difficulties or events.

The study questions were:

1 Among high-consuming general practice patients with vague somatic complaints, what are the relations between somatic complaints, somatization trait and serious somatization?

2 What are the relations between somatic complaints, somatization trait and serious somatization on the one hand and depressive complaints, major depressive disorder and dysthymia on the other?

3 Are social support, chronic difficulties and/or major life events related to somatic complaints, somatization trait and/or serious somatization?

4 Does deprivation in youth explain relations of support, difficulties and/or events with somatization trait?

\section{Methods}

\section{Subjects}

Patients were selected on a high medical consumption, absence of interfering somatic or psychiatric problems, and a comparable medical history (in order to obtain acceptable homogeneity). This was accomplished by a two-stage selection procedure, first on age and health problems in the Registration Network of Family Practices (RNH) of the Universiteit Maastricht, then on medical consumption in the general practitioners' files. ${ }^{20} \mathrm{~A}$ computerized selection was made on age (20 - 44 years), history of chronic or recurrent back, neck or abdominal complaints, absence of active serious somatic diseases and absence of (a history of) psychiatric disorders other than mood and anxiety disorders. ${ }^{20}{ }^{21}$ Then the general practitioner selected patients with 15 or more consultations in the previous three years without compelling somatic reason for encounter and invited 
them to participate. ${ }^{22}$ " If they agreed, the interviewer visited them at home. After complete description of the study to the patients, written informed consent was obtained. The protocol has been described in detail elsewhere. ${ }^{23}$

\section{Instruments}

Somatization trait, major depressive disorder and dysthymia were assessed by means of the relevant sections of the Diagnostic Interview Schedule (DIS). ${ }^{24} 25$ Somatization trait was operationalized as a more comprehensive version of the DSM-III-R criterion for somatization disorder, with 5 instead of 13 complaints (and start of first complaint before age 30). ${ }^{5}{ }^{23}$ The number of patients with somatization disorder was too low for meaningful analyses. Therefore a slightly more inclusive criterion was used for 'serious somatization': 10 complaints. ${ }^{26} \mathrm{v}$ For major depressive disorder and dysthymia original DIS criteria (based on DSM-III) were used, except that major depressive disorder was not used as exclusion criterion for dysthymia. Somatic and depressive complaints in the previous week were assessed with the SCL-90 subscales for somatic complaints and depression, standardized for the normal Dutch population of the same $\operatorname{sex} .^{10}$ ${ }^{28}$ To enable comparison of the ordinal SCL- 90 subscales with the somatization trait, major depressive disorder and dysthymia variables, the SCL-90 subscales were dichotomized. Cut-off points were chosen to yield about the same prevalences.

Social support was assessed using the seven-item Groningen Network list C (GNC).(Ormel J, unpublished manuscript) The GNC closely resembles the Social Support Questionnaire of Schaefer et al, that is judged to be a good measure of perceived support. ${ }^{29}{ }^{30}$ The patients were asked to name the five persons most important in their life and to fill out the GNC for each of them. Difficulties and events were measured with questionnaires adapted from the Dutch (interview) version of Brown and Harris' Life Events and Difficulties Schedule. ${ }^{18}$ For difficulties we used the 16-item Groningen List of Chronic Difficulties (GLIM), with subscales for 'relational difficulties' and 'other difficulties' (difficulties at work, etc.). ${ }^{31} 32 \mathrm{We}$ added a question about difficulties in leisure activities. Events were measured with a self-designed 55-item checklist, adapted from the Groningen

The average number of consultations with Dutch general practitioners (for all reasons for encounter) with patients in the age group $25-44$ years is about 3.5 per year. 
Events List (GGL). ${ }^{32}$ We divided it into positive (e.g. 'found new partner'), indeterminate ('moving house') and negative ('divorce') events.

\section{analysis}

The dimensional structure and reliability of the GNC, GLLM and the events checklist were assessed. Results, and details of other analyses (gender differences, logistic regression) are available from the authors.

Interrelations of somatization and depression were described as odds ratios, and tested by means of the $\mathrm{Chi}^{2}$ test or Fisher exact test (where indicated). For relations with support, difficulties and events we used the Mann-Whitney U test.

Somatization trait and serious somatization are dichotomous variables based on a single (ordinal) variable, which resulted in data being analyzed twice. We also analyzed somatization as a trichotomous variable (no somatization: $\leq 4$, mild: $5-9$, serious somatization: $\geq 10$ complaints), testing overall significance with the $\mathrm{Chi}^{2}$ test for linear trend and the Kruskal-Wallis test. In the tables we present results as if somatization trait and serious somatization were separate variables, as these results are valid in themselves (if one does not combine them), more comparable to the literature, and more easily presented. Where relevant, results of the trichotomous analyses are mentioned in the text.

The fourth question (relations after adjustment for parental deprivation) was investigated with logistic regression analysis (likelihood ratio probability-to-enter 0.10 , probability-to-remove 0.20 ).

Unless otherwise stated, there were no missing values. Significance levels for bivariate analyses are one-sided, for logistic regression analyses two-sided. All analyses were done with SPSS-PC+ version 4.0.

\section{Results}

\section{Patient selection and sociodemographic variables}

The general practitioners invited 166 patients to participate (185 eligible, 19 excluded by the general practitioner). Fifty-five patients refused; 5 were excluded because of missing data. Results from 106 patients are presented here. Except for one patient, this is the same group as reported on earlier. ${ }^{17}$

Women were slightly overrepresented ( 65 women, 41 men), mean age was 35 year. Most of the patients were living with partner (87) and/or children (75). 
Forty percent (42) had at least intermediate vocational or general secondary education. Half of them (53) had a paid job or studied.

\section{Relations between operationalizations of somatization}

Patients reported many somatic complaints in the previous week; half of them scored 'high' or 'very high' in comparison to the normal Dutch population (see table 1). Somatization trait was reported by 51 patients ( $48 \%$ ). There were four patients with DSM-III-R somatization disorder. For further analyses a slightly more inclusive criterion of 'serious somatization' was used (10 instead of 13 complaints, $\mathrm{n}=15$ ).

Somatic complaints were related to somatization trait; odds ratio $2.0, \mathrm{p}=$ 0.040 . The relation was modest, the overlap ( 30 patients) being only 4.5 patients more than expected by chance (kappa $=0.17$ ) At higher thresholds (serious somatic complaints and serious somatization) the relation might be stronger, but it did not reach significance because of small numbers. Gravity of somatization (coded as 'no', 'mild', 'serious') was probably related to somatic complaints ( $\mathrm{p}=$ 0.055).

\section{Relations of somatization with depression}

Depressive complaints in the previous week were not particularly frequent; median score was 'average' (as compared to the normal Dutch population, data not shown). A lifetime depressive disorder was reported by 34 patients ( $32 \%$ ). Five of them were currently depressive. For further analyses they were joined up with the 14 patients who had been depressive the previous year ('recent depression'). Dysthymia was reported by 15 patients (14\%), nine of whom had 'double depression' (both major depressive disorder and dysthymia).

Somatic complaints were clearly related to depressive complaints and to depression, both recent and lifetime. A relationship with dysthymia was not found. Somatization trait, on the other hand, was related to dysthymia, while the relationship with depressive complaints seemed to be weaker. The relation between somatization trait and recent depression did not reach significance. The relation between somatization trait and lifetime depression was about as strong as the one between somatization trait and dysthymia.

Gravity of somatization was significantly related to all operationalizations of depression. Dysthymia specifically differentiated between no somatization ( $\leq 4$ complaints) and mild somatization (5 - 9 complaints) (odds ratio $3.6, p=0.042$ ). 


\section{Chapter 6}

Table 1: Interrelations of somatization and depression

\begin{tabular}{|c|c|c|c|c|}
\hline odds ratio & $\begin{array}{l}\text { somatic } \\
\text { complaints }^{1} \\
N=53\end{array}$ & $\begin{array}{l}\text { serious } \\
\text { somatic compl. } \\
13\end{array}$ & $\begin{array}{l}\text { somatization } \\
\text { trait } \\
51\end{array}$ & $\begin{array}{l}\text { serious } \\
\text { somatization } \\
15\end{array}$ \\
\hline somatic complaints ${ }^{\top}$ & & $(13)^{3}$ & 30 & $g$ \\
\hline serious somatic compl. ${ }^{2}$ & n.a. ${ }^{3}$ & & 8 & 4 \\
\hline somatization trait & $2.0 *$ & 1.9 & & $(15)^{3}$ \\
\hline serious somatization & 1.6 & $3.3^{\wedge}$ & n.a. ${ }^{3}$ & \\
\hline depressive complaints ${ }^{2}$ & $16.9 * *$ & $14.3 * * *$ & $3.1 *$ & 1.8 \\
\hline recent depression & $3.4 *$ & $3.5^{\wedge}$ & 1.6 & $5.8 *$ \\
\hline ever depression & $2.9 *$ & 2.0 & $2.7 *$ & $4.0^{*}$ \\
\hline dysthymia & 0.6 & $3.3^{\wedge}$ & $3.5 *$ & 1.6 \\
\hline
\end{tabular}

Relations between operationalizations of somatization and depression are presented in the lower left triangle of the table as odds ratios with indication of significance levels, normal type. Additionally, the data themselves are shown as the overlap of operationalizations in the upper right triangle labsolute numbers, italic type, there were no missing values). Significance levels: ${ }^{\wedge}=p<0.1$, * $=p<0.05, \quad * * p<0.01, \quad * *=p<0.001$ (one-sided Chi ${ }^{2}$ or Fisher exact)

Recent depression differentiated between mild and serious ( $\geq 10$ complaints) somatization (odds ratio 7.0, $\mathrm{p}=0.009$ ).

Stress and somatic complaints

Relations between somatic complaints and overall support, difficulties or events were not found (see table 2). We did find a relation with other (= non-relational) difficulties, and with indeterminate (= not clearly positive or negative) events. Since positive events -if at all- were negatively related to complaints, we repeated the analysis for indeterminate/negative events: $p=0.036$.

Choosing a higher threshold for somatic complaints influenced results: although the number of patients was smaller, strong relations with difficulties were found, and an almost-significant relation with events (after restriction to indeterminate and negative events significant: $p=0.014$ ). 
Table 1: (continued)

$\begin{array}{lllll}\begin{array}{l}\text { depressive } \\ \text { complaints }^{2}\end{array} & \begin{array}{l}\text { recent } \\ \text { depression }\end{array} & \begin{array}{l}\text { ever } \\ \text { depression }\end{array} & \text { dysthymia } & \text { N of patients } \\ 14 & 19 & 34 & 15 & 106\end{array}$

\begin{tabular}{ccccc}
13 & 14 & 23 & 6 & 53 \\
7 & 5 & 6 & 4 & $\llcorner 13$ \\
10 & 11 & 22 & 11 & 51 \\
3 & 7 & 9 & 3 & \multicolumn{1}{c}{15} \\
$4.6^{\circ}$ & 6 & 7 & 4 & 14 \\
$2.4^{2.9}$ & n.a. $^{3}$ & $(19)^{3}$ & 4 & $r^{19}$ \\
\hline
\end{tabular}

'high' or 'very high' versus 'very low' to 'above average' (compared to the normal Dutch population) 'very high' versus 'very low' to 'high' (compared to the normal Dutch population)

Overlap by definition: one group was selected out of the other.

In the relations with stress, depressive complaints and recent depression were clearly distinct from somatic complaints; depressive complaints and recent depression were related to support, and not at all to events.

\section{Stress and somatization trait}

Somatization trait was clearly related to difficulties. A relation with support in general was not found. There was a strong relation with support from parents, though, that could not be explained by coincidence; it was significant for support from both the mother $(\mathrm{n}=63, \mathrm{p}=0.007)$ and the father $(\mathrm{n}=38, \mathrm{p}=0.013)$. Somatization trait was probably related to life events.

These results were largely independent from the threshold chosen; for serious somatization, the relation with chronic difficulties (especially other difficulties) was somewhat stronger, allowing for the smaller number of patients. 


\section{Chapter 6}

Table 2: Relations of stress with somatization and depression (significance values)

$\begin{array}{llll}\text { somatic } & \text { serious } & \text { somatization } & \text { serious } \\ \text { complaints' }^{\prime} & \text { somatic compl. } & \text { trait } & \text { somatization } \\ \mathbf{N}=53 & 13 & 51 & 15\end{array}$

\begin{tabular}{cllll}
\hline social support $(n=106)^{3}$ & 0.429 & 0.238 & 0.147 & $0.097^{\wedge}$ \\
from partner (94) & 0.873 & 0.428 & 0.107 & 0.130 \\
from children (72) & 0.534 & 0.246 & 0.620 & 0.480 \\
from parents (71) & 0.528 & 0.332 & $0.002{ }^{* *}$ & $0.057^{\wedge}$ \\
from others (94) & $0.044^{*}$ & 0.333 & 0.652 & 0.752
\end{tabular}

$\begin{array}{cllll}\text { chronic difficulties } & 0.108 & 0.007^{* *} & 0.006^{* *} & 0.002^{* *} \\ \text { in relations } & 0.480 & 0.010^{*} & 0.014^{*} & 0.007^{* *} \\ \text { other } & 0.047^{*} & 0.010^{*} & 0.040^{*} & 0.002^{* *}\end{array}$

$\begin{array}{lllll}\text { major life events } & 0.190 & 0.050^{\wedge} & 0.069^{\wedge} & 0.073^{\wedge} \\ \text { positive } & 0.673 & 0.550^{\wedge} & 0.125 & 0.112 \\ \text { indeterminate } & 0.032^{*} & 0.005^{* *} & 0.047^{*} & 0.212 \\ \text { negative } & 0.064^{\wedge} & 0.075^{\wedge} & 0.383 & 0.108\end{array}$

A significance value greater than 0.500 means that the observed relation was contrary to the direction expected; one-sided tests were used. Significant and near-significant relations are marked: ${ }^{\wedge} \approx p<0.1, \cdots p<0.05, \cdots=p<0.01,{ }^{* * *}=p<0.001$ (Mann-Whitney U)

Gravity of somatization was related to support from parents $(p=0.007)$ and difficulties $(p=0.003)$, both relational and others. Support from parents specifically differentiated between no somatization and mild somatization $(p=0.006)$, other difficulties between mild and serious somatization $(p=0.004)$.

Somatization could be distinguished from major depressive disorder and dysthymia in the relations with stress. The distinction between major depressive disorder and dysthymia was more striking, however. 
Table 2: (continued)

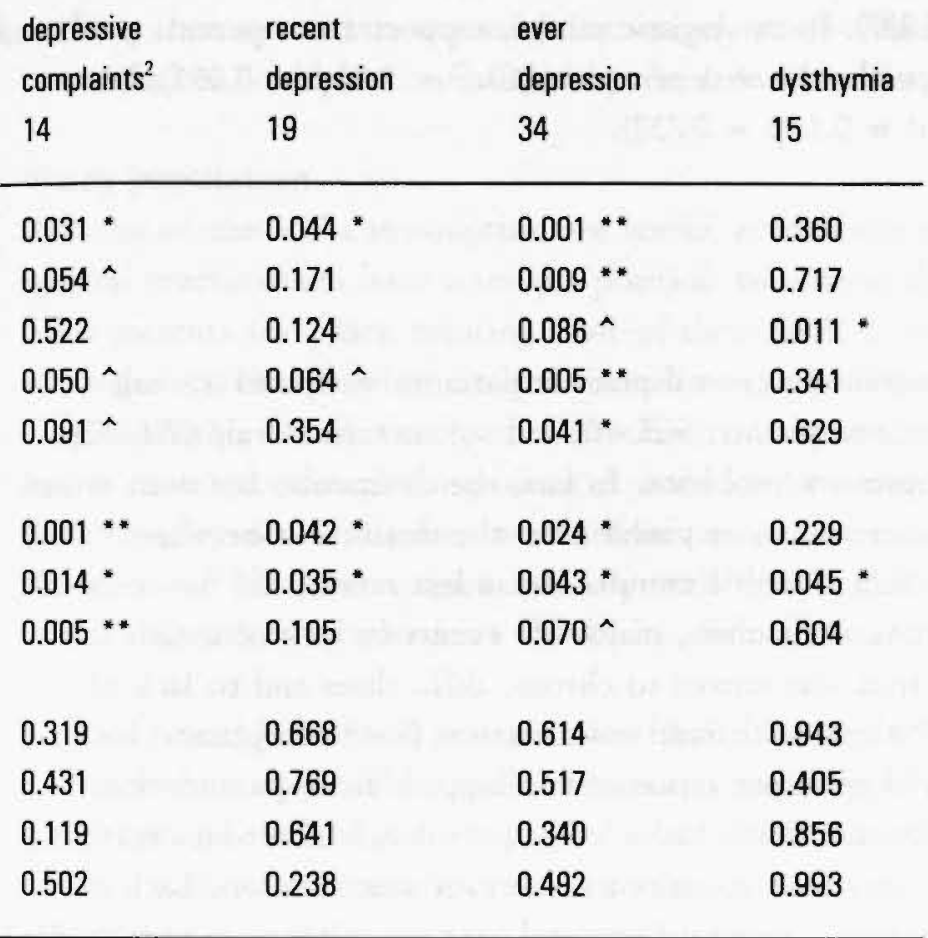

1. 'high' or 'very high' versus 'very low' to 'above average' Icompared to the normal Dutch population)

2. 'very high' versus 'very low' to 'high' (compared to the normal Dutch population)

3 Relations with social network constitution (whether partner was mentioned, number of children, etc.) were not found.

\section{Gender}

Serious somatization was more frequent in women (odds ratio $4.9, p=0.030$ twosided). No gender differences were found on other dependent or independent variables. In general, men and women reacted to stress similarly.

\section{Independent predictors or intermediate varables?}

Could it be that lack of support from parents is a sequel of deprivation of parental care in youth, and not an independent predictor of somatization trait? ${ }^{17}$ 
Deprivation was related with later difficulties (Spearman rank correlation 0.31, $\mathrm{p}$ $=0.001$ ), but not significantly with later lack of support from parents (rank correlation $0.07, p=0.287$ ). In the logistic model, support from parents predicted somatization trait independently of deprivation $\left(\mathrm{Chi}^{2}=8.9, \mathrm{p}=0.003\right)$, but difficulties did not $\left(\mathrm{Chi}^{2}=0.1, \mathrm{p}=0.732\right)$.

\section{Discussion}

In our group of high-consuming general practice patients we found a weak relation between somatic complaints (SCL-90) and somatization trait (SSI 5/5). Both were related to depressive problems. In fact, the distinction between recent problems and lifetime ones was more visible than the distinction between somatization and depression. Somatic complaints, unless severe, did not seem to be related to stress (chronic difficulties, major life events or lack of social support). Somatization trait was related to chronic difficulties and to lack of support from parents. Patients with mild somatization (5 - 9 complaints) had a higher prevalence of dysthymia and reported less support from parents than patients without somatization. They had a lower prevalence of recent depression and fewer 'other' difficulties than patients with serious somatization. Lack of support from parents and deprivation of parental care in youth were independent predictors of somatization trait. Are these results valid, and if so, do they add to our understanding of concepts of somatization?

\section{Methodological considerations}

The SCL-90 has been criticized as being more a measure of general distress than of specific psychopathology. ${ }^{33}$ This partly explains the very strong relation between somatic and depressive complaints, but not our other results. Our support questionnaire is reported to be valid (Ormel J, unpublished manuscript). ${ }^{29}$ ${ }^{30}$ Somatization or depression may have influenced recall of events or difficulties. This cannot be prevented with the questionnaire format. Apart from this, the difficulties questionnaire is a valid measure. ${ }^{31}$ Events checklists have been criticized sharply; Raphael et al found "devastatingly poor levels of consistency" comparing the specific events reported in 12 monthly events checklists similar to ours with the results of a structured interview at the end of the year. ${ }^{34}$ However, a count of the number of events is reported to be more reliable. ${ }^{34}{ }^{35}$ Still, this might explain our inconsistent results. 
Our dependent variables (somatization / depression in various operationalizations) overlap considerably. This does not invalidate specific analyses, but serves as a warning that -in any study- relations between stress and somatization could be confounded by depression, or the other way around.

\section{Study population}

Patterns of medical consumption are stable, even across generations. ${ }^{36}$ The Dutch general practitioners have a unique position to observe this stability, knowing most patients for years, treating most of their medical problems themselves, serving as gatekeepers for medical specialists and having complete records. Consequently, Dutch family medicine has concentrated on somatizing patients rather than episodes of complaints. A code for back pain in the RNH database, for example, means chronic or recurrent pain, and we counted consultations over three years. ${ }^{20}$ Our data represent fairly well the population of potentially somatizing patients, selections of which other physicians see at specific moments.

\section{Somatic complaints and somatization trait}

As researchers, we could handle the various meanings of the term 'somatization'; we chose and defined a synonym for each. Other researchers could make other choices without necessarily creating confusion. A practising physician cannot define his terms in his records, referral letters or communication with the patient. If definitions can be distinguished empirically, and if these distinctions are relevant for health care, then separate terms should be introduced and defined. Consensus on these terms and their definitions should be sought.

Recent somatic complaints should be distinguished from long-term somatization trait. Somatic complaints may be a symptom of or sequel to depression. They are related to major life events and social support. ${ }^{37}$ Finding this relation at a high threshold (serious somatic complaints) only is quite understandable, as self-limiting diseases and daily hassles can cause somatic complaints too. The operationalization of somatization trait fits better Lipowski's general definition of somatization; it defines a stable characteristic ('tendency'), it excludes complaints caused by somatic problems, and it specifically includes complaints designated as stress-related by the attending physician. ${ }^{3}$ It can be criticized for using a symptom count, and for doing so on a lifetime basis. What is the conceptual difference between recurrent backache (only one complaint, no somatization) and a different complaint each consultation? And can complaints that may have worn off decades ago still be relevant? Are we not measuring 


\section{Chapter 6}

memory rather than somatization? While these problems may weaken the operationalization, they do not invalidate it. Relations with depressive complaints, somatic complaints and chronic difficulties show that somatization trait is relevant for present well-being. Somatization trait starts in youth somehow and consequently one must expect it to be relatively persistent in the future. ${ }^{7}$ Our finding that its relation with chronic difficulties is explained by deprivation in youth, is supported by Craig et al. ${ }^{9}$ The importance of support from parents can only be explained by its presumed stability in time; apparently the long-term relation with parents is more important than more recent relations with partner or children.

Knowing about somatization trait can help the physician identify dysthymic patients; 11 of the 15 dysthymic patients in our sample somatized. This result (also found by others) is important, since the impact of dysthymia on public health is underestimated. ${ }^{16}$ Moreover, pharmacotherapy trials in dysthymia have yielded promising results. ${ }^{16}$ Pharmacotherapy might be effective in these patients for the somatic complaints as well.

Somatization trait can be distinguished from somatic complaints as measured with the SCL-90 by consistently using 'somatic complaints scale' instead of 'somatization scale' for the latter (both names are used now).

\section{Somatization trait and Bridges' concept of somatization}

Distinguishing somatization trait from Bridges' concept of somatization is necessary (the overlap between them is small), but more difficult. ${ }^{13}$ With our family medicine bias, we are tempted to accuse Bridges and colleagues of a psychiatricocentric viewpoint, and state that a depressive patient presenting with a somatic complaint is just as ordinary as a patient with hyperthyroidism who complains about 'nerves'. ${ }^{8}$ If primary care physicians cannot see beyond the complaint presented, working conditions or training should be improved, not a new 'diagnosis' of somatization invented. So we suggest that the term 'somatization' be reserved for somatization trait (also because of the relation with somatization disorder) and that Bridges' concept be indicated with the adjective 'somatized', as in 'somatized depression'. But we are biased.

\section{Somatization trait and somatization disorder}

Our threshold of 10 complaints for 'serious somatization (trait)' can be used as a surrogate for somatization disorder. ${ }^{26} 27$ These patients have more severe difficulties and more frequent episodes of depression, as indicated by the high 
frequency of recent (within the previous year) depression. Lifetime prevalence of depression $(9 / 15=60 \%)$ is as high as found by Brown et al. for somatization disorder patients. ${ }^{38}$ These findings illustrate an important though probably blurred distinction. Somatization disorder is a psychiatric disorder, that is: maladaptive. Mild somatization (trait) may be adaptive within the social context of the patient: helpful for eliciting support and getting release from duties. It is probably maladaptive within the health care and social security systems, because of the risks of medicalization and welfare dependence. The real difference may therefore be visible only in patients' interaction with their personal networks.

Somatization as a psychological problem of the patient is easily overestimated by physicians. Beating one's wife or alcohol dependence is more maladaptive, but does not automatically involve the physician. Mild somatization trait in our view is a risk factor, not a psychiatric diagnosis. These patients need specific attention, like screening for dysthymia or major depressive disorder, and more guidance during episodes of complaints, not psychiatric treatment.

So for the time being, we think it best to accept somatization trait as a specific problem in primary care and somatic medicine that is largely undefined in psychiatric nosology. For psychiatrists this may seem contrived. If it affects wellbeing and needs attention, why not call it a disorder? Psychiatrists are used to the vague distinction between disorder and normality. For many somatizing patients the distinction is crucial: they want to convince their doctor that there is something wrong with their body, that they are not exaggerating or weird. The general practitioner does not need this nosological label. He can explain that some patients have tightly set bowels, just like others (red-haired patients) have a sensitive skin. This may not be what the patient likes to hear, but in our experience is acceptable. After all, being red-haired sometimes is not that easy either, and no reason for conflict in the physician - patient relation. The primary care physician can use this model to devise with the patient a strategy for prevention of medicalization and iatrogenic harm. ${ }^{12}$

\section{References}

1 Quill TE. Somatization disorder: One of medicine's blind spots. JAMA 1985; 254: 3075-3079

2 Smith GR, Monson RA, Ray DC. Psychiatric consultation in somatization disorder: A randomized controlled study. N Engl J Med 1986; 314: 1407-1413 


\section{Chapter 6}

Lipowski ZJ. Somatization: The concept and its clinical application. Am J Psychiatry 1988; 145: 1358-1368

4 Escobar JI. Cross-cultural aspects of the somatization trait. Hosp Community Psychiatry 1987; 38: 174-180

5 Escobar JI, Rubio-Stipec M, Canino G, Karno M. Somatic symptom index (SSI): A new and abridged somatization construct: Prevalence and epidemiological correlates in two large community samples. J Nerv Ment Dis 1989; 177: 140-146

6 Portegijs PJM, Kraan HF, Knottnerus JA, Stoffers HEJH. Wat heet somatisatie? 1. Een zoektocht in de internationale literatuur naar een definitie voor huisartsgeneeskundig onderzoek. [What do we call somatization? 1. A search of the international literature for a definition to be used in general practice research.] Huisarts en Wetenschap 1992; 35: 18-25,43

Bridges KW, Goldberg DP. Somatic presentation of DSM-III psychiatric disorders in primary care. J Psychosom Res 1985; 29: 563-569

8 Bridges K, Goldberg D, Evans B, Sharpe T. Determinants of somatization in primary care. Psychol Med 1991; 21: 473-483

Craig TK, Drake H, Mills K, Boardman AP. The South London Somatisation Study: II. Influence of stressful life events, and secondary gain. Br J Psychiatry 1994; 165: 248-258

${ }^{10}$ Derogatis LR, Creary PA. Confirmation of the dimensional structure of the SCL-90: A study in construct validation. J Clin Psychology 1977; 33: 981-989

1 Springs FE, Friedrich WN. Health risk behaviors and medical sequelae of childhood sexual abuse. Mayo Clin Proc 1992; 67: 527-532

12 Janssen HJ, Cuisinier MC, Hoogduin KA, de Graauw KP. Controlled prospective study on the mental health of women following pregnancy loss. Am J Psychiatry 1996; 153: 226-230

13 Kirmayer LJ, Robbins JM. Three forms of somatization in primary care: Prevalence, co-occurrence, and sociodemographic characteristics. J Nerv Ment Dis 1991; 179: $647-655$

14 Smith GR. The epidemiology and treatment of depression when it coexists with somatoform disorders, somatization, or pain. Gen Hosp Psychiatry 1992; 14: 265-272

${ }^{15}$ Rief W, Schaefer S, Hiller W, Fichter MM. Lifetime diagnoses in patients with somatoform disorders: Which came first? Eur Arch Psychiatry Clin Neurosci 1992; 241: $236-240$

${ }^{16}$ Howland RH. General health, health care utilization, and medical comorbidity in dysthymia. Int J Psychiatry Med 1993; 23: 211-238

17 Portegijs PJM, Jeuken FMH, Horst FG van der, Kraan HF, Knottnerus JA. A troubled youth: Relations with somatization, depression and anxiety in adulthood. Fam Pract 1996; 13: 1-11

${ }^{18}$ Brown GW, Harris TO. Social origins of depression: A study of psychiatric disorder in women. London, Tavistock Publications, 1978

${ }^{19}$ Brown GW. Life events and affective disorder: Replications and limitations. Psychosom Med 1993; 55: 248-259

${ }^{20}$ Metsemakers JFM, Höppener P, Knottnerus JA, Kocken RJJ, Limonard CBG. 
Computerized health information in the Netherlands: A registration network of family practices. Br J General Pract 1992; 42: 102-106

21 Sandlow LJ, Bashook PG. Problem oriented medical records: Self instruction for practitioners. Chicago, Michael Reese Hospital and Medical Center, 1978

22 Centraal Bureau voor de Statistiek. Statistisch jaarboek 1991. [Statistical yearbook 1991] 's-Gravenhage: SDU/uitgeverij, 1991.

23 Portegijs PJM, Horst FG van der, Proot IM, Kraan HF, Gunther NCHF, Knottnerus JA. Somatization in frequent attenders of general practice. Soc Psychiatry Psychiatr Epidemiol 1996; 31: 29-37

24 Robins LN, Helzer JE, Croughan J, Ratcliff KS. National Institute of Mental Health Diagnostic Interview Schedule: Its history, characteristics, and validity. Arch Gen Psychiatry 1981; 38: 381-389

${ }^{25}$ Dingemans $\mathrm{P}$, Engeland $\mathrm{H}$ van, Dijkhuis JH, Bleeker J. De 'diagnostic interview schedule' (DIS). Tijdschrift voor Psychiatrie 1985; 27: 341-359

${ }^{26}$ Katon W, Lin E, Von Korff M, Russo J, Lipscomb P, Bush T. Somatization: a spectrum of severity. Am J Psychiatry 1991; 148: 34-40

27 deGruy F, Columbia L, Dickinson P. Somatization disorder in a family practice. J Fam Pract 1987; 25: 45-51

28 Arrindel WA, Ettema JHM. SCL-90: Handleiding bij een multidimensionele psychopathologie-indicator. [SCL-90: Manual for a multidimensional psychopathology-indicator.] Lisse, Swets \& Zeitlinger, 1986

29 Schaefer C, Coyne JC, Lazarus RS. The health-related functions of social support. J Behav Med 1981; 4: 381-406

${ }^{30}$ House JS, Kahn RL. Measures and concepts of social support. in: Cohen S, Syme SL (eds.). Social support and Health. Orlando etc., Academic Press, 1985

${ }^{31}$ Hendriks AAJ, Ormel J, Willige $G$ van de. Langdurige moeilijkheden gemeten volgens zelfbeoordelingsvragenlijst en semi-gestructureerd interview. [Long-term difficulties measured with self-report questionnaire and semi-structured interview] Gedrag en Gezondheid 1990; 18: 273-283

${ }^{32}$ Leenstra AS, Ormel J, Giel R. Positive life change and recovery from depression and anxiety: A three-stage longitudinal study of primary care attenders. Br J Psychiatry 1995; 166: 333-343

${ }^{33}$ Cyr JJ, McKenna-Foley JM, Peacock E. Factor structure of the SCL-90-R: Is there one? J Pers Assess 1985; 49: 571-578

${ }^{34}$ Raphael KG, Cloitre M, Dohrenwend BP. Problems of recall and misclassification with checklist methods of measuring stressful life events. Health Psychol 1991; 10: 62.74

${ }^{35}$ Cui XJ, Vaillant GE. Antecedents and consequences of negative life events in adulthood: A longitudinal study. Am J Psychiatry 1996; 153: 21-26

36 Huygen FJA. Family medicine: The medical life history of families. Nijmegen, Dekker \& van de Vegt, 1978

${ }^{37}$ Monroe SM. Social support and disorder: Toward an untangling of cause and effect. Am J Community Psychol 1983; 11: 81-97

38 Brown FW, Golding JM, Smith GR. Psychiatric comorbidity in primary care somatization disorder. Psychosom Med 1990; 52: 445-451 
Chapter 6 


\section{Somatizing patients react very similarly to non-somatizers in everyday life "}

\section{Abstract}

Objective: Do somatizing patients differ from non-somatizers in their contextcomplaint reactions? If so, in what respect? The answer may give an impression of causal mechanisms likely to be important in somatization. Context was defined as thoughts, activities, motivation, place, presence of others, perceived support, use of medication or alcohol, microstressors and time of day.

Method: Ninety-two Dutch general practice patients aged 20 - 44 years with recurrent or chronic vague somatic complaints and high medical consumption kept an Experience Sampling diary for a week. They received a wristwatch that signalled them at unexpected moments, up to ten times a day. Eacht time they filled in a small questionnaire on complaints and contexts that pertained to the moment just before the signal. Complaints were divided in specific somatic complaints, tiredness, negative affectivity and positive affectivity. Somatization was operationalized as a more comprehensive version of somatization disorder, with 5 instead of $13 \mathrm{com}$ plaints (SSI 5/5) For each patient, context-complaint reaction was defined as mean complaints in that context minus mean complaints not in the context. In total 131 contexts were analysed.

Results: Somatizing patients ( $n=46$ ) felt slightly more tired and had specific somatic complaints somewhat more frequently than non-somatizers. Differences in contexts were not found. Patients clearly reacted to all domains of contexts. Yet, differences in context-complaint reactions between somatizing and non-somatizing patients were not found. Only with serious somatization or recent depression as criterion variable, however, we did find differences in context-complaint reactions.

Conclusions: Mild somatization hardly influences daily life in an average week. Our results fit a model of mild somatization as a personality trait that is evident 
only when the person is under stress or ill, with more serious forms resembling a personality disorder, maladaptive and inflexible, and thereby more visible in everyday life. Results suggest that the general practitioner may influence prognosis favourably or unfavourably.

\section{Introduction}

Somatizing patients request medical diagnosis and treatment for somatic complaints that are not primarily somatic in origin. This medical attention generally brings them no lasting relief and consumes health care resources that may be badly needed for other patients. Risk factors for somatization have been identified, but little is known about causal mechanisms. ${ }^{12}{ }^{3}$ In this article we report on an exploratory study of possible causal mechanisms in somatization. We concentrate on mild forms of somatization, operationalized as a more comprehensive version of DSM-III-R somatization disorder definition. ${ }^{145}$ Thus defined, somatization is best seen as a personality trait. ${ }^{56}$ This is a much more prevalent problem in health care than somatization disorder itself, and its causal mechanisms may be more indicative of the problem of somatization, less of chronicity per se. ${ }^{14}$ We also exclude somatization as defined as a symptom of psychiatric disorder.'

The most widely accepted definition of somatization is a descriptive one: " $a$ tendency to experience and communicate somatic distress and symptoms unaccounted for by pathological findings, to attribute them to physical illness, and to seek medical help for them. ${ }^{18}$ However, Lipowski continues: "It is usually assumed that this tendency becomes manifest in response to psychosocial stress brought about by life events and situations that are personally stressful to the individual." With this addendum he indicates his preference for a diathesis-stress model of somatization, but does not specify which. Stress theories concentrating on major life events or on microstressors ('daily hassles') predict higher symptom levels when someone is under stress, but so do most other theories. ${ }^{69}$ Whether somatization is explained as a language ('expression of distress') or as the result of somatic attributional style, maladaptive coping, alexithymia (inability to verbalize emotions), defence against unacceptable thoughts or emotions, deprivation of parental care or traumatic experiences in youth, the model predicts a stress - somatic symptom relation. ${ }^{28} 10 \mathrm{H1}$ 121314 This stress-symptom relation could even be interpreted as supporting a behavioural mechanism of somatization, if, for example, the need for support from the partner, or for relief from childrens' demands were felt only (or predominantly) 
when under stress. ${ }^{10}$ Not surprisingly, studies on stress-symptom relations in somatization have yielded conflicting results. ${ }^{9}$

Knowledge about the specific circumstances in which somatizing patients experience symptoms and the types of stressors these symptoms are associated with, would help to organize these theoretical models and select the one(s) most promising for subsequent hypothesis-testing studies with time-series analysis, with in-depth measurements, or in the laboratory. Instead of testing specific hypotheses to falsify or support a particular theoretical model, one would explore whether somatizing patients differ from non-somatizers in broader domains of context variables. Finding differences in content or phrasing of thoughts, at all times or when having somatic symptoms, would support an attributional model. Activities, motivation, use of medication or alcohol when having somatic symptoms give some insight into coping strategies. Alexithymia might be noticeable in content or phrasing of thoughts, in a lack of variability in mood, or in reporting somatic symptoms in situations that are associated with bad mood in non-somatizers. A model of somatization as an idiom of distress would imply that somatic complaints are fairly strongly associated with bad mood, microstressors and maybe (distressing) thoughts. Behavioural mechanisms presuppose that reporting somatic complaints is reinforced, which might show in the activities, physical and social contexts in which patients report most symptoms. With the present study, therefore, we aimed to narrow down the range of likely mechanisms by exploring which domain of context variables have explanatory value in somatization. The combination in a single study prevented comparisons being distorted by differences in study population, instrument or compliance. This was more important to us than in-depth specification of all hypotheses compatible with a particular model.

The key question was: Do somatizing patients differ from non-somatizers in their context-complaint reactions? If so, in what respect? Context domains studied were thoughts (both content and phrasing), activities, motivation, place, presence of specific social network members, perceived social support, use of medication or alcohol, microstressors (type, gravity) and time of day. By 'complaints' we mean both physical and psychological complaints (mood). For simplicity, in the following we describe the context variables as independent variables and complaints as dependent variables. This is not meant to imply the direction of causation; it may be the other way around, or a circular model of causation. To interpret the results on this key question, some preliminary questions had to be answered first. Do somatizing patients differ from non-somatizers in complaints and contexts? And what are context-complaint reactions in the patient group as a whole? 
These questions were studied with the Experience Sampling Method (ESM), an adaptation of diary methods that gives multiple records per patient of specific moments in time. The ESM has been developed and validated in psychiatry and personality psychology, but is fairly new in general practice populations. ${ }^{15} 161718$ Therefore we tested the ability of ESM to demonstrate meaningful differences by repeating analyses with criterion variables other than somatization. For this comparison we chose:

- serious somatization and recent depression (expecting differences in contextcomplaint reactions)

somatic complaints and chronic difficulties (complaints)

gender (context variables).

These variables had been found relevant in an earlier study. ${ }^{6}$

\section{Methods}

\section{Subjects}

Patients were selected on high medical consumption, absence of interfering somatic or psychiatric problems, and a comparable medical history (in order to obtain acceptable homogeneity). This was accomplished by a two-stage selection procedure, first on age and health problems in the Registration Network of Family Practices (RNH) of the Universiteit Maastricht, then on medical consumption in the practitioners' files. ${ }^{19}$ A computerized selection was made on age (20 - 44 years), history of chronic or recurrent back, neck, or abdominal complaints, absence of active serious somatic diseases and absence of (a history of) psychiatric disorders other than mood and anxiety disorder. ${ }^{19}$ Then the general practitioner selected patients with 15 or more consultations in the previous three years without compelling somatic reason for encounter and invited them to participate. If they agreed, the interviewer visited them at home. The protocol has been described in detail elsewhere. ${ }^{20}$

\section{Instruments}

Somatization trait was operationalized as a more comprehensive version of the DSM-III-R criterion for somatization disorder, with 5 instead of 13 complaints (and start of first complaint before age 30). ${ }^{1}{ }^{20}$ For serious somatization the threshold was 10 complaints, near enough to the somatization disorder criterion to be taken as a rough equivalent. ${ }^{2122}$ Recent depression was defined as a depressive episode, current 
or within the previous year. Somatization and depression were assessed with the Diagnostic Interview Schedule (DIS). Recent somatic complaints and chronic difficulties were assessed with the SCL-90 somatic complaints scale and the Groningen List of Chronic Difficulties respectively, dichotomized. ${ }^{23}$

Complaints and context variables at specific moments were assessed by the Experience Sampling Method (ESM). ${ }^{15} 1617$ This is an adaptation of the diary method to minimize experimental artefacts and nuisance for the patient. Instead of asking the patient to fill in a diary at specified intervals (requiring him or her to think about the study frequently), the patient is given a preprogrammed wristwatch that signals when to fill in the questionnaire at (pseudo-)random intervals. Simple language is used. The questionnaire pertains to the moment just before the signal and to concrete situations or feelings. This further reduces doubts and interference. Our version contained open questions about thoughts ("What did you think just before the signal?") activities, place, presence of specific social network members, and Likert-type questions about mood, physical complaints, motivation, need for support and perceived support. Questions about events (microstressors) and use of medication or alcohol since the previous signal were included too. ${ }^{24}$

Patients were asked to participate for six consecutive days, with a maximum of 10 questionnaires a day (the watch signalled once in every 90-minute period from $7.30 \mathrm{am}$ to $10.30 \mathrm{pm}$ ). Patients were instructed to turn off the watch during sleep or when responding was very difficult or embarrassing (swimming, going to church). At the end of the week they were visited again for collection of the questionnaires, check for illegible or ambiguous answers and discussion of the study. Answers to the open-ended questions were later coded by the interviewer according to a scheme developed in earlier studies. ${ }^{17} 25$ Interrater reliability of this scheme was satisfactory..$^{25}$ Patients were included for the analysis if they had contributed at least 20 valid (response within 30 minutes after the signal) questionnaires.

\section{Analysis}

A priori, we had grouped the questions on somatic complaints and mood (the dependent variables) into specific somatic complaints, general somatic complaints, negative affectivity and (lack of) positive affectivity. ${ }^{26}$ This categorization was evaluated by factor anlaysis. We tested stability of factors by:

splitting the ESM data file into a file containing mean scores per patient (patient-level) and one containing 'deviation scores'; actual score minus mean score for that patient ( $\mathrm{n}=$ total $\mathrm{n}$ of ESM records). Both files were analysed, to compare the between-patient and within-patient dimensional structure. 


\section{Chapter 7}

varying extraction and rotation procedures. ${ }^{27}$

Positively phrased items ('feeling energetic', for example) were recoded, so a high score on a factor means high complaints. These factors were the dependent variables for subsequent analyses, and will further be referred to as 'complaints'.

The ESM data file contained multiple records per patient, one for each signal the patient had responded to. Simple statistical analysis of this file would violate the assumption of independently collected records. Therefore, it was summarized into a file with a single record per patient, containing measures of the relevant contextcomplaint reactions of that patients. ${ }^{9}$ For open-ended questions this was done as follows. First the relevant context codes were converted into dummy variables (such as: 'with partner yes/no'). Then for each patient both mean complaints in that context (for example specific somatic complaints when partner present) and mean complaints not in that context were computed. Subtracting the second from the first gave a measure of the reaction of that patient to that particular context. Significance of context-complaint reactions for the parient group as a whole was tested with the Wilcoxon test. To test whether somatizing patients differed from non-somatizers in these context-complaint reactions, we used the Mann-Whitney U test. For Likert-type context variables like perceived support, we computed (for each patient) the Pearson correlation between context variable and complaints instead.

Wanting our exploratory analysis to be comprehensive, we defined 131 possibly relevant context variables (dummy variables plus Likert-type variables), within nine domains: thoughts (content/phrasing), activities, motivation, place, presence of specific social network members, perceived social support, use of medication or alcohol, microstressors and time of day.

The procedure described above yielded 4478 statistical tests. Therefore, instead of specific analyses we present numbers of significant results for the context in general, and where relevant, for specific domains of the context. As one may expect 7 significant results out of 131 tests (with $\alpha=0.05$ ) based on chance alone, some criterion was necessary to allow for multiple tests. We computed the $90 \%$ confidence interval for the expected number of spuriously significant results out of a given number of tests (with Student correction). For 131 tests this yielded a criterion of 12 significant results or more, with $\alpha=0.05$ one-sided. This criterion was uniform, simple, and much more conservative regarding our main conclusion than the Bonferroni correction (see discussion). It did require that the tests within a domain are independent. This was an important consideration in our choice of the 


\section{Somatizing patients in everyday life}

contexts to be tested. The list of contexts analysed, the Experience Sampling questionnaire and the codebook used, are available from the authors.

Two-sided significance tests were used, except for the numbers of significant results expected (see above).

\section{Results}

\section{Patients}

Of the 107 patients described earlier, 92 contributed 20 valid questionnaires or more and were included in the analyses. ${ }^{6}{ }^{28}$ In most respects they formed a representative subsample, but disadvantaged patients (chronic difficulties, lack of social support, deprivation of parental care in youth) were somewhat overrepresented. There were 57 women and 35 men, median age was 37 years. Most of the patients were living with partner $(85 \%)$ and/or children $(72 \%), 55 \%$ of the patients had a paid job were studying.

\section{Factor analyses of complaints and mood}

Factor analyses suggested some minor changes to our a priori dimensional structure, which resulted in the following factors as dependent variables for further analyses. - Specific somatic complaints: 'pain', 'main complaint' (most important physical complaint in the previous week, specified beforehand), 'other complaints'.

- Tiredness (originally: general somatic complaints): '(not) energetic', 'tired'.

- Negative affectivity: 'brooding', 'gloomy', 'angry', 'anxious', 'lonely', 'tense' (originally in general somatic complaints)

- Positive affectivity: '(not) pleasant thought', '(not) able to concentrate', '(not) cheerful', '(not) content'.

The variable 'miserable' (originally in general somatic complaints) did not fit within this structure and was dropped.

\section{Complaints, contexts and somatization}

Somatizing patients $(n=46)$ were more tired than non-somatizers: median (of patient mean scores) 3.4 versus 3.0 on a scale from one to seven $(p=0.041)$. A difference in specific somatic complaints was not found. Regarding frequencies of a score of four or higher instead of mean levels, we did find a difference: $13 \%$ of time for somatizing patients, $3 \%$ for non-somatizers $(p=0.035)$. No differences were found in negative or positive affectivity. 


\section{Chapter 7}

Somatizing patients could not be distinguished from non-somatizers in the way they thought, their activities, motivation, physical or social context, social support, use of medication or alcohol, or daily events. That is, a significant difference was found only four times in 131 analyses, which was even less than the seven times expected by chance alone.

\section{Context-complaint reactions}

The patients in our study clearly reacted to the context with complaints, or the other way around. Many significant context-complaint reactions were found in all context domains. Tiredness (58 significant relations out of 131 tests, criterion was $12)$, negative affectivity (57) and positive affectivity (51) were most clearly contextrelated with, specific somatic complaints to a lesser degree (30). Complaint-complaint reactions were all highly significant $(p<0.001)$; median correlation (see Methods) ranged from 0.11 (specific somatic complaints - negative affectivity) to 0.52 (negative affectivity - positive affectivity).

\section{Context-complaint reactions and somatization}

The main result was negative. Somatizing patients could not be distinguished from non-somatizers at all in the reactions between context on the one hand and specific somatic complaints, tiredness or positive affectivity on the other: four, five and six significant differences, respectively, out of 131 tests, while the criterion was 12 . If at all, somatizing patients differed from non-somatizers in context - negative affectivity reactions, but here too the number was too small to be interpreted as evidence: 10 significant differences. Even within specific context domains the number of significant differences met the criterion specified only once; four significant differences in thought - negative affectivity relations out of 25 analyses (criterion four). This should not be interpreted as evidence, as the overall number did not reach the criterion. Differences in complaint-complaint reactions were not found either.

\section{Sensitivity of the Experience Sampling Method}

With results so far suggesting that somatizing patients in their daily life are almost indistinguishable from non-somatizers, one wants to be very sure that the instrument used was sensitive enough to detect relevant differences. So we repeated the analyses with criterion variables found relevant earlier: serious somatization, recent depression, somatic complaints, chronic psychosocial difficulties and gender. ${ }^{6}$

The 15 patients with 'serious somatization' (threshold 10 complaints instead of five) were more tired than the 77 patients with mild or no somatization $(p=0.043)$, 
and possibly had lower positive affectivity $(p=0.084)$. We found differences in context variables (13 significant differences), and more specifically in thought variables ( 5 out of 25 ). We also found differences in context-tiredness (18 differences) and context - positive affectivity reactions (14). These differences were most visible in reactions to thoughts, and to presence of social network members. One we elaborate here, more to illustrate what is behind our numbers of significant differences, than because it is that important as such: thinking of working or maintenance activities in relation to tiredness. Patients with serious somatization thought of working or maintenance activities less often than other patients: median $19 \%$ of time versus $24 \%, p=0.035$. In the study group as a whole, patients were less tired when thinking of working or maintenance activities, median score 3.02 versus $3.23(p=0.002)$ This result was accounted for completely by the 15 seriously somatizing patients, however; they were much less tired in this context: median 3.00 versus 3.64 . For the other patients the difference was negligible: median 3.07 versus 3.05 . The difference in reaction was significant; $p=0.005$.

Patients with high somatic complaints in the previous week (SCL-90, $n=46$ ) clearly had higher specific somatic complaints, tiredness and negative affectivity $(p<0.001)$. A difference in context variables was not found. In context - complaint reactions too, patients with high somatic complaints were indistinguishable from other patients.

Results with recent depression $(n=17)$, high chronic difficulties $(n=44)$ and gender as criterion variables supported the sensitivity of ESM. Differences in complaints were found for recent depression and high chronic difficulties, differences in context variables for recent depression and gender, differences in context complaint reactions for recent depression and gender. A more detailed account of the results is available from the authors.

\section{Discussion}

As expected, patients in our study group clearly reacted to the context with com* plaints (or the other way around). Contrary to our expectation, somatizing patients were indistinguishable from non-somatizers in their context - complaint reactions. We did find differences if the threshold was heightened ('serious somatization'), and between patients with and patients without recent depression. Did we correct for multiple tests too rigorously? Is ESM irrelevant for somatization, or not sensitive enough for subtle differences? Is our operationalization of somatization invalid? Did 


\section{Chapter 7}

we choose the wrong comparison group? Or do somatizing patients really react very similarly to non-somatizers in everyday life?

\section{Dealing with multiple tests}

Being unable to translate each potential causal mechanism of somatization into a single hypothesis, we had to deal with multiple statistical tests somehow. Theoretically, this did not worry us too much; the question whether somatizing patients react differently to the context in general is a legitimate one, and 'context' just cannot be captured in one variable. With our results suggesting a negative answer, we could not use the Bonferroni correction. This procedure corrects for spuriously significant findings, not for spuriously insignificant ones. So we tested, with $\boldsymbol{\alpha}=$ 0.05 one-sided, the number of significant results in a given context domain against the number expected by chance alone. This criterion is valid statistically if the tests within a domain are independent. The context variables themselves were interrelated though, and some redundancy was unavoidable; both leisure activities in general, and doing active sports were analysed, for instance. So one cannot ascribe an exact significance level to our 12 out of 131 criterion, but it should be valid for comparing somatization to other criterion variables.

\section{Validity of Experience Sampling data}

Our ESM questionnaire and coding scheme have evolved in a series of studies on normal subjects and several patient groups. ${ }^{15}$ It has proved to be sensitive for differences in context-complaint reactions. ${ }^{29}$ It is ecologically valid; in both our study and others, patients generally indicated that the study did not interfere unduly with their daily life, and that all questionnaires together gave a good impression of their experiences during the six study days. Compliance $(86 \%$ of those included in our earlier reports, $55 \%$ overall) was satisfactory given the intrusive and time-consuming character of ESM, and good compared to other ESM studies. ${ }^{6} 182830$

The comparison with serious somatization and recent depression yielded the strongest evidence for the validity of both the ESM results themselves and the multiple test correction. Here we did find differences, even though the statistical power of the primary analyses was lower due to the smaller numbers of patients.

\section{Validity of the operationalization of somatization}

A cumulative, lifetime symptom count may seem an unreliable operationalization at the low cut-off point of five (the DSM-III-R criterion for somatization disorder is 13). For research purposes it performs well, though. An extensive literature study at 


\section{Somatizing patients in everyday life}

the start of our project yielded Escobars Somatic Symptom Index (virtually identical to our operationalization) as the best operationalization. ${ }^{15}$ Since then it has, in one form or another, gained broad acceptance. ${ }^{321}$ The results of our preliminary study $(\mathrm{n}=80)$ and in the present study group also firmly support its validity. ${ }^{6} 2028$ Besides, the conclusion would have been the same if the SCL-90 somatic complaints scale had been used as criterion instead.

\section{Choice of comparison group}

The study group as a whole had been selected on vague somatic complaints and a fairly high medical consumption. The contrast between somatizing and nonsomatizing patients was smaller, therefore, than it would have been with a control group of low-consuming patients. ${ }^{20}$ Again, our earlier findings show that lack of contrast does not explain our negative results. ${ }^{6028}$ Moreover, we did find differences at a higher threshold. Our results do not say anything about differences between our high-consuming somatizing patients and low-consuming nonsomatizers. For the practising physician, however, differences within the risk group of high utilizers are most important; this information may help to define the patients who need special care, and indicate what kind of care is needed.

\section{Somatization in daily life}

With methodological weaknesses of the study being unlikely explanations for our negative results, we conclude that (mild) somatization hardly influences daily life in an average week. We suppose that results would have been different if we had studied our patients in special circumstances, for example, when in danger of losing their jobs, when having influenza, or maybe even when an influenza epidemic was in the country. Indeed, it is difficult to conceive of somatization as not influencing daily life at all. This hypothesis is consistent with Lipowski's description of somatization as a stable attribute of a person that is manifest only at times of psychosocial stress (see introduction). A concept of somatization as a personality trait fits with the strong relations between youth experiences and later somatization. ${ }^{28}$ It also fits with our finding that serious somatization did influence context - complaint reactions. Earlier we have argued that somatization disorder should be seen as a personality disorder, on axis II of DSM-III. ${ }^{51}$ According to DSM-III the difference between a personality disorder and a personality trait is that the former is a psychiatric disorder, inflexible, maladaptive, causing impairments in social or professional roles. So the most visible difference between trait and disorder could be the extent to which it influences everyday life. Curiously, the description of somatization 


\section{Chapter 7}

disorder in DSM-III, and in much of the literature resembles that of a personality disorder, but a transfer to axis II has, to our knowledge, not been considered.

For non-psychiatric physicians this transfer would be quite important. Mild somatization could then be classified properly as a stable personality trait, not a psychiatric disorder, but relevant for care. For it is a serious problem within the somatic health care system (and social security system) because of its risk of medicalization and iatrogenic harm, even if it is a healthy coping mechanism within the social network of the patient.

\section{Causal mechanisms in somatization}

While this study may not provide evidence for a specific causal mechanism in somatization, it does give evidence against some mechanisms, those that should be detectable in an average week. Behavioural mechanisms typically stipulate a frequent seeking of the reinforcer; a reward, like attention from the partner, can only become a reinforcer if it is both highly valued and scarce. Therefore one would expect that somatizing patients seek out specific contexts and behave differently in these contexts, anytime. Our results also conflict with a causal role of alexithymia. ${ }^{14}$ Alexithymic patients would only experience the somatic sensations or complaints normally accompanying emotions, and hardly ever think about abstract or emotional subjects. No differences in context - mood (negative and positive affectivity) reactions, somatic complaints - mood reactions, or thought content or phrasing were found.

\section{Implications for care}

With the tendency to somatize being stable (that is: resistant to change), but its manifestations variable, primary care physicians should concentrate on guiding somatizing patients through episodes of complaints. Controlled trials are scarce, but experienced clinicians have given advice on how to do this. ${ }^{83233} 3435$ Quite a few patients in our study reported that talking with us and observing themselves with ESM, though upsetting at the time, had helped them deal with their complaints. General practitioners confirmed this. Curiosity about the patient and the way he or she interprets the complaints might help the general practitioner in his relation to the somatizing patient. Having to offer cure might hinder him. This fits with evidence that disclosure of emotionally important memories lowers subsequent somatic complaints and medical consumption. ${ }^{36}$ 37 The following analogy might be fruitful; we suggest that the attitude of the physician to a somatizing patient with a productive cough of two weeks' duration would be similar as to that patient if his 


\section{Somatizing patients in everyday life}

best friend had died last month with lung cancer. In neither case is there a reason for more extensive investigation than the physician would ordinarily do (investigations just for reassurance often do not reassure). In both cases the patient needs special attention, opportunity to express his worries and explanation.

The potential influence of the physician must be emphasized. Physicians do not see their patients in an average week but in real or perceived illness. The way physicians deal with the situation may not change their patients' tendency to experience complaints; in the long run it must influence the patients' attributions, the chances of them seeking health care and - most important - their requests to the physicians, if they does. Suppose a patient visits his physician and says: "I have back pain now, and I am getting worried. Please give me check up and tell me whether my body is playing tricks again." Risks of iatrogenic harm or a disturbed patient physician relation are low for this patient. In trying to help somatizing patients the physican has to compensate for medicalizing effects inherent in the western health care system and in society at large. 


\section{References}

Escobar JI, Rubio Stipec M, Canino G, Karno M. Somatic symptom index (SSI): A new and abridged somatization construct: Prevalence and epidemiological correlates in two large community samples. J Nerv Ment Dis 1989; 177: 140-146

2 Kirmayer LJ, Robbins JM, Paris J. Somatoform disorders: Personality and the social matrix of somatic distress. J Abnorm Psychol 1994; 103: 125-136

3 Walker EA, Katon WJ, Hansom J, Harrop Griffiths J, Holm L, Jones ML, Hickok L, Jemelka RP. Medical and psychiatric symptoms in women with childhood sexual abuse. Psychosom Med 1992; 54: 658-664

4 Escobar JI. Cross-cultural aspects of the somatization trait. Hosp Community Psychiatry 1987; 38: 174-180

5 Portegijs PJM, Kraan HF, Knottnerus JA, Stoffers HEJH. Wat heet somatisatie? 1. Een zoektocht in de internationale literatuur naar een definitie voor huisartsgeneeskundig onderzoek [What do we call somatization? 1. A search of the international literature for a definition to be used in general practice research]. Huisarts en Wetenschap 1992; 35: $18-25,43$

6 Portegijs PJM, Kraan HF, Horst FG van der, Meertens HMHJ, Knottnerus JA. Somatization and somatic complaints in primary care: Relations with depression and stress. Submitted

Bridges KW, Goldberg DP. Somatic presentation of DSM III psychiatric disorders in primary care. J Psychosom Res 1985; 29: 563-569

8 Lipowski ZJ. Somatization: The concept and its clinical application. Am J Psychiatry 1988; 145: 1358-1368

9 Affleck $\mathrm{G}$, Tennen $\mathrm{H}$, Urrows S, Higgins P. Person and contextual features of daily stress reactivity: Individual differences in relations of undesirable daily events with mood disturbance and chronic pain intensity. J Pers Soc Psychol 1994; 66: 329-340

10 Katon W, Ries RK, Kleinman A. The prevalence of somatization in primary care. Compr Psychiatry 1984; 25: 208-215

"Kellner R. Somatization: Theories and research. J Nerv Ment Dis 1990; 178: 150-160

12 Kotler T, Buzwell S, Romeo Y, Bowland J. Avoidant attachment as a risk factor for health. Br J Med Psychol 1994; 67: 237-245

13 Lloyd GG. Psychiatric syndromes with a somatic presentation. J Psychosom Res 1986; 30: 113-120

14 Taylor GJ. Alexithymia: History and validation of the concept. Transcultural Psychiatric Research Review 1987; 24: 85-95

15 deVries MW (ed.). The experience of psychopathology: Investigating mental disorders in their natural settings. Cambridge UK: Cambridge University Press, 1992

16 Hormuth SE. The sampling of experiences in situ. J Pers 1986; 54: 262-293

17 Delespaul PAEG. Assessing schizophrenia in daily life: The Experience Sampling Method [dissertation]. Maastricht: Rijksuniversiteit Limburg, 1995

is Eck MMM van. Stress, mood, and cortisol dynamics in daily life [dissertation]. Maastricht: Universiteit Maastricht, 1996

19 Metsemakers JFM, Höppener P, Knottnerus JA, Kocken RJJ, Limonard CBG. Computerized health information in the Netherlands: $A$ registration network of family practices. Br J General Pract 1992; 42: 102-106 


\section{Somatizing patients in everyday life}

${ }^{20}$ Portegijs PJM, Horst FG van der, Proot IM, Kraan HF, Gunther NCHF, Knottnerus JA. Somatization in frequent attenders of general practice. Soc Psychiatry Psychiatr Epidemiol 1996; 31; 29-37

${ }^{21}$ Katon W, Lin E, Von Korff M, Russo J, Lipscomb P, Bush T. Somatization: a spectrum of severity. Am J Psychiatry 1991; 148: 34-40

22 deGruy F, Columbia L, Dickinson P. Somatization disorder in a family practice. J Fam Pract 1987; 25: 45-51

${ }^{23}$ Hendriks AAJ, Ormel J, Willige $\mathrm{G}$ van de. Landurige moeilijkheden gemeten volgens zelfbeoordelingsvragenlijst en semi-gestructureerd interview [Long-term difficulties measured with self-report questionnaire and semi-structured interview]. Gedrag en Gezondheid 1990; 18: 273-83

24 Stone AA, Kessler RC, Haythornthwaite JA. Measuring daily events and experiences: decisions for the researcher. J Pers 1991; 59: 575-607

${ }^{25}$ Kraan HF, Meertens HMHJ, Hilwig M, Volovics L, Dijkman-Caes CIM, Portegijs PJM. Selecting measures, diagnostic validity and scaling in the study of depression. In: deVries MW (ed.). The experience of psychopathology: Investigating mental disorders in their natural settings. Cambridge UK: Cambridge University Press, 1992

26 Watson D, Tellegen A. Toward a consensual structure of mood. Psychol Bull 1985; 98: 219-235

27 Tabachnick BG, Fidell LS. Using Multivariate Statistics. New York: HarperCollins Publishers, 1989 (2nd ed.)

28 Portegijs PJM, Jeuken FMH, Horst FG van der, Kraan HF, Knottnerus JA. A troubled youth: Relations with somatization, depression and anxiety in adulthood. Fam Pract 1996; 13: 1-11

29 Eck MM van, Nicolson NA. Perceived stress and salivary cortisol in daily life. Ann Behav Med 1994; 16: 221-227

${ }^{30}$ Csikszentmihalyi M, Larson R. Validity and reliability of the Experience Sampling Method. J Nerv Ment Dis 1987; 175: 526-536

31 Portegijs PJM, Kraan HF, Knottnerus JA, Stoffers HEJH. Wat heet somatisatie? 2. Een antwoord uit de internationale literatuur getoetst aan 19 jaar Huisarts en Wetenschap. [What do we call somatization? 2. An answer from the international literature tested in 19 jaar of 'Huisarts en Wetenschap'] Huisarts en Wetenschap 1992; 35: 65-69

32. Smith GR Jr, Rost K, Kashner TM. A trial of the effect of a standardized psychiatric consultation on health outcomes and costs in somatizing patients. Arch Gen Psychiatry $1995 ; 52: 238-243$

33 Bass C, Benjamin S. The management of chronic somatisation. Br J Psychiatry 1993; 162: $472-480$

${ }_{34}$ Mabe PA, Jones LR, Riley WT. Managing somatization phenomena in primary care. Psychiatr Med 1990; 8: 117-127

35 Quill TE. Somatization disorder: One of medicine's blind spots. JAMA 1985; 254: 3075 . 3079

36 Pennebaker JW, Beall S. Confronting a traumatic event: Toward an understanding of inhibition and disease. J Abn Psychology 1986; 95: 274-281

37 Pennebaker JW, Colder M, Sharp LK. Accelerating the coping process. J Pers Soc Psycho$\log y 1990 ; 58: 528-537$ 
Chapter 7 


\section{Somatization and health care utilization"}

\section{A prospective study}

\section{Abstract}

Background: For somatization, the health care system is not only the intended solution, it is part of the problem too. Describing somatizing patients' interaction with the health care system is therefore essential. Within a group of frequent attenders of general practice we studied differences between somatizing and nonsomatizing patients in subjective well-being, health care utilization, specific health problems and quality of doctor-patient communication. In addition, we studied general practitioners' recognition of somatization, general practitioners' views on causal mechanisms in somatizing patients, and course of complaints.

Methods: The study was a sequel to a study on relations of somatization with depression, anxiety, youth experiences and stress. Somatization was defined according to Escobars' Somatic Symptoms Index 4/6 (SSI 4/6), slightly modified. Eight and 16 months after the initial interview (including a structured interview on somatization and several other instruments) patients received a set of postal questionnaires. The SCL-90, questionnaires on chronic difficulties, major life events, somatic complaints and health care utilization were included. After each consultation both patient and general practitioner filled in a short questionnaire on reasons for encounter, diagnostic conclusions, gravity of complaints and evaluation of the consultation. At the end of the 16-month follow-up period the general practitioner gave a summary of the medical records and his (or her) overall assessment on somatizing behaviour and function of complaints. Results: Somatizing patients reported higher SCL-90 scores, more major life events and more medication in the previous week. A difference in absenteeism or quality of life was not found. Differences between somatizing patients and nonsomatizers in their consultations with the general practitioner were few. Soma-

Portegijs PJM, Knottnerus JA, deVries MW, Horst FG van der, Blankenstein AH, Kraan HF. Somatization and health care utilization: A prospective study. 


\section{Chapter 8}

tizing patients had more diverse reasons for encounter and experienced their complaints as more troublesome than non-somatizers. The medical records showed a higher frequency of consultations without compelling somatic reason for encounter in somatizing patients. Somatizing patients were referred more frequently for psychosocial problems. In their overall assessment of difficult ('somatizing') behaviour the general practitioners rated somatizing patients about as high as non-somatizers. The relation between (SSI) somatization and somatization as judged by the general practitioner was not clear. Medicalization decreased in the course of the follow-up. Changes in psychological or somatic complaints were not found.

Discussion: Differences between somatizing patients and non-somatizers were smaller than expected. Somatizing patients seem to function as well as nonsomatizers; they (and/or their general practitioners) succeed in controlling medicalization and maintaining a reasonably good doctor-patient relation. However, they feel worse subjectively. Somatization according to the general practitioner seems to mean more 'difficult patient' than (SSI) somatization. The decrease in medicalization after participating in the study is promising for future intervention studies.

\section{Introduction}

Illness without disease, or somatization, has long been accepted as an important health care problem. Lipowski has defined it as: "a tendency to experience and communicate somatic distress and symptoms unaccounted for by pathological findings, to attribute them to physical illness, and to seek medical help for them. ${ }^{\circ 1}$ Investment in research and health care policy has not been commensurate with this publicly acclaimed relevance of the subject. Growth of knowledge, both theoretical and applied, has been rather slow. This may be due to the elusive character of somatization, definition and operationalization problems, its interdisciplinary status with concomitant uncertainty which doctor, or which researcher, should deal with it. Possibly the lack of public pressure plays a role too (as far as we know, there is no patients' association for self-acclaimed somatizing patients).

Both the increasing need to control health care expenditures in the western world and the strengthening of the position of the patient make the problem more difficult to evade for the physician; he (or she) cannot pass on the patient to another specialist, nor can he send the patient home with paternalistic advice either.

The health care system is more intricately related to somatization than to most other health problems. It does not just figure as the (more or less effective) solution, it must be regarded as part of the problem too. ${ }^{23}$ The problem of 
somatization would be different (not absent), had not a health care system been present that sanctions illness behaviour in some instances and condemns it in others, seems to promise cure for anything except cancer, AIDS, some psychiatric problems and, recently, bovine spongiform encephalopathy. Therefore, study of somatizing patients' interaction with the health care system is essential. However, it proved to be difficult to translate clinical observations and case studies into quantitative studies without losing much of the detail. Relevant variables are often difficult to extract from patient records, and the contribution of patient and physician are impossible to sort out in retrospect. Researchers have resorted to the thickness of the patient record to characterize the impact of somatization on the health care provider! ${ }^{4}$

Conditions for research in this area have improved recently. Consensus has grown that somatizing patients need a lasting relationship with a physician who can both assess the risk of serious disease (do a physical examination and reassure, order tests or refer if necessary) and guide the patient in the way he deals with complaints or stress. As a consequence, somatization is now clearly a general practice problem. Psychiatric knowledge on somatization and related problems as depression and anxiety has been structured with the advent of DSM-II and thereby is much more accessible for non-psychiatrists. Epidemiological methods and their use in clinical decision analysis have shown medical specialists the influence of the a priori probability of disease on prognostic value of their tests. These specialists are more inclined now to see the primary care physician as essential for them to be able to do their own job. Financial pressures on the health care system and models of managed care being developed in response to these pressures have helped too. Within general practice, the recognition of the reason for encounter (RFE) as an essential element of the consultation, and the possibility to classify both RFE and diagnostic conclusion in the International Classification for Primary Care (ICPC) have made the consultation more accessible for research. ${ }^{5}$ Furthermore, one may hope that the growing interest in milder forms of somatization -as opposed to DSM-somatization disorder- will lead to more insight into factors that strengthen or counteract mechanisms of somatization in vulnerable patients. For patients with DSM (-III or -IV) somatization disorder are at the extreme of the somatization continuum. Somatizing behaviour in these patients is probably so deeply ingrained that original causal factors lie in the distant past, and that the effect of any therapeutic strategy will be limited and short-lived. Moreover, the impact on health care costs and risks of iatrogenic harm must be greater for milder forms of somatization, because of the larger number of patients.

Earlier we reported on relations of somatization with depression, anxiety, youth experiences and stress within a study group of frequent attenders of general practice. ${ }^{678}$ Somatization was operationalized according to Escobars Somatic 


\section{Chapter 8}

Symptom Index (SSI), slightly modified.' This operationalization, a more comprehensive version of the DSM-III-R operationalization of somatization disorder, defines a stable attribute of a person, best interpreted as a personality trait. ${ }^{10}$ Somatizing patients did have more somatic complaints in the previous week than non-somatizers, but relations of somatization with lifetime depressive disorder and dysthymia were more striking. 'Deprivation of parental care in youth was the strongest predictor of somatization. ${ }^{6}$ The relation of somatization and chronic psychosocial difficulties was explained by deprivation, the relation of somatization and major life events did not reach significance? Social support from the parents was related to somatization, while social support from partner, children or others did not seem to be make a difference. In an average week, somatizing patients were slightly more tired and had somatic complaints a bit more frequently. ${ }^{8}$ Somatizing patients reacted (with tiredness, somatic complaints and mood) to the context (place, activity, specific others present, stressors, etc.) very similarly to non-somatizers. In a preliminary study in a smaller study group we had found that somatizing patients had higher consultation frequency than non-somatizers and more recurrent or chronic health problems as diagnosed by the general practitioner, especially psychological ones. ${ }^{11}$ A difference in (general practitioner diagnoses of) vague somatic complaints was not found.

These results supported our view of (SSI) somatization as a personality trait with its origins in youth. Somatization was relevant for present well-being, but seemed to be a kind of underlying characteristic, influencing several aspects of everyday life, but more visible in retrospect than in the present or in specific current problems. However much this picture may be true, it does not help the general practitioner very much in dealing with somatizing patients. For one must assume that a stable personality trait can change or that a patient can learn to deal with the trait differently, by repeatedly experiencing the effect of acting or thinking otherwise. It is with those current problems that somatizing patients ask their doctors for help, and it is these reinforcing or counteracting mechanisms that the doctor needs knowledge of to be able to influence long-term prognosis.

The main aim of the present study was to describe the consequences of somatization for health problems, health care utilization and the doctor-patient relation. In this description, we wanted to supplement the general practitioner's (medical) point of view (in which somatizing patients are often seen as difficult patients) with data from the perspective of the patient as a competent actor with his (or her) personal goals in the communication. ${ }^{12}$ Furthermore we were interested in changes over time, and in the way participating general practitioners defined somatization.

We expected somatizing patients to report more symptoms, both physical and psychological, more chronic difficulties and major life events. ${ }^{13}$ Further we expected them to report a higher number of new complaints, more absenteeism 
and lower quality of life. ${ }^{14}$ Somatizing patients would use more medication and consult more health care workers apart from the general practitioner (we were especially interested in alternative healers). ${ }^{15}$ Somatizing patients consult their general practitioner more frequently. ${ }^{4}{ }^{16}{ }^{17} 18$ This difference persists after controlling for objective need. ${ }^{19}$ Somatizing patients are referred more frequently to medical specialists, and to a lesser extent also to mental health care. ${ }^{18}{ }^{20}$ We did not expect qualitative differences between somatizing and non-somatizing patients' RFEs. ${ }^{21}$ However, somatizing patients would have more diverse RFEs, and more vague somatic complaints. ${ }^{4}{ }^{2122}{ }^{23}$ Somatization is related to common psychiatric disorders and psychosocial difficulties. ${ }^{7}$ Although somatization has long been interpreted as a defense mechanism against becoming aware of these problems, empirical evidence does not support this view. ${ }^{11}{ }^{24}$ So more psychosocial RFEs are expected in somatizing patients. General practitioners generally diagnose only about half of all psychiatric problems in their patients. ${ }^{25}$ ${ }^{26}$ However, there is no reason to think that general practitioners would diagnose depression or anxiety in somatizing patients worse than in non-somatizers. ${ }^{26}{ }^{27} \mathrm{By}$ definition, one may expect that the general practitioner diagnoses 'no disease' and functional complaints (somatic complaints related to psychological causes) more frequently in somatizing patients. Somatizing patients would perceive their complaints as more severe. ${ }^{13}{ }^{17}$ Somatizing patients would be less satisfied with the care they received, and judge doctor-patient communication less favourably. ${ }^{15} 28$ We expect that somatization is visible in the general practitioner's assessment of difficult or somatizing (demanding, helpless, etc.) patient behaviour. General practitioners are less satisfied with the care rendered to somatizing patients. ${ }^{4}{ }^{29}$ Communication problems might also reveal less correspondence in somatizing patients between the RFE as reported by the patient, and the RFE recorded by the general practitioner, or maybe in more discrepancies between RFE (general practitioner-recorded) and diagnosis.

Quite a few theories on causal mechanisms of somatization have been proposed. ${ }^{10}$ What causal mechanisms the general practitioner recognizes in a particular patient is interesting in itself, and important if one later wanted the general practitioner to differentiate between subgroups of somatizing patients. One does not expect somatizing patients' symptoms to change much over time.

Against the background of the considerations mentioned above, the key question of this study was: Do somatizing patients differ from non-somatizers in subjective well-being, health care utilization, specific health problems and physician-patient communication? In addition, we studied general practitioners' recognition of (SSI) somatization, general practitioners' views on causal mechanisms in somatizing patients, and the course of complaints. 


\section{Chapter 8}

\section{Methods}

\section{Patients}

The study was carried out within study group with a high-risk for somatization: patients who had or had had recurrent or chronic abdominal, neck or back complaints and had visited their general practitioner at least 15 times in three years without compelling somatic RFE (exact criteria and procedure have been described earlier). ${ }^{611}$ After data collection for the cross-sectional study (two interviews at the patient's home) the patients were requested to participate in the prospective study or parts of it.

\section{General practitioners}

The study was conducted within 8 practices ( 23 general practitioners) participating in the Registration Network of Family Practices of the Universiteit Maastricht (RNH: 'RegistratieNet Huisartspraktijken'). ${ }^{30}$ Practices participating in the RNH have long-term commitment to scientific research, and experience in data collection for various studies. They have summarized the medical history of their patients in problem lists and classified these with the ICPC.

The willingness to accept a researcher looking behind the scenes and the lasting enthusiasm for development of general practice through research might mean that the participating general practitioners form a positive selection of general practitioners in the Netherlands. In the weight they attach to psychosocial aspects of the general practitioner's work, they probably are an unbiased sample. Quite a few general practitioners were young university researchers with a parttime appointment in practice. Women were a bit underrepresented.

The total population of $\mathrm{RNH}$ practices is representative for the Dutch population on sociodemographic variables, but has a distinct cultural background due to the location in the province of Limburg, far from the urban agglomeration of western Holland (geographically small distances by international standards signify relatively large cultural differences in the Netherlands).

Almost everyone in the Netherlands is registered with a general practitioner, who explicitly has a gatekeeper function for access to medical specialists, physiotherapy and (to a lesser extent) mental health care. The general practitioner therefore has an overview of his patients' contacts with the health care system. $\mathrm{He}$ has a lasting relation with the patient, and doctor-shopping (within primary care) is relatively infrequent.

\section{Instruments}

Somatization was operationalized as a more comprehensive version of the DSMIII-R criteria for somatization disorder, with 5 instead of 13 complaints (and start 
of first complaint before age 30). " It was assessed with the Diagnostic Interview Schedule (DIS) at the time of the initial interview.

Eight and 16 months after the initial (cross-sectional study) interview the patients received a set of postal questionnaires, which included the Symptom Checklist-90 (SCL-90), the Groningen List of Chronic Difficulties, an events checklist adapted from the Groningen Events List, and questions on complaints, quality of life, absenteeism (work/household chores), consultation of health care workers (emphasis on alternative healers, social workers and others that the general practitioner might not have information on) and use of medication in the previous week.

Both patients and general practitioners were requested to fill in a short questionnaire immediately after each consultation. In the patient questionnaire we asked what the RFE(s) (later to be coded with the ICPC) had been and 21 Likerttype questions on evaluation of complaints, both the general practitioner's and the patient's own contribution to the communication, and satisfaction with the consultation as a whole.

In the general practitioner questionnaire both RFE(s) and diagnoses or working hypotheses of the general practitioner were asked. In line with standard procedure with the ICPC these diagnoses or working hypotheses were the diagnostic conclusions of the general practitioner at the highest level of refinement which can be reasonably defended. This could be a disease or syndrome (component 7 of the ICPC) but if a diagnosis could not be made according to standard criteria, it could also be a complaint (component 1) or process code (request for diagnostic procedure, component 2, for instance). To avoid confusion, we will reserve the term 'diagnosis' for component 7 , and designate the general practitioner's diagnosis or working hypothesis with 'diagnostic conclusion'. The general practitioner questionnaire further consisted of 14 Likert-type questions on somatizing behaviour (theatrical presentation, demanding attitude, helpless behaviour, nagging), alexithymia (inability to express emotions) and evaluation of the consultation. An explicit question on the general practitioner's assessment of somatization was part of the somatizing behaviour scale.

Both patient and general practitioner consultation questionnaires were distributed by the receptionist, using a marker on the patient record (paper or computerized). In an (unrelated) study of the department, general practitioners filled in a short questionnaire in only $60 \%$ of all consultations, despite all kinds of incentives and monitoring. We decided that a sample of consultations was good enough for this study, and that we should be careful about the general practitioners' workload (they were participating in several studies simultaneously). So we instructed the receptionist that filling in a questionnaire was not necessary if the last one had been less than a week previously, made sure that enough questionnaires were available and phoned the receptionist every now and then, 


\section{Chapter 8}

but did not bother the general practitioner or monitor compliance closely (we did after concluding data collection).

After 16 months the general practitioner was asked summary data from his medical records, and his final assessment of the patient. This data included consultation frequency (total, and without compelling somatic RFE) in the 16 months before and the 16 months after the initial interview, referrals (specialist/therapist referred to, reason for referral and specialist/therapist conclusion) and Likert-type questions on somatizing behaviour (8) and function of complaints in the patients life (that is, the theoretical model or models of somatization he recognized in the patient, 8 questions). Questions on somatizing behaviour were roughly similar to the ones in the consultation questionnaire. In addition, the general practitioner was explicitly asked to assess for himself somatization and somatic fixation. During follow-up, several patients had mentioned that their participation in the study, though upsetting at the time (of the initial interview) had helped them cope with their complaints. The general practitioners generally had the same impression. Therefore all somatizing behaviour questions were supplemented with questions on change in comparison to the time before the initial interview. The 'function of complaints' questions concentrated on alexithymia, psychodynamic, cognitive, behavioural, and language (individual, family, subcultural level) models of somatization. A question on conscious manipulation by the patient was added.

\section{Analysis}

The aim of the study being descriptive (and covering a range of topics) multiple statistical tests were inevitable. We decided that using the Bonferroni correction would narrow attention too much to the few relations that by coincidence were strong enough to survive the correction. Therefore, uncorrected significance values are presented, and the distinction between primary and post-hoc analyses is emphasized. A special problem were the ICPC-codes used to classify RFEs, diagnostic conclusions and reasons for referral. Usually ICPC-data are analysed by chapter ( $\approx$ organ system), by component (type of RFE, e.g. request for diagnostic procedure), or the most frequent specific codes are described in a 'top-ten' fashion. For large-scale descriptive studies (international comparisons of RFEs, for instance) this strategy works well. Other researchers, interested in a specific problem or group of problems, analysed these in detail and lumped the rest in one or a few 'other' categories. For our study this was not an option; the 'other' category was the most important one for somatization: diversity of complaints, specificity of complaints, the way RFEs are phrased (radiating back pain, herniated disc, request for an X-ray, or request for surgery, for example). In addition, we were interested in specific psychological and social problems. This problem was partly solved by rearranging specific ICPC-codes into 'chapters' of 
our own. A list of ICPC-codes for 'vague somatic complaints' had been defined earlier by translating DSM-III-R somatization disorder items into ICPC-codes. ${ }^{11}$ We were interested in chronic diseases and serious somatic diseases, both to evaluate prognosis and to see whether somatizing patients presented themselves with these diagnoses. A list of chronic diseases was available from another study of the department. ${ }^{31}$ A list of exclusion criteria for our study was used as 'serious somatic disease'. Of course we were specifically interested in psychosocial (chapters $\mathrm{P}$ and $\mathrm{Z}$ ) problems, with a subdivision into psychological (P) and social (Z) problems. Within the psychological problems, we distinguished depressive (P03, P73, P76, P77), anxiety (P01, P74), crisis (P02) and neurasthenia (or somatization, P75, P78) problems. In addition, we defined functional complaints as a psychosocial diagnosis in a consultation with a somatic (complaint), no psychosocial RFE. Diversity of complaints was counted, both at ICPC-code and ICPC-chapter level, and for the consultation questionnaires (lack of) consistency between patient-reported and general practitioner-reported RFEs and between general practitioner-reported RFEs and diagnostic conclusions.

Since we had specific expectations on the direction of relations, primary analyses were one-sided. For post-hoc analyses we report two-sided significance levels. All analyses were done with SPSS-PC+ version 4.0.

\section{Results}

\section{Subjects and compliance}

Of the 111 patients originally included in the initial study, 83 patients returned our postal questionnaires both after 8 months and after 16 months. Six patients returned the 8-month questionnaire only. Results presented here are averages of 8 month and 16-month data where possible, 8-month data in these six patients.

Consultation registration questionnaires were filled in until all patients in a practice had finished the 16-month follow-up period. This resulted in the number of patient consultation registration questionnaires per month being fairly constant until 18 months after the initial interview, then falling sharply. This enabled us to extend the follow-up period for the consultation registration to 18 months. Within this period, we received 275 patient consultation registration questionnaires from 71 patients. The average number of consultations reported on was 4.1 for somatizing patients and 3.7 for non-somatizers (see table 2). Comparison (of data from the first 16 months) with the summary medical records yielded a compliance of $36 \%$ in somatizing patients participating in this part of the study, and $41 \%$ in non-somatizers. In further analyses, we do not correct for number of consultations reported on. 


\section{Chapter 8}

The general practitioner consultation registration not being dependent on patient compliance (after initial consent), both the number of patients reported and the number of consultations per patient were slightly higher. Within the 18month period, we received 334 general practitioner consultation registration questionnaires, pertaining to 77 patients, from the general practitioners. Complete (both patient and general practitioner questionnaire) data were available for 263 consultations, pertaining to 70 patients.

For 85 patients the general practitioner gave summary data from his medical registration and his overall impression of the patient on the final assessment questionnaire. The discrepancy with the 111 patients included was largely due to one of the general practitioners (the one who had contributed the greatest number of patients to the study) dropping out at the final stage of the study.

For only 53 patients complete data were available. In further analyses, the number of patients is maximized; that is, all patients with valid data for a specific comparison are analysed.

\section{Scale construction}

Our a priori division of the questions in which the patient gave his evaluation of the consultation was refined after factor and reliability analyses. The six questions on the complaint were divided in 'bothersome' and 'fear of serious disease'. The question "were your complaints aggravated by stress?" did not fit in either. For the sake of completeness, it was further analysed as a scale of its own. Six questions on the general practitioner's contribution to the communication, and three on the patient's contribution combined to form a scale 'communication'. The six questions on overall satisfaction with the consultation were kept unchanged.

The Likert-type questions in the general practitioner consultation registration questionnaire had a priori been divided in somatizing behaviour, alexithymia and overall evaluation. It was modified on one point after factor and reliability analyses; the question "did the conversation give you a feeling of impotence" (originally in overall evaluation) fitted best in somatizing behaviour and was replaced.

Factor analysis of the questions on patient behaviour in the overall assessment by the general practitioner yielded two factors, with the negatively phrased items in one factor, and the positively phrased items in the other. Because of our suspicion that this factor structure might represent phrasing rather than content, we present results on item level. 
Table 1: Postal questionnaires

$\begin{array}{lll}\text { somatizing } & \text { non- } & \\ \text { patients } & \text { somatizers } & \text { significance } \\ \mathrm{N}=45 & \mathrm{~N}=44 & \text { Mann-Whitney U }\end{array}$

\begin{tabular}{|c|c|c|c|}
\hline SCL-90 total score & 4.8 & 4.1 & $0.042^{*}$ \\
\hline somatic complaints & 5.5 & 5.1 & $0.078^{\wedge}$ \\
\hline anxiety & 4.7 & 4.3 & $0.098^{\wedge}$ \\
\hline agoraphobia & 4.3 & 4.0 & 0.185 \\
\hline depression & 4.8 & 4.3 & $0.094^{\wedge}$ \\
\hline chronic difficulties & 1.4 & 1.3 & $0.061^{\wedge}$ \\
\hline in relations & 1.4 & 1.3 & 0.108 \\
\hline other & 1.5 & 1.3 & $0.079^{\wedge}$ \\
\hline life events / year & 5.6 & 4.0 & $0.003 *$ \\
\hline positive & 1.8 & 1.2 & $0.037^{*}$ \\
\hline indeterminate & 1.5 & 1.0 & $0.038 *$ \\
\hline negative & 2.3 & 1.8 & $0.088^{\wedge}$ \\
\hline number of new complaints & 0.9 & 0.8 & 0.119 \\
\hline quality of life $(0-100)$ & 57 & 60 & 0.251 \\
\hline absenteeism (work/other) (weeks) & 3.9 & 3.2 & 0.427 \\
\hline number of health care workers & 1.0 & 1.0 & $0.503^{*}$ \\
\hline number of medicines & 1.0 & 0.6 & $0.007 *$ \\
\hline thoc painkillers & 0.9 & 0.5 & $0.016(2.5)$ \\
\hline other symptomatic & 0.9 & 0.5 & $0.016(2-s)$ \\
\hline
\end{tabular}

Significant and near-significant relations of primary analyses are marked: ${ }^{\wedge}=p<0.1$, * $=p<0.05,{ }^{* *}=p<0.01$

" In primary analyses, a significance value greater than 0.500 means that the observed relation was contrary to the direction expected; one-sided tests were used for these analyses.

\section{Postal questionnaires}

Somatizing patients had higher SCL-90 scores than non-somatizers (see table 1). This difference could not be ascribed to a specific subscale; somatizing patients probably scored higher on somatic complaints, depression and anxiety. Somatizing patients probably had more chronic difficulties than non-somatizers. They 
reported many more life events per year. A difference was found for positive and indeterminate events, a probable difference for negative ones.

Somatizing patients reported about as many new complaints that had troubled them a lot as non-somatizers. Conspicuous differences in the specific complaints mentioned were not found; for both groups musculoskeletal complaints were most prominent, with about half of all new complaints (data not shown). Somatizing patients had used more medication in the week before filling in the questionnaires. Post-hoc tests (2-sided) yielded significant differences for painkillers, other symptomatic and digestive medication. A difference in absenteeism (disability for work or household chores) or number of health care workers consulted (except for the general practitioner) was not found. Nor was any difference in quality of life observed; both groups rated their quality of life as barely acceptable.

\section{Patient registration of consultations}

Neither in number of vague somatic complaints, nor in the frequency of psychosocial problems (ICPC chapters P or Z), as RFE was a difference found (see table 2). The frequency of these psychosocial RFEs was too low for more specific analyses to be done. Somatizing patients did have more diverse RFEs; that is, RFEs in a larger number of ICPC chapters. If the comparison was made on the level of specific ICPC codes, the difference did not reach significance.

The most frequent specific RFE in both somatizing and non-somatizing patients was back complaints (LO2, see table 3). General weakness/tiredness (AO4) was conspicuously frequent in somatizing patients. Otherwise somatizing and non-somatizing patients' top-fives of RFEs were similar.

In figure 1 the distribution of somatizing and non-somatizing patients' RFEs is given by ICPC chapter and component. Again, similarities were more striking than differences. Somatizing patients had remarkably many RFEs in chapter A (general and unspecified) and X (female genital system), non-somatizers in chapter $\mathrm{L}$ (musculoskeletal). For both somatizing and non-somatizing patients, symptoms and complaints (component 1) were by far the most frequent RFEs. Requests for diagnostic, screening or preventive (component 2) and treatment or medication (component 3) procedures were comparatively few. Somatizing patients had many diagnoses (component 7 ) in chapter $\mathrm{R}$ (respiratory). This was largely due to upper respiratory tract infections ( $R 74$ ) and sinusitis ( $R 75)$, codes that have the status of diagnoses, but are frequently used as descriptors of complaints as well. Post-hoc tests indicated that chapter A and (in women) chapter X might be more prevalent in somatizing patients. Differences in chapter $\mathrm{L}$ or component 7 were not found.

Somatizing patients reported more bothersome complaints than non-somatizers (see table 2). They tended to atribute their complaints more strongly to 
Figure 1: Reasons for encounter (patient questionnaire)

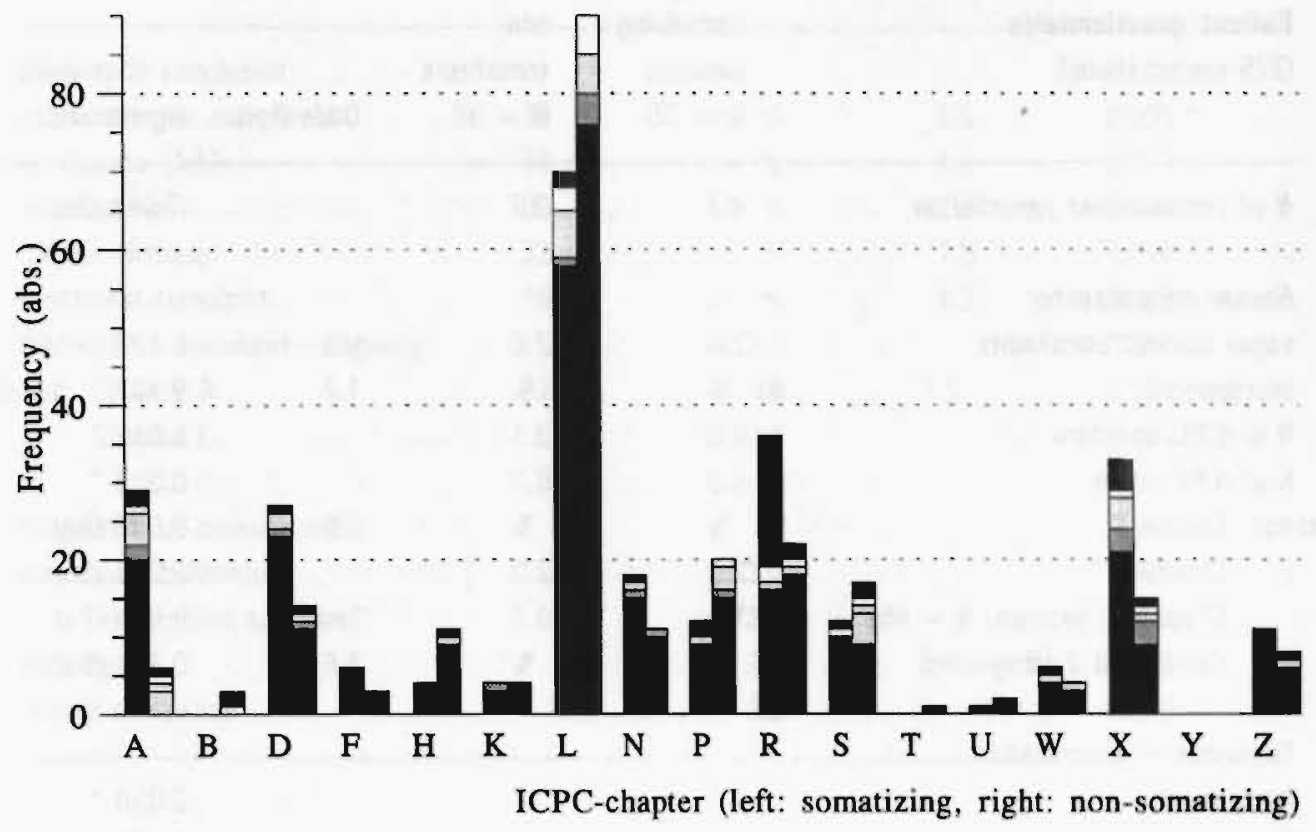
1: symptoms / compl.
2: diagnostic
3: treatment proced.
4: test results
5: administration
7: diagnoses, diseas,

stress. Differences in fear of serious disease, communication or overall satisfaction were not found.

General practitioner registration of consultations

Results on RFEs were similar to those obtained from the patient consultation questionnaires. No differences were found in numbers of vague somatic complaints or psychosocial problems. More specific analyses on psychological problems, anxiety and social problems did not yield any indication of a difference (data not shown, prevalences of depressive, crisis and neurasthenia problems were too low to analyse). At ICPC chapter level, the data tended to support the greater diversity of somatizing patients' RFEs found in the patient questionnaires. The top-fives of complaints were almost identical to the ones recorded by the patients (see table 3).

A diagnosis of vague somatic complaints (which means that the complaints could not be ascribed to a specific syndrome or disease) was made about as frequently in somatizing patients as in non-somatizers. If present at all, the 
Table 2: Registration of consultations

Patient questionnaire

(275 consultations) somatizing non-

patients somatizers

$\mathrm{N}=35 \quad \mathrm{~N}=36 \quad$ Odds Ratio significance

$N$ of consultations reported on

4.1

3.7

$0.441(2 \cdot s)$

Reason for encounter

vague somatic complaints

psychosocial

$\mathrm{N}$ of ICPC chapters

$\mathrm{N}$ of ICPC codes

Post-hoc Chapter A

Chapter L

2.8

2.6

0.176

$43 \%$

$31 \%$

1.7

0.141

4.0

3.1

$0.011^{*}$

6.3

5.1

$54 \%$

$11 \%$

$0.063^{\wedge}$

Chapter $X$ (women, $\mathrm{N}=45$ )

2.0

2.5

$0.000(2-5)$

1.4

0.7

$0.939(2 \cdot s)$

Component 7 (diagnoses)

$34 \%$

$25 \%$

$0.018(2-s)$

1.6

0.391 (2-s)

Evaluation of consultation

troublesome

fear of serious disease

stress (causal role of)

communication

overall (dis)satisfaction
4.3

2.1

2.3

2.8

2.5
3.7

2.0

2.0

2.6

2.3
$0.030^{*}$

0.456

$0.081^{\wedge}$

0.295

0.177

\begin{tabular}{lllll}
$\begin{array}{l}\text { General practitioner questionn. } \\
334 \text { consultations }\end{array}$ & $\begin{array}{l}\text { somatizing } \\
\mathrm{N}=38\end{array}$ & $\begin{array}{l}\text { non-somat. } \\
\mathrm{N}=39\end{array}$ & Odds Ratio & significance \\
\hline$N$ of consultations reported on & 4.5 & 4.2 & 0.565 (2-s)
\end{tabular}

Reason for encounter

vague somatic complaints

2.6

$45 \%$

psychosocial

$\mathrm{N}$ of ICPC chapters

$\mathrm{N}$ of ICPC codes

Post-hoc Chapter A

Chapter L

\section{4}

7.0

$42 \%$

1.7
3.1

$0.777^{\circ}$

0.288

0.068 ^

0.271

6.6

2.1

0.127 (2-s)

0.261 (2-s)

Table continued next page 
Table 2 (continued)

somatizing non-somat. Odds Ratio significance

\section{Diagnostic conclusion}

vague somatic complaints

no disease (A97)

$32 \%$

$46 \%$

0.5

$0.905 "$

$18 \%$

$15 \%$

1.2

0.361

psychosocial

$53 \%$

$44 \%$

1.4

0.214

chronic disease

$32 \%$

$23 \%$

$0.799^{a, b}$

functional complaint

$34 \%$

$28 \%$

1.5

0.285

discrepancy complaint - diagnosis

3.2

2.3

1.3

$0.039 *$

Post-hoc Chapter A

$37 \%$

$31 \%$

$0.573(2-s)$

Chapter L

1.2

2.1

$0.194(2-s)$

\section{Evaluation of consultation}

somatizing behaviour

"did patient somatize?"

alexithymia

overall evaluation

Both patient and general practitioner questionnaire 263 consultations

somatizing

non-somat.

$\mathrm{N}=34 \quad \mathrm{~N}=36 \quad$ Odds Ratio significance

(N of consultations reported on

4.0

3.6

0.349 (2.s)

patient RFE not mentioned by GP

4.9

3.7

$0.074^{\wedge}$

patient RFE without GP RFE in

2.6

1.5

$0.008^{\cdots}$

same chapter

GP RFE not mentioned by patient

GP RFE without patient RFE in

4.6

4.2

0.244

2.3

2.1

0.253

same chapter

The variables in the consultation questionnaires were ordinally scaled, so we used the Mann-Whitney $\mathrm{U}$ test. In the body of the table, means are given (not medians). However, variables that were heavily skewed (overall mean 0.5 or lower), were dichotomized and analysed with the Chi ${ }^{2}$ test. In these cases percentages and odds ratios are reported. Significant and near-significant relations of primary analyses are marked: ${ }^{\wedge}=p<0.1,{ }^{*}=p<0.05,{ }^{* *}=p<0.01$

a In primary analyses, a significance value greater than 0.500 means that the observed relation was contrary to the direction expected; one-sided tests were used for these analyses.

b A lower frequency in somatizing patients was expected 


\section{Chapter 8}

Table 3: Most frequent RFEs, diagnostic conclusions and reasons for referral

somatizing patients

freq. ICPC title non-somatizers

freq. ICPC title

\begin{tabular}{lrrllrll}
\hline reason for & 1 & 15 & L02 & back complaints & 18 & L02 & back complaints \\
encounter & 2 & 11 & A04 & general weakness/tiredn. & 12 & L08 & shoulder complaints \\
patient form & 3 & 10 & L01 & neck complaints & 11 & L01 & neck complaints \\
& 4 & 9 & N01 & headache & 8 & L17 & foot \& toe complaints \\
& 5 & 9 & R74 & upper resp. tr. infection & 8 & N01 headache \\
total & & 269 & & & 231 & & \\
\hline
\end{tabular}

\begin{tabular}{lrrllrll} 
reason for & 1 & 12 & L01 & neck complaints & 18 & L08 & shoulder complaints \\
encounter & 2 & 11 & R05 & cough & 17 & L02 & back complaints \\
GP form & 3 & 9 & L02 & back complaints & 11 & L01 & neck complaints \\
& 4 & 9 & N01 & headache & 10 & N01 & headache \\
& 5 & 7 & A04 & general weakness/tiredn. & 9 & R05 & cough \\
total & & 302 & & & 307 & & \\
\hline diagnostic & 1 & 14 & L18 & muscle pain/fibrositis & 12 & L92 & shoulder syndrome \\
conclusion & 2 & 10 & R75 & sinusitis & 9 & R74 & upper resp. tract inf. \\
(GP form) & 3 & 8 & R74 & upper resp. tr. infection & 8 & L18 & muscle pain/fibrositis \\
& 4 & 7 & A97 & no disease & 7 & L01 & neck complaints \\
& 5 & 7 & P01 & feeling anxious/nerv.Itense & 7 & L02 & back complaints \\
total & & 221 & & & 247 & &
\end{tabular}

The top-fives of most frequent RFEs and diagnostic conclusions are presented here, for illustration. All RFEs of a patient over all consultations are added, which precludes statistical analysis /we analysed theoretically relevant RFEs or groups of RFEs in table 2).

relation was in the other direction. A difference in the frequency of diagnoses of 'no disease' (A97), psychosocial problems (or psychological, social, anxiety or neurasthenia problems, data not shown) was not found, nor was a difference in frequency of chronic diseases. Functional complaints, defined as a psychosocial diagnosis in a consultation with a somatic complaint, not a psychosocial RFE, were about as frequent in somatizing as in non-somatizing patients. Somatizing patients did have more discrepant RFEs (RFE without diagnosis in the same ICPC chapter) than non-somatizers. 
Figure 2: Diagnostic conclusions (GP questionnaire)

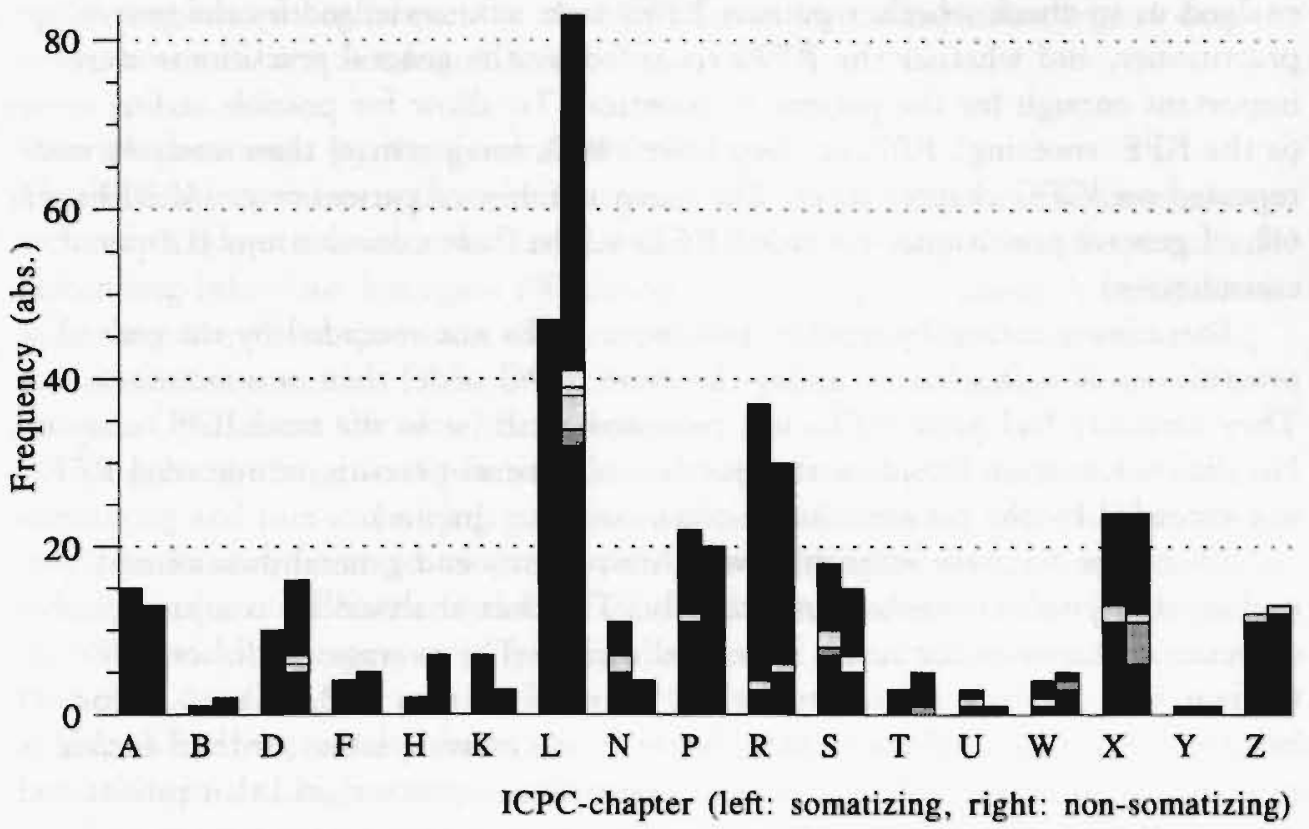

1: symptoms / compl.

4: test results

\section{2: diagnostic}

5: administration
3: treatment proced.

7: diagnoses, diseas.

Sinusitis, 'no disease' and 'feeling anxious/nervous/tense' were conspicuously frequent diagnostic conclusions in somatizing patients (see table 3). Shoulder syndromes (a 'diagnosis' of questionable status) and several musculoskeletal complaints were most frequent in non-somatizers.

The distribution of the general practitioner's diagnostic conclusions in somatizing and non-somatizing patients, by ICPC chapter and component, is given in figure 2. Again, similarities were more striking than differences. Nonsomatizers had almost twice as many musculoskeletal (chapter L) problems, largely due to a greater number of component 7 (diagnoses, diseases) problems. Post-hoc tests, however, did not yield a significant difference; the picture was distorted by four non-somatizers with six to ten musculoskeletal diagnoses, as opposed to none of the somatizing patients. The median number of musculoskeletal diagnoses was 1 in both groups.

No differences were found in the general practitioner's ratings of somatizing behaviour, alexithymia or overall evaluation (see table 2). Nor was a difference found for the question "Did the patient somatize" (part of somatizing behaviour). 


\section{Chapter 8}

\section{Patient and general practitioner registration of specific consultations}

Linking patient and general practitioner questionnaires of specific consultations enabled us to check whether patient RFEs were acknowledged by the general practitioner, and whether the RFEs recorded by the general practitioner were important enough for the patient to mention. To allow for possible coding errors (is the RFE 'sneezing', R07, or 'hay fever', R97, for instance) these analyses were repeated on ICPC chapter level. The mean number of patient-recorded RFEs was 6.8, of general practitioner-recorded RFEs 6.9 in these consultations (1.8 per consultation).

Somatizing patients probably had more RFEs not recorded by the general practitioner as such (that is, under the same ICPC code) than non-somatizers. They certainly had more RFEs not recorded at all (= in the same ICPC chapter). No differences were found in the number of general practitioner-recorded RFEs not recorded by the patients (same code, or same chapter).

Of course we were interested whether patients and general practitioners evaluated a specific consultation similarly. This was analysed by comparing correlations between the scales described earlier. The average of all 'across' (patient with general practitioner scales) correlations was 0.18 , versus 0.25 for 'within' correlations, which is remarkable if one considers that 'within' correlations had been minimized by the scale construction process, and that patient and general practitioner questionnaires contained quite a few similar questions. Overall satisfaction of the general practitioner with the consultation correlated only 0.15 with satisfaction of the patient, and 0.22 with the patient's evaluation of the communication.

\section{Summary of medical records}

The mean consultation frequency in the period 16 months before to 16 months after the initial interview was 6.7 per year, about double the country average for this age group. Somatizing patients probably had a higher consultation frequency than non-somatizers (see table 4). If consultations with compelling somatic RFE were excluded from the analysis, the difference was obvious. This higher medical consumption was not reflected in the number of referrals to other health care workers, though; no difference at all was found. A breakdown into referrals to medical specialists, psychosocial care and physiotherapy did not yield conclusive results; probably somatizing patients were referred to psychosocial care more frequently.

More informative were the analyses of the reasons for referral, and of specialists' conclusions. Somatizing patients were referred for psychosocial problems more often. They were diagnosed by the specialist (or other health care worker) as having a psychosocial problem more frequently. This difference was mostly due to social problems. No differences were found in specialists' diagnoses 
of 'no disease' (A97), vague somatic complaints or chronic diseases. Post-hoc analyses indicated that somatizing patients might have been referred for neurological problems more frequently. A difference in (specialist) neurological diagnoses, however, was not found at all.

\section{Overall assessment by the general practitioner}

The general practitioners thought that participating patients were somewhat inclined to adopt the sick role. Helpless behaviour was judged less frequent, and demanding behaviour less again (Wilcoxon test; $p<0.012$-sided) A comparison with the other three questions was not possible because of the reversed coding (one cannot assume that ' 4 ' is the centre of a 7-point Likert scale). These three questions had about the same mean scores.

In general, the general practitioners did not seem to differentiate between somatizing and non-somatizing patients in their assessment of patient behaviour; only for the inclination to adopt the sick role and helpless behaviour were some indications for a difference found. A relation between somatization (according to the SSI) and somatization as judged by the general practitioner was not found. However, we did find a relation between (SSI) somatization and somatic fixation as judged by the general practitioner. Noteworthy is that the general practitioners rated the patients higher on somatization than on somatic fixation.

The general practitioners explained somatic complaints in the participating patients primarily as a result of cognitive processes. Alexithymia, psychodynamic and family culture mechanisms were frequently endorsed as well (the difference with the cognitive explanation was not significant). An explanation of somatic complaints as an individual, or subculturally sanctioned language ('idiom of distress') was thought less important than the cognitive explanation, (Wilcoxon test: $p<0.05)$. Generally, the general practitioners did not think that operant conditioning or conscious manipulation by the patient could explain complaints. As these results may represent real causal mechanisms of complaints or presupposition of the participating general practitioners or (most likely) a mix of the two, we were very interested in a comparison of somatizing and non-somatizing patients. The general practitioners recognized psychodynamic, behavioural and individual language mechanisms more strongly in somatizing patients than in non-somatizers. Probably they saw more cognitive mechanisms as well.

\section{General practitioner recognition of somatization}

As mentioned above, the overlap between somatization (and to a lesser extent somatic fixation) as judged by the general practitioner and the SSI was relatively small. For a comparison of the construct validity of the general practitioner's judgement and the SSI, we computed the mean of the general practitioner's judgements, giving equal weight to the consultation and the final assessment data, 


\section{Chapter 8}

Table 4: Final assessment of the general practitioner

$\begin{array}{ll}\text { somatizing non- } & \text { patients } \\ & \text { somatizers }\end{array}$

$N=40 \quad N=45 \quad$ Odds Ratio significance

consultations / year

consultations without compelling somatic RFE / year
7.4

4.2
6.2

2.6 $0.065^{\wedge}$

$0.001 *$

\section{referrals}

referrals / year

to medical specialist

0.9

0.9

0.355

to psychosocial care

1.1

1.2

$0.823^{\circ}$

to physiotherapy

$25 \%$

$13 \%$

2.2

$0.085^{\wedge}$

0.6

0.6

0.439

for psychosocial problems

$25 \%$

$11 \%$

2.7

$0.047^{*}$

for vague somatic complaints

concl. psychosocial concl. psychic concl. social

concl. vague somatic complaints

concl. no disease

concl. chronic disease

post-hoc for neurological problems

concl. neurological problems

0.9

1.0

0.435

$20 \%$

$4 \%$

5.4

$0.029 *$ a

$10 \%$

$4 \%$

2.4

0.283

$10 \%$

$0 \%$

$\approx 11.2^{\circ} \quad 0.045^{* a}$

$15 \%$

$18 \%$

0.8

0.635 "

$20 \%$

$20 \%$

1.0

0.500

$18 \%$

$13 \%$

1.4

0.703 c.d

$23 \%$

$4 \%$

6.2

0.013 (2-s)

$10 \%$

$9 \%$

1.1

$1.000(2 \cdot s)^{\text {a }}$

Evaluation of patient behaviour sick role

- open psychosocial causes "

helpless behaviour

demanding behaviour

- show emotions ${ }^{a}$

4.0

- open about life problems ${ }^{\circ}$

0.149

\section{Continued next page}


Table 4 (continued)

somatizing non-somat. Odds Ratio significance

\begin{tabular}{lllll}
$\begin{array}{l}\text { Function of complaints } \\
\text { alexithymia } \\
\text { psychodynamic }\end{array}$ & 3.8 & 4.1 & & $0.848^{\mathrm{c}}$ \\
$\begin{array}{l}\text { cognitive } 4.7 \\
\text { behavioural }\end{array}$ & 4.4 & 3.7 & $0.087^{\wedge}$ & $0.049^{*}$ \\
conscious manipulation & 4.0 & & \\
language individual & 3.5 & 2.9 & $0.048^{*}$ \\
family culture (llanguage) & 2.7 & 2.6 & 0.363 \\
language (sublculture & 4.2 & 3.4 & $0.020^{*}$ \\
total scale & 4.2 & 4.0 & $0.352^{\circ}$ \\
\hline
\end{tabular}

The independent variables in this table were ordinally scaled, so we used the Mann-Whitney $U$ test. In the body of the table, means are given (not medians). However, variables that were heavily skewed (overall mean 0.5 or lower), were dichotomized and analysed with the $\mathrm{Chi}^{2}$ test. In these cases percentages and odds ratios are reported. Significant and near-significant relations of primary analyses are marked: ${ }^{\wedge}=p<0.1,{ }^{*}=p<0.05,{ }^{* *}=p<0.01$

a Fisher's exact test

- After adding 0.5 to each cell to avoid empty cells

- In primary analyses, a significance value greater than 0.500 means that the observed relation was contrary to the direction expected; one-sided tests were used for these analyses.

- A lower frequency in somatizing patients was expected

- Coding of these questions was reversed; a high score here indicates not open, etc.

1 The general practitioner only filled in this question if he knew the patient's parents; valid $\mathbf{N}=46$

and dichotomized it. This summary measure was not (significantly) related to the SSI: odds ratio $1.5, p=0.166$, one-sided. Construct validity of this summary measure could not be demonstrated; a relation with (chronic) relational difficulties was found, but not with 16 other variables both theoretically relevant for somatization and related to the SSI. ${ }^{7}$ These analyses were repeated, using the scale totals instead of the specific questions (somatizing behaviour scale and evaluation of patient behaviour). This way we measured not what the general practitioner judged to mean somatization, but his assessment of specific behaviours generally thought characteristic for somatization. Now a near-significant relation with the SSI was found; odds ratio $1.7, \mathrm{p}=0.096$ one-sided. This broader 
construct was related to anxiety disorders, social support from the partner, social support from parents and chronic relational difficulties $(p<0.05$ one-sided). Reanalysis of our earlier SSI findings on the same group of patients (to correct for the smaller number of cases as compared to our earlier reports) yielded significant relations of the SSI with depressive and dysthymic disorder, somatic and depressive complaints in the previous week (SCL-90), support from parents, chronic relational difficulties, deprivation of parental care and other life events in youth.

\section{Clinical course}

For a limited set of variables, information on clinical course was available. For the SCL-90 and its subscales and chronic difficulties, initial interview data could be compared to follow-up data. Frequency of consultations, frequency of consultations without compelling somatic RFE and all referral data could be distinguished into the 16 months before, and the 16 months after the initial interview. At follow-up, the patients had assessed changes in their main complaint and general health since the initial interview. In their final assessment, the general practitioners had done the same for their evaluation of patient behaviour.

Frequency of consultations without compelling somatic RFE was judged to be a better indicator of prognosis than total number of consultations. Total number of referrals, referrals for vague somatic complaints and referrals with specialist conclusion 'no disease' (A97) were judged indicative. Some pushing was necessary to summarize these nine variables in three factors (with $58 \%$ explained variance); the factor analysis originally yielded 5 factors with eigenvalue greater than 1, the scree plot suggested four factors, but neither structure was readily interpretable. The final structure consisted of (changes in) illness behaviour, somatic complaints and psychosocial complaints. Changes in frequency of consultations without compelling somatic RFE, total number of referrals, referrals for vague somatic complaints and referrals with specialist conclusion 'no disease' were combined into 'medicalization' (alpha $=0.61$ ). Changes in main complaints and in general health formed 'somatic complaints' (correlation $=0.53$ ). General practitioner evaluation of changes in patient behaviour, changes in chronic difficulties and in SCL-90 scores were combined into 'psychosocial complaints' (alpha 0.56).

A significant decrease in medicalization was found (Wilcoxon test: $p=0.013$ two-sided). No change whatsoever in somatic complaints $(p=0.488)$ or psychosocial complaints (non-significant decrease: $p=0.244$ ) could be demonstrated. 


\section{Discussion}

In general, similarities between somatizing and non-somatizing patients were more striking than differences. The differences that were found were in degree more than in kind and could, at least partly, be ascribed to the higher consultation frequency of somatizing patients. What good is it knowing whether a patient somatizes according to the SSI, if that knowledge has no predictive value for relevant outcomes? On the other hand, one could assume that the SSI is a valid measure of a relevant concept, and search for a general interpretation that fits reasonably well with the differences we found, and the ones we did not find (negative findings should be interpreted cautiously because of the rather low numbers of cases). This interpretation would emphasize the level of adaptation somatizing patients have achieved in their social functioning: no (significant) differences in absenteeism, number of health care workers consulted, fear of serious disease, evaluation of the communication with the general practitioner, satisfaction with the consultation, or in 'somatizing' behaviour. In this interpretation the other side of the coin would be the strain on the patient as evidenced by a higher SCL-90 score, use of medication, number of consultations without compelling somatic RFE, the more diverse and troublesome complaints somatizing patients have. Furthermore, somatizing patients are referred more frequently for psychosocial reasons (confirmed by the specialist's conclusion) and the general practitioners do recognize specific mechanisms of somatization in these patients. In this interpretation, the general practitioner deserves credit for the way he deals with the problem; the higher consultation frequency is not translated into a higher referral frequency or more dissatisfaction of patient or general practitioner, while the general practitioner does recognize the problem and acts accordingly. On the other hand, the general practitioner may do so partly by not hearing some RFEs.

\section{Methodological considerations}

Our aim of giving a fairly broad description, with the lack of standard instruments to summarize the results, led to a large number of statistical tests being performed. Each of these analyses should be valid in itself; we tried to specify analyses blind to results of other analyses. The probability of spurious results in the whole picture emerging from these analyses is -of course- far greater than the customary 0.05 . We have tried not to overinterpret our results, and advise the reader to decide for each analysis whether it is crucial for the general picture.

The emphasis on subjective assessment by the general practitioner might have led to bias if the general practitioner had been aware of the somatization status of the patients. This may have played a role in the few patients for whom we contacted (with permission) the general practitioner because of suicidal thoughts, 


\section{Chapter 8}

personal crisis or first disclosure of serious sexual abuse in childhood. For all others, the general practitioner was blind to somatization status.

As mentioned before, the patient population of the RNH is fairly representative of the Dutch population at large. The participating general practitioners are not; the willingness to accept a researcher looking behind the scenes and the lasting enthusiasm for scientific development of general practice must influence their work in the consulting room too. We guess that this may have led to an underestimate of differences between somatizing and non-somatizing patients (assuming that a very good general practitioner can partly compensate for a somatizing tendency in the patient).

Our survey design within a high-risk population undoubtedly yielded less contrast between the somatizing and non-somatizing group than a case-control design with normal controls would have done. This decision was made on theoretical grounds (patients who do not have complaints cannot tell how they deal with them), and to increase practical utility of the results (the general practitioner will not be interested in the somatization concept if it does not distinguish meaningfully within his group of frequent attenders). ${ }^{11}$ In earlier analyses, unequivocal and meaningful differences were found. ${ }^{6}$ ?

All patients had been selected on (a history of) abdominal, neck or back complaints, chronic or recurrent enough to warrant inclusion on the problem list, to assure that patients' medical histories were more or less comparable. A higher frequency of digestive (D) and musculoskeletal (L) RFEs and diagnostic conclusions was to be expected, therefore. Whether this has influenced other analyses we cannot say. However, whether a patient had abdominal, neck or back complaints, one or more, was not (significantly) related to somatization in our preliminary study. ${ }^{11}$

Data for the study were collected in three separate phases; we sent postal questionnaires to the patients, the receptionists or GPs distributed the consultation registration forms, and the GP filled in the final assessment at the end of follow-up. As a consequence, complete data were available for a small number of patients. However, only with the postal questionnaires we were directly dependent on patient compliance. The GP was the one who decided whether he returned our final assessment questionnaires (most patients had given permission). Compliance of consultation registration depended more on practice organization and number of patients in the waiting room, than on patients factors. Beforehand, we had accepted that the consultation registration data would give a sample of consultations, not a full account.

\section{Description of the somatizing patient}

With the methodological and theoretical caveats described above, one can say that the patient with mild somatization this study focusses on does not fit the rather 
stereotypical description derived from somatization disorder patients. Somatization disorder patients are sent to the psychiatrist as a last resort unwillingly and after years of conflict. The somatizing patients in our study (and their general practitioners) have managed to keep the patient-general practitioner relation reasonably good; no differences were found in either patient or general practitioner evaluation of consultations. They are as able to work, to fulfill other social roles, and differences in number of health care workers consulted or referrals were not found. In their final assessment too, the general practitioners evaluated the behaviour of somatizing patients hardly more critically than that of non-somatizers.

If one looks at somatizing patients' subjective experience, instead of indicators of their social behaviour, the picture is less favourable: higher SCL-90 scores, chronic difficulties (if one combines data with those of the initial interview), more troublesome complaints. Somatizing patients seem to translate this subjective unwellbeing into the socially least disruptive behaviour: use of medication and consultation of the general practitioner. So the balance has its price for the patient. What is also relevant here is the greater number of life events somatizing patients have experienced. Events are a reasonably valid measure of stressors, while chronic difficulties may indicate stressors, stress responses or, most likely, a mixture. So somatizing patients live in more stressful circumstances than nonsomatizers. Strictly speaking, these events cannot have caused the somatization; the events took place after the initial interview. However, most models of somatization are models of circular causation.

The general practitioners in our study deserve credit for the way they deal with the somatizing patients; these patients have more consultations without compelling somatic RFE, more troublesome complaints, but this does not lead to a higher referral frequency, a more negative attitude toward the patient, or a less satisfied patient. The general practitioners do recognize somatization, although they do not show this in the variables we thought they would. What they mean by the terms 'somatization' and 'somatic fixation', what they rated in the somatizing behaviour questions, might signify 'difficult patient' more than 'somatizing patient'. These somatizing behaviour questions had been inspired by the extensive literature on DSM-III-R somatization disorder. Somatization disorder patients are both 'difficult' patients and 'somatizing' patients. Presumably, (SSI) somatizing patients are much less difficult, so probably we asked the wrong questions. Instead, the general practitioners' judgement on functions of complaints is related to (SSI) somatization. In retrospect this is easily understood: these questions correspond to most of the psychological mechanisms for somatic complaints that have been proposed. Together these questions therefore correspond to the concept of functional complaints, and somatization can be defined as a tendency to experience functional complaints. ${ }^{32}$ This matches Lipowski's views on somati- 


\section{Chapter 8}

zation; to his definition of somatization he added: "It is usually assumed that this tendency becomes manifest in response to psychosocial stress brought about by life events and situations that are personally stressful to the individual". ${ }^{1}$ The general practitioners must have relied on fairly subtle clues for this. With our more crude definiton of functional complaints in the consultation registration no difference was found. Furthermore, the general practitioners recognize psychosocial problems in their somatizing patients and act accordingly in their referrals.

The general practitioners might be criticized for not hearing (or not giving the opportunity to mention) some of the somatizing patients' RFEs. These might be general weakness/tiredness (A04) or female reproductive RFEs that the general practitioner knows he frequently cannot solve. What bothers us too, is the curious lack of consistency in patients' and general practitioner's evaluation of a consultation for the study group as a whole. What is the quality of the communication if patient and general practitioner do not evaluate it more or less similarly? We tentatively interpret this as patients and general practitioners having their individual goals in the consultation and measuring success against these goals without bothering too much about the other one's goals. This means that, on average, communication does seem to be less than optimal. ${ }^{12}$

\section{Psychological health of the non-somatizers}

When planning our study (in 1988) we had some worries that the SSI, when used within a group of frequent attenders with recurrent or chronic abdominal, neck or back complaints, might be sensitive more to type than to gravity of somatization. We might get patients with varying complaints in the 'somatizing' group, and patients who stick to a single complaint, just as disabled, in the 'non-somatizing' group. In DSM-III terms, these 'non-somatizers' could be patients with psychogenic pain disorder, an important diagnosis within the chapter of somatoform disorders. There was some empirical evidence then that this might happen; in a secondary analysis of social security (absenteeism) data, Cloninger et al. distinguished 'diversiform' and 'high-frequency' somatization, with the 'highfrequency' somatizing patients being even more disabled than the diversiform group. ${ }^{33}$ The relations with depressive complaints (SCL-90) and consultation frequency, and the relatively small gender difference we found in the preliminary study were reassuring. ${ }^{14}$ For we explained the large gender difference for somatization disorder with the stronger taboo on showing weakness or complaining for men; only back pain and a few orher wear and tear symptoms can men have without being a weakling. The strong relations we found in the initial study with youth experiences, chronic difficulties, depressive and dysthymic disorder were further evidence for construct validity of the SSI. ${ }^{67}$ 
The results of this prospective part are more ambiguous. On one hand, patient data (SCL-90, life events, medication, bothersome complaints) and consultation frequency without compelling somatic RFE and the recognition of somatization by the general practitioner in the function of complaints support validity. On the other hand, finding more diverse but not more vague somatic RFEs in the somatizing patients consultation questionnaires raises doubts. In the general practitioner consultation questionnaires too, the differences that were found (diversity of RFEs, discrepancy RFE - diagnostic conclusion, inconsistency patient RFE - general practitioner RFE) could well be explained by a definition biased in the direction of 'diversiform' somatization. Non-somatizers according to the SSI might be troublesome patients with chronic or recurrent complaints of the musculoskeletal system. The diagnostic conclusion of 'shoulder syndrome' (L92), so frequent in the non-somatizers, might also be classified as a descriptor of complaints. Noticeable too is the low quality of life both somatizing patients and non-somatizers reported. With some reservation (operationalizations were slightly different) we conclude that patients in our study view their quality of life as low as (or even lower than) patients with rheumatism, muscular disorders or cancer. ${ }^{35}$ ${ }^{36}{ }^{37}$ Based on the limited literature we assume that this is due to uncertainty about causes and prognosis of complaints. Apparently gravity of disease is less important.

The final assessment data (with the qualifications discussed above) generally supported the validity of the SSI.

All in all, we think that a minority of the non-somatizers according to the SSI did somatize according to Lipowski's theoretical definition, and that differences between somatizing and non-somatizing patients may have been underestimated in this study as a result. Assessing the extent of this bias is almost impossible; if a patient has a single complaint, one cannot assume that the disability, depression, etc., it is associated with, are valid measures of somatization. Some subtle somatic problem may have triggered the problem, with secondary depression. It is the averaging out over a diversity of complaints that makes this assumption tenable for the SSI (at least on a group level).22 32

Earlier we have argued that somatization as studied here should not be seen as a (psychiatric) disorder, but as a personality trait. ${ }^{10}{ }^{11}{ }^{32}$ We then thought of somatization as somewhere halfway between 'normalcy' and somatization disorder. However, somatization might as well be a risk factor for, or early stage of, chronic low back pain, irritable bowel syndrome, fibromyalgia, etcetera. ${ }^{38}$ Somatizing patients would be more heterogeneous with respect to health care problems and prognosis. Negative findings can be explained in this interpretation; Somatization not being a necessary condition for development of these syndromes, the non-somatizing group in our study might have consisted too of 


\section{Chapter 8}

patients with early stages of these syndromes, based on other risk factors not included in this study.

\section{Function of complaints}

Above we have discussed the importance of the general practitioner's recognition of somatization through the psychological mechanisms causing complaints. Our reasons for including these questions in the questionnaire had been different. First, we were interested in the general practitioner's expert opinion on causal mechanisms in specific patients. Second, if the initial study gave evidence that one or two mechanisms were particularly important, we wanted to know whether the general practitioner would be able to recognize these mechanisms. Findings of the initial study were compatible with most of the mechanisms mentioned, so our second reason is no longer relevant. We interpret the results as advice from the participating general practitioners not to spend our time studying the contribution of alexithymia to development of somatization. Conscious manipulation is judged as fairly infrequent, and the general practitioner's assessment on this question does not differentiate between somatizing patients and non-somatizers. This is important as a validation of the distinction between somatization and malingering. For the family culture and (sub-)cultural language mechanisms too no difference between somatizing patients and non-somatizers was found. As for the family culture mechanism, this contrasts with both clinical experience and research data. ${ }^{39}$ However, statistical power of this analysis was low because of missing data (if the general practitioner did not know the patient's parents). The explanation of somatization as a characteristic of a (sub-)culture (idiom of distress and/or way of manipulating relationships) is popular among Dutch general practitioners for the complaints of patients from Mediterranean descent. Few nonDutch patients participated in our study because of the location of the participating practices in areas with a predominantly Dutch population. Maybe the general practitioners also excluded non-Dutch patients because of language problems. ${ }^{6}$ The general practitioners rated somatizing patients higher than nonsomatiziers on individual language, psychodynamic, behavioural mechanisms, and probably on cognitive mechanisms too. If (the rating on) only one mechanism had been strongly related to somatization, we would have recommended research on therapeutical strategies based on that mechanism; it would have proved its relevance and the general practitioners' ability to recognize it. This was not the case, and we can only say that our results seem to be representative of current knowledge on causal mechanisms in somatization; several theories are valuable in themselves, but have not been integrated, and their places in relation to the others have not been defined. Behavioural mechanisms have proven their worth in chronic pain problems. Re-attribution techniques (fitting in the cognitive model) have been developed for general practitioners in their care of somatizing 
patients. ${ }^{40}$ Individual language and psychodynamic mechanisms match a model of somatization as a personality trait, and indicate that disclosure (expressing oneself on important events in one's life and on one's emotional reactions to them) might help in these patients. A twin study on effectiveness of re-attribution techniques and disclosure has recently started at our institutes.

\section{Clinical course}

Some patients during follow-up reported spontaneously that participating in the study had helped them to cope with their complaints. Answering our questions on chronic difficulties and youth experiences, observing how they dealt with complaints in the Experience Sampling diaries had upset them at first, but afterwards they had felt better. From the participating general practitioners we have heard the same. As a result, analysis of prognosis became more important than we had expected when planning the study; having conceptualized somatization as a personality trait, we had not anticipated much change. However, we had to make do with the information available. Results should therefore be interpreted with caution. It is safe to say that the study has had a beneficial effect on medicalization. However, this may have been due to changes in general practitioner behaviour as much as patient behaviour. Information on medicalization could retrospectively be collected from the medical records. Changes in chronic difficulties and SCL-90 scores (part of 'psychosocial complaints') also could be measured accurately. General practitioner evaluation of changes in patient behaviour, changes in main complaint and in general health were based on retrospective recall and therefore possibly biased. Moreover, variance of these variables was low. As a result, analyses had little power, especially for the somatic complaints scale; relevant improvement may have been missed. We assume that participating in the study has been beneficial to the patients, be it directly or through better care by the general practitioner. A decrease in medicalization signifies a lower risk of iatrogenic harm and probably a better understanding between patient and general practitioner. In the long run, this must influence well-being too. Our findings correspond with trials on therapeutic strategies for somatization and somatization disorder, where effects on costs of care were stronger than effects on more proximal variables. ${ }^{41}{ }^{42}$

\section{Conclusions}

The findings of this study cannot easily be interpreted within a simple, unidimensional concept of somatization. Mild somatization as studied here is relevant for present well-being, related to psychiatric (depressive, dysthymic) disorders, can easily be recognized retrospectively, and can be traced back to origins in 
youth.$^{6}$ Its relations with present complaints, disability, health care utilization and the doctor-patient relation are less clear. A replication study and/or prospective studies on somatization as risk factor for specific syndromes as chronic low back pain, irritable bowel syndrome and fibromyalgia would be very welcome.

\section{References}

1 Lipowski ZJ. Somatization: the concept and its clinical application. Am J Psychiatry 1988; 145: 1358-1368

2 Padgett D, Johnson TM. Somatizing distress: hospital treatment of psychiatric co-morbidity and the limitations of biomedicine. Soc Sci Med 1990; 30: 205-209

3 Elks ML. On the genesis of somatization disorder: the role of the medical profession. Med Hypotheses 1994; 43: 151-154

4 deGruy F, Columbia L, Dickinson P. Somatization disorder in a family practice. J Fam Pract 1987; 25: 45-51

5 Lamberts $\mathrm{H}$, Wood M, Hofmans-Okkes I (eds.). The International Classification of Primary Care in the European Community: With a multi-language layer. Oxford, etc., Oxford University Press; 1993

6 Portegijs PJM, Jeuken FMH, Horst FG van der, Kraan HF, Knottnerus JA. A troubled youth: Relations with somatization, depression and anxiety in adulthood. Fam Pract 1996; 13: 1-11

7 Portegijs PJM, Kraan HF, Horst FG van der, Meertens HMHJ, Knottnerus JA. Somatization and somatic complaints in primary care: Relations with depression and stress. Submitted

8 Portegijs PJM, Kraan HF, Knottnerus JA, Proot IM, deVries MW, Horst FG van der. Somatizing patients react very normally in everyday life. submitted

9 Escobar JI, Rubio Stipec M, Canino G, Karno M. Somatic symptom index (SSI): a new and abridged somatization construct. Prevalence and epidemiological correlates in two large community samples. J Nerv Ment Dis 1989; 177: 140-146

10 Portegijs PJM, Kraan HF, Knottnerus JA, Stoffers HEJH. Wat heet somatisatie? 1. Een zoektocht in de internationale literatuur naar een definitie voor huisartsgeneeskundig onderzoek [What do we call somatization? 1. A search of the international literature for a definition to be used in general practice research]. Huisarts en Wetenschap 35; 1992: 18-25,43

"Portegijs PJM, Horst FG van der, Proot IM, Kraan HF, Gunther NCHF, Knottnerus JA. Somatization in frequent attenders of general practice. Soc Psychiatry Psychiatr Epidemiol 1996; 31: 29-37

12 Stimson G, Webb B. Going to see the doctor: The consultation process in General Practice. London / Boston, Routledge \& Kegan Paul; 1975

13 Dickson LR, Hays LR, Kaplan C, Scherl E, Abbott S, Schmitt F. Psychological profile of somatizing patients attending the integrative clinic. Int J Psychiatry Med 1992; 22: $141-153$

14 Wohlfarth TD, van den Brink W, Ormel J, Koeter MW, Oldehinkel AJ. The relati- 


\section{Somatization and bealth care nitization}

onship between social dysfunctioning and psychopachology among primary care attenders. Br J Psychiatry 1993; 163: 37-44

15 Sato T, Takeichi M, Shirahama M, Fukui T, Gude JK. Doctor-shopping patients and users of alternative medicine among Japanese primary care patients. Gen Hosp Psychiatry 1995; 17: 115-125

16 Dworkin SF. Somatization, distress and chronic pain. Qual Life Res 1994; 3 Sup: S77-83

17 Smith GR Jr. The course of somatization and its effects on utilization of health care resources. Psychosomatics 1994; 35: 263-267

18 Simon GE. Psychiatric disorder and functional somatic symptoms as predictors of health care use. Psychiatr Med 1992; 10: 49-59

19 Miranda J, Perez Stable EJ, Munoz RF, Hargreaves W, Henke CJ. Somatization, psychiatric disorder, and stress in utilization of ambulatory medical services. Health Psychol 1991; 10: 46-51

20 van Hemert AM, Hengeveld MW, Bolk JH, Rooijmans HG, Vandenbroucke JP. Psychiatric disorders in relation to medical illness among patients of a general medical out-patient clinic. Psychol Med 1993; 23: 167-173

21 Fink P. Physical complaints and symptoms of somatizing patients. J Psychosom Res 1992; 36: 125-136

22 Kellner R. Psychosomatic syndromes, somatization and somatoform disorders. Psychother Psychosom 1994; 61: 4-24

23 Craig TK, Boardman AP, Mills K, Daly Jones O, Drake H. The South London Somatisation Study. I: Longitudinal course and the influence of early life experiences. Br J Psychiatry 1993; 163: 579-588

24 Parsons CD, Wakeley P. Idioms of distress: somatic responses to distress in everyday life. Cult Med Psychiatry 1991; 15: 111-132

25 Ormel J, Van Den Brink W, Koeter MW, Giel R, Van Der Meer K, Van De Willige G, Wilmink FW. Recognition, management and outcome of psychological disorders in primary care: A naturalistic follow-up study. Psychol Med 1990; 20: 909-923

${ }^{26}$ Kirmayer LJ, Robbins JM, Dworkind M, Yaffe MJ. Somatization and the recognition of depression and anxiety in primary care. Am J Psychiatry 1993; 150: 734-741

27 Coyne JC, Schwenk TL, Smolinski M. Recognizing depression: a comparison of family physician ratings, self-report, and interview measures. J Am Board Fam Pract 1991; 4: $207-215$

28 Wyshak G, Barsky A. Satisfaction with and effectiveness of medical care in relation to anxiety and depression. Patient and physician ratings compared. Gen Hosp Psychiatry 1995; 17: 108-114

29 Hahn SR, Thompson KS, Wills TA, Stern V, Budner NS. The difficult doctor-patient relationship: somatization, personality and psychopathology. J Clin Epidemiol 1994; 47: 647-657

30 Metsemakers JF, Hoppener P, Knottnerus JA, Kocken RJ, Limonard CB. Computerized health information in The Netherlands: a registration network of family practices. Br J Gen Pract 1992; 42: 102-106

31 Knottnerus JA, Metsemakers J, Höppener P, Limonard C. Chronic illness in the community and the concept of 'social prevalence'. Fam Pract 1992; 9: 15-21 


\section{Chapter 8}

32 Portegijs PJM, Kraan HF, Knottnerus JA, Stoffers HEJH. Wat heet somatisatie? 2. Een antwoord uit de internationale literatuur getoetst aan 19 jaar Huisarts en Wetenschap [What do we call somatization? 2: An answer from the international literature tested against 19 years of 'Huisarts en Wetenschap']. Huisarts en Wetenschap 35; 1992: 65-69

33 Cloninger CR, Sigvardsson S, von Knorring AL, Bohman M. An adoption study of somatoform disorders: II. Identification of two discrete somatoform disorders. Arch Gen Psychiatry 1984; 41: 863-871

34 Wool CA, Barsky AJ. Do women somatize more than men? Gender differences in somatization. Psychosomatics 1994; 35: 445-452

${ }^{35}$ Haes JCJM de. Kwaliteit van leven van kankerpatienten [Quality of life in cancer patients]. Amsterdam / Lisse, Swets en Zeitlinger; 1988

36 Witte LP de, Tilli DJP, Ticheler AJG, Winants BAC, Horst FG van der, Linden Sj van der. Leven met een reumatische aandoening: Een onderzoek naar de ervaren kwaliteit van het leven bij 372 mensen met een reumatische aandoening [Living with a rheumatic disorder: A study on quality of life in 372 persons with a rheumatic disorder]. Hoensbroek, Instituut voor Revalidatie Vraagstukken; 1989

37 Tilli DJP, Terpstra SJ, Witte LP de. De rol van een patientenorganisatie in de zorg voor chronisch zieken en hun gezin: Een evaluatie van de activiteiten van de Vereniging Spierziekten Nederland [The role of a patients' association in the care for the chronically ill and their families: An evaluation of the activities of the Dutch Association for Muscle Disorders]. Hoensbroek, Instituut voor Revalidatie Vraagstukken; 1990

38 Haug TT, Svebak S, Wilhelmsen I, Berstad A, Ursin H. Psychological factors and somatic symptoms in functional dyspepsia: A comparison with duodenal ulcer and healthy controls. J Psychosom Res 1994; 38: 281-291

39 Huygen FJA. Family medicine: The medical life history of families. Nijmegen, Dekker \& van de Vegt; 1978

to Goldberg D, Gask L, O'Dowed T. The treatment of somatization: Teaching techniques of reatribution. J Psychosom Res 1989; 33: 689-695

${ }^{41}$ Smith GR Jr, Monson RA, Ray DC. Psychiatric consultation in somatization disorder. A randomized controlled study. N Engl J Med 1986; 314: 1407-1413

42 Smith GR Jr, Rost K, Kashner TM. A trial of the effect of a standardized psychiatric consultation on health outcomes and costs in somatizing patients. Arch Gen Psychiatry 1995; 52: 238-243 


\section{General discussion}

In this chapter we will join conclusions of the earlier chapters together into a more or less coherent picture of 'the' somatizing patient. However, in an attempt not to bore the reader(s) who has/have read the entire thesis up to this chapter, we will refrain from repeating earlier chapters' discussions here. Then we will discuss some methodological aspects that have not received the attention they deserved in earlier chapters. We go into the relation between somatization as we defined it and somatic fixation. Finally we will highlight recommendations for practice, and for research.

\section{Picture of the somatizing patient}

In chapter 2 we have argued that a definition of somatization for general practice should be less restictive than the DSM-III somatization disorder definition, should not imply psychiatric disorder, but should be logically connected to this disorder. We suggested moving somatization disorder from axis I (psychiatric disorders in the narrow sense) to axis II (stable personality characteristics, both traits and disorders). We doubted whether a relation with psychosocial conflicts should be included in the definition. An operationalization of somatization as a more comprehensive (that is; lower threshold) version of the somatization disorder definition was suggested, following Escobar. Almost five years later, this chapter must seem a bit out-of-date, since, much to our pleasure, interest in milder forms of somatization has grown. The Escobar operationalization has become more or less the accepted operationalization. More is known about the relation with psychosocial problems, but in our view not enough for this relation to be included in the defintion. A move of somatization disorder to axis II has to our knowledge not been considered in the development of DSM-IV.

In chapter 3 we concluded that for patient-related studies, general practice research did not offer a better operationalization of somatization. The Escobar operationalization we had chosen was supported by articles on 'nervous-functional complaints' and 'somatization'.

Chapter 4 was intended primarily as a preliminary study to test feasibility of the protocol for patient selection and to estimate prevalence of somatization within the intended study population (for efficiency reasons we wanted a prevalence of about $50 \%$ in the main study). As a result of this part the inclusion 
criterion of 12 consultations (without compelling somatic reason for encounter) was adjusted slightly into 15 consultations. Results supported validity of the somatization concept. However, we did not find specific health problems related to somatization, so we must assume that somatization is more or less invisible in the GP's medical records.

Chapters 5 and 6 dealt with the first question (cross-sectional data) of the main study. To our surprise, the overlap of somatization, (lifetime) depression and (current) anxiety was largely accounted for by 16 patients with 'triple problem'. With depressive patients excluded, no relation whatsoever between somatization and anxiety was found. Somatization proved to be distinct from depression in the youth experiences that precede it; deprivation of parental care was an independent predictor of later somatization, while other ( $=$ unrelated to deprivation or abuse) life events were related more strongly to later depression. Abuse (sexual and/or physical) predicted 'any problem' (somatization and/or depresion and/or anxiety).

With an operationalization of somatization that is essentially a lifetime count of somatic symptoms, one might dismiss the youth deprivation-somatization relation as something of the past, irrelevant today. Some support for this was found in chapter 6; the distinction between recent (somatic and depressive complaints in the previous week) and lifetime (somatization, depressive episode and dysthymia) was more clear than the distinction between somatic (somatic complaints and somatization ) and depressive (- complaints, episode and dysthymia). However, somatization was certainly relevant for present well-being; It was related to somatic and depressive complaints, and to dysthymia (chronic, mild depression). We found a strong relation with chronic psychosocial difficulties, and a relation with specifically support from the parents (which we ascribed to the presumed stability in time of the relationship with the parents and thereby to youth experiences).

Differences between somatizing patients' and non-somatizers' reactions to the momentaneous contexts of everyday life were the subject of chapter 7. Quite to our surprise the answer was unequivocally negative; Somatizing patients reacted very similar to non-somatizers in an average week. They did have specific somatic complaints a bit more frequently, and were a bit more tired. The negative results could not be explained by limitations of the Experience Sampling instrument; when comparing seriously somatizing patients with all others we did find differences, as we did when comparing recently depressive patients with all others. So we concluded that indeed (mild) somatization hardly influences everyday life. We suppose that results would have been different inf the patients had filled in their Experience Sampling diaries in a period of heightened stres, or of illness. 
In chapter 8 the prospective part of the study (the third question) was reported. What we had found earlier in the problem lists (summary of the medical records) of chapter 4 we saw again in our analyses of specific consultations; somatization was hardly visible in absenteeism, patients' reasons for encounter, nor in the GPs' diagnostic conclusions, nor in the evaluations of the physician-patient interaction by either patients or GPs. Still, somatizing patients felt worse subjectively, used more medication, consulted more frequently and reported more major life events.

So in the end our picture of the typical somatizing patient is one of a person in strained equilibrium. In his/her reactions to everyday life, overt behaviour like absenteeism, reasons for encounter, interaction with the GP he/she is hardly distinguishable from a non-somatizer. However, he/she feels worse subjectively, reports more stressors, and is more vulnerable, as is evident in youth experiences, prevalence of lifetime depression and of dysthymia.

\section{Methodological considerations}

In the study we have tried to assess construct validity of the SSI and to figure out how somatization is related to relevant variables. Still, a result, unless strongly positive, can only be interpreted once. A weaker than expected relation of the SSI with (SCL-90) somatic complaints must be interpreted either as an indication of low validity of the SSI or SCL-90 (if one assumes that somatization must be related to somatic complaints in the previous week), or as evidence of somatization being apparent only in special circumstances (stress). In general, we have used relations that have been well-established in the literature for constructvalidation (the relation somatization - depression, for instance). With more specific analyses we tried to fill in the picture of somatization (as in our finding of a relation of somatization and specifically dysthymia). Some results both supported construct-validity and provided descriptive information; the strong somatization - deprivation in youth relation, for instance.

We have analyzed somatization as if it were a dichotomous variable (in parts of chapter 6 as a trichotomous one). This may look strange, after our efforts to promote use of a 'continuum' definition in chapters 2 and 3. Here we emphasize that in our view these choices were unrelated. The decision to report analyses with somatization dichotomized only, was wholly based on practical considerations. First, it was necessary for consistency (some analyses could only be done with a dichotomous somatization variable). Second, we felt that results presented in two by two tables, or in differences in median (age, for instance), would be easier to grasp for the reader than correlations, etc. Third, it saved us from the temptation to polish up results. 
Throughout the thesis we have compared the somatizing patients to other frequent attenders with (a history of) chronic or recurrent abdominal, neck or back complaints. In the introduction we have explained this choice, and we have touched on this in several other chapters. With this approach, we deliberately diminished the potential contrast between clearly somatizing patients and evident non-somatizers. Negative findings should be interpreted cautiously; low contrast implies low statistical power. And negative findings do not say anything about differences between somatizing patients in our study and infrequently consulting non-somatizers. To some extent one can extrapolate from our findings to get a picture of our somatizing patients as compared to the open population. As far as we can see, the number of consultations without compelling somatic reason for encounter was the most important inclusion criterion. The preselection on (a history of) chronic or recurrent abdominal, neck or back complaints was meant mainly to economize on the number of patients whose consultations had to be counted. Abdominal, neck and back complaints are highly prevalent in somatizing patients and cover two important organ systems. In the preliminary study (chapter 4) we did not find important differences between patients with abdominal, with neck, and with back complaints. Compared to the open population, somatizing patients had higher consultation frequency, more (chronic or recurrent) health problems, especially vague somatic complaints (see chapter 4). Somatizing patients must have experienced more parental deprivation, other life events and probably abuse in their youth (for we even found differences compared with the non-somatizing frequent attenders, chapter 5). They have increased risk of depressive episode and dysthymia, and experience more chronic difficulties (chapter 6). They report much higher somatic complaints than the Dutch average on the SCL-90, and higher anxiety and depressive complaints as well (chapter 8). They rate their quality of life as low as patients with serious chronic diseases like rheumatism or muscular disorder.

\section{Somatic fixation or somatization?}

In the following we will discuss differences and similarities of the somatic fixation studies and our approach. In the introduction (chapter 1) we have argued that knowledge in medicine is organized around diagnoses more than around theories, and that especially in psychiatry an a-theoretical approach has been in fashion in recent years. As far as we can judge, the concept of somatic fixation (best defined as: "a reduction of more comprehensive problems to merely medical-somatic ones in the interaction between doctor and patient") and the concept of somatization we pretended to measure overlap empirically to a large extent. ${ }^{1}$ Both Huygen and we stress that on the one hand a disorder-type criterion is too restrictive, and that on 
the other hand some degree of stability in time is essential for it to be called a problem. Occasional functional complaints ('nerveus-functionele klachten' as Huygen calls them) should be considered a normal phenomenon, and as such are no reason for concern to the general practitioner. We also agree that having objective disease does not exclude somatic fixation/somatization (for simplicity's sake we limited our study to patients without diagnosed serious somatic disease). The contribution of the general practitioner in the somatic fixation definiton must lead to some patients of 'somatizing' general practitioners meeting somatic fixation criteria but not somatization criteria and the other way around in 'nonsomatizing' or 'somatization reducing' general practitioners (integrated working style, Huygen suggests). ${ }^{2}$ The theoretical definition can to a certain degree accommodate this influence of the general practitioner; the tendency to somatize could be reinforced in the contacts with a 'somatizing' general practitioner, and lessen in the contacts with a general practitioner who offers structured guidance and is sensitive to the patient's worries.

There are some potential discrepancies, but they are more in the translation of Lipowski's theoretical definition into the SSI as operationalization than in the comparison Lipowski's definiton - somatic fixation. In the first place the SSI is not a measure of the strength of a tendency to somatize, but a lifetime count of the different complaints this tendency has manifested itself in. ${ }^{3}$ This implies that a 'diagnosis' of somatization can only be made years after this tendency has become apparent. This would be a serious drawback of the SSI if one wanted to study why some adolescents start somatizing and others do not (somatization is thought to originate in youth, become apparent in puberty or adolescence and be relatively stable thoughout adult life). Even more seriously, this implies that theoretically, somatization according to the SSI can improve only if or when someone's memory (of ever having had certain complaints) deteriorates. So this inherent insensitivity to change must make the SSI a poor candidate for both prospective studies on risk factors for onset of somatization and for trials of therapeutic strategies (it can be analyzed as effect modifier, of course).

In the second place the SSI is biased towards patients with diverse complaints. The patient with low back pain and low back pain only, cannot somatize according to the SSI, which is not plausible. This problem worried us when we were designing the study. Our experiences in the interviews and the results of the preliminary study and the cross-sectional part of the main study (chapter 4 through 6) were reassuring; in practice this bias did not seem to matter much. However, in the prospective data we did find indications that results were influenced by this bias (see Chapter 8). Then again, the bias was not strong enough to render the SSI less construct-valid than the general practitioner's assessment. So the conclusion is that bias is likely, but that this bias is unlikely to 


\section{Chapter 9}

be so strong as to invalidate the SSI, and that we do not have the data to estimate its strength more precisely.

Huygen c.s. have in their studies on somatic fixation concentrated on making the theory of somatic fixation testable in empirical research. Departing from their finding that 'nervous-functional complaints' were very difficult to record reliably and were related to the total morbidity presented to the GP, the dependent variables in their studies were indicators of medical consumption like consultation frequency, referrals, or use of medication. The theoretical model could be tested by analyzing relations between demographic variables, social network variables, self-esteem etc. and these medical consumption variables. The influence of the working style of the GP, and effects of interventions could be analysed as well. To our knowledge, however, they have not in their empirical studies endeavoured to translate the theory into a 'diagnosis' on the individual level. If one wanted to assess somatic fixation for a particular patient (in his/her relationship with a particular GP), one would have to collect in-depth data on the 'more comprehensive problems' and to observe several consultations to see whether these problems are reduced to 'merely medical-somatic ones'. Meanwhile, Huygen c.s. in their recommendations to practising GPs discussed somatic fixation as if it were a diagnostic label in an individual patient, and so has the concept been used among practising GPs. ${ }^{14}$ Cox did translate the somatic fixation model into a diagnostic instrument: the Scoring list Somatic Fixation (SSF). ${ }^{5}$ The SSF consists of 11 ordinal items to be assessed by the GP, covering two of the three somatic fixation cycles: the internal cycle (based on the way in which the patient himself copes with complaints or problems) and the GP-patient cycle (based on the interaction between the patient's way of reacting and the GP's reaction to this). The SSF being dependent on subjective assessment of the GP, however, empirical research with the SSF on the contribution of the GP to somatic fixation will be difficult to perform.

A second point is that the term somatic fixation is used for both the phenomenon and the theory that explains its development and should guide therapeutical action. This may interfere with research on causal mechanisms of the phenomenon. The value of the somatic fixation model (in explaining the somatic fixation phenomenon) can hardly be compared to the value of other theoretical models, because the model is included in the phenomenon to be explained.

In the above, we have commented on somatic fixation as a definition of a phenomenon, a 'diagnosis'. At the same time, however, the theoretical model of somatic fixation has inspired a generation of GPs and in our view still is tenable. In the preceding chapters, our enthusiasm for the model was hardly visible; to conform with current terminology we wrote about 'cognitive model' instead of 'internal cycle' (of the somatic fixation model). We also emphasized empirical data and epidemiological methodology at the expense of theoretical depth, in view 
of the weight attached to these aspects nowadays. We do take the view that the theoretical model of somatic fixation can be anchored to current theoretical models that fit within the cycles (internal cycle: cognitive model, stress theory, for instance; external cycle: behavioural model, language model). This would explicitly give the model of somatic fixation the metatheoretical character it may implicitly have had all the time (it was very difficult to grasp when I was doing my general practice internship, PP). The third cycle (physician-patient cycle) might in this option be retained, or it might be replaced by a warning that the GP is an important member of some patients' social networks, and that the GP may have important side effects.

\section{Recommendations for practice}

Our first advice for patient care would be not to overemphasize too much the importance of somatization. For if somatization is seen as a maladaptive way of coping with life, it is for the general practitioner the most visible form, but probably not the most maladaptive. Alcohol abuse and intrafamilial violence are more difficult to detect, but no less serious and (as far as detection is concerned) as much the concern of the general practitioner. Moreover, somatizing patients are not the first to be responsible for the amount of money spent on unnecessary tests or diagnostic procedures; The health care system itself is organized to preferentially detect and treat somatic problems. Our culture does not accept medical mistakes easily. And, having interpreted occasional somatization as a normal psychological mechanism, one cannot expect patients to stop requesting these services. Likewise, the huge sums of money spent in The Netherlands on disability pensions (with vague complaints like back complaints ranking high) and absenteeism cannot be ascribed to somatization alone. In our data we did not even find a significant relation between work situation and somatization (chapter 5; it was one of the socio-demographic variables). In our view, the individual somatizing patient represents only part of the broader problem of medicalization and one must expect that this broader problem of medicalization can only partially be solved by influencing (through the general practitioners therapeutic strategy) somatizing patients.

The second advice would be to pay attention to possible somatized depression or anxiety (Bridges' concept of somatization) before trying to establish whether the patient somatizes according to our (Lipowski/Escobar) definition. Reasonably effective therapies are available for depressive and anxiety disorders, and that is more than the structured guidance we can offer a somatizing patient. The underdiagnosis of these problems in general practice seems largely to be the result of self selection by the patients and the way they phrase their reasons for 
encounter; When the english general practitioner Blackwell and his consulting psychiatrist Goldberg switched places, Goldberg was the one who missed depressive patients. However, this underdiagnosis should be minimized. It is difficult to see how patients could benefit from not discussing possible psychological problems with the general practitioner (general practitioners can, it saves time). Patients who are aware of their problem, but feel confident they can handle it themselves, might be relieved to have the general practitioner look over their shoulder. And if a depressive patient denies having a problem, an uninformed general practitioner does not help either. A reason for active detection of these problems might even be prevention of lasting somatization after a depressive episode where mood has improved but the underlying conflict has not been solved (this hypothesis does not really match a model of somatization as a personality trait). The reader cannot go by the figures in our study for an estimate of the relevance of Bridges' concept of somatization; Many of these patients must have failed our inclusion criterion of 15 consultations without compelling somatic reason for encounter in three years. Patients not depressive or anxious when we interviewed them, might have been when they last visited their general practitioner. On the other hand, we do not know how may of these patients would have presented with exclusively somatic complaints. All in all, Bridges' concept of somatization must be quite a bit more important for the general practitioner than our study suggests. However, it must overlap our trait concept of somatization considerably.

Thirdly, we would emphasize to the practising general practitioner the (personality) trait character of somatization as we studied it. The strong relations we found with youth experiences and support from the parents serve to illustrate this. This does not imply that nurture is more important than nature; a hypothetical genetic factor for 'low pain threshold' would fit in nicely in this model. It does imply that in the individual, environmental and genetic factors will be almost inextricably intermingled. It also implies that the issue is not how to mitigate this trait, but how to deal with it - for both patient and general practitioner. If the patient and the general practitioner can accept the somatization and cooperate, that may be enough to solve the problem for the time being. Take the hypothetical patient in Chapter 7, who visits his physician and says: "I have back pain now, and I am getting worried. Please check up on me and tell me wherher my body is playing tricks again." Compare him with a patient who says: "It's my back again. There's got to be something. I want a scan." Moreover, the underlying somatization trait may slowly diminish as a result of reassuring experiences of the patient. The above might be summarized as: somatization is not the problem, but a vulnerability. We described this vulnerability and studied its determinants, but have little information on the transition from high-risk to actual problem. 


\section{General discussion}

What we do know is that this hypothesis could explain many of the negative findings of the prospective part of the study (chapter 8).

Fourthly, lacking knowledge on that hypothetical genetical influence on pain threshold, we suggest to the general practitioner Katons hypothesis of somatization as a learned response as a model to be used heuristically: a child learning by differential reinforcement "how to elicit nurturance from a caregiver: complaining about a headache rather than about being sad" and learning to attribute symptoms to somatic causes. ${ }^{6}$ In our study we could not test this model. However, it fits the unexpected specificity of the youth deprivation - somatization relation (see chapter 6) and the theoretical mechanisms of somatization the general practitioners recognize in somatizing patients (chapter 8). This model of somatization might partly explain the difficulties doctors have in dealing with somatizing patients (which we could not demonstrate in our study, though). These patients, through their complaints, may request from their general practitioners personal attention and care. If they had done so for psychosocial problems, it would be obvious that the general practitioner cannot satisfy their need; he/she gives advice and guidance, but cannot take responsibility for the patients life, being an outsider and a professional, not a member of the patients personal network. However, these patients consult with somatic complaints, thereby making difficult for the general practitioner not to assume responsibility. Several psychodynamic theories can explain why patients in distress have a need to become attached to the caregiver. It would als fit Habermas' ideas on the drawbacks of a society in which roles that used to be fulfilled in interpersonal interaction, are more and more taken over by professionally organized services. Somatizing patients might be the ones for whom a professionals services are not enough, who need the personal care of someone in their intimate network. In this view, the general practitioner is both part of the medical system and a kind of lubricant between the patients personal sphere and this medical system. This might be possible if the general practitioner acknowledges the patients need of a personal relationship, explains that as a professional he/she really cannot meet this need, and then sees whether he/she can, partly and for a limited time, nevertheless do so. This would presuppose a personal effort of the general practitioner for some of his/her patients part of the time, in addition to (not replacing) his professional efforts. Which is only possible if the general practitioner as a person is interested in the specific patient. It can never be demanded of the general practitioner.

The personal involvement of the general practitioner discussed above, and the complexity of the problem somatization, mean that the possibilities to prepare a clinical guideline for somatization are rather limited. Perhaps efforts to stimulate discussion with and among practising general practitioners, would be more effective. 


\section{Recommendations for research}

With our study we hoped to stimulate interest in somatization in general practice. If our study has raised more questions than it has answered, therefore, we do not regard this as a failure. Then what are the most important new questions?

Interest in somatization and related issues has grown in the previous five years. Several studies have been carried out in referred patients, and on psychiatric consultation within general practice ${ }^{8}$ In collaboration with the EMGOinstitute of the Free University (Amsterdam), we are performing a trial on effectiveness of reattribution techniques and of disclosure (expressing oneself on important events in one's life and on one's emotional reactions to these events) in somatizing patients. The disclosure part of this study is a direct sequel to our study. We know of several other initiatives, concentrating on development of somatization in adolescence, and on the influence of cognitive factors on the transition from acute to subchronic low back pain. In the following we give our views on the issues most worthy of further study.

The definition of somatization as a problem of a patient is like the shadow of a dancer on a sheet. Had the lamp and sheet been oriented differently, the image would have been different too. Likewise, the general problem that somatization is the patient projection of, can also be projected on the general practitioner, or on society. While the parient perspective must remain the point of reference for general practice research, it must be connected to other perspectives.

General practitioner perspective: From this perspective, study of the characteristics of general practitioners (gender, experience, attitudes, knowledge and skills) that influence clinical course and the physician-patient relation in somatizing patients is important.

Perspective of society: The influence of social security regulations, interventions by company doctors and medical advisers of insurance companies on disability, social participation, quality of life and subjective complaints in somatizing patients is an important issue from this perspective

Patient perspective: From this perspective, we are most interested in:

* diagnostic instruments for somatization to be used by the general practitioner

* further validation of the SSI (the operationalization used in this study) or development of a new instrument to assess somatization for research

* prospective study of development of somatization in adolescence

* relations between somatization on the one hand and specific syndromes as chronic low back pain, fibromyalgia and chronic fatigue syndrome

* intervention studies in general practice. 


\section{References}

1 Huygen FJA. Preventie van somatische fixatie: I. Geschiedenis van een onderzoeksproject. Huisarts en Wetenschap 1978; 21: 363-365

2 Huygen FJ, Mokkink HG, Smits AJ, van Son JA, Meyboom WA, van Eijk JT. Relationship between the working styles of general practitioners and the health status of their patients. Br J Gen Pract 1992; 42: 141-144

3 Portegijs PJM, Horst FG van der, Proot IM, Kraan HF, Gunther NCHF, Knottnerus JA. Somatization in frequent attenders of general practice. Soc Psychiatry Psychiatr Epidemiol 1996; 31: 29-37

4 Grol R (ed.). Huisarts en somatische fixatie. Utrecht / Antwerpen, Bohn, Scheltema en Holkema; 1983

5 Cox MF. De vroegtijdige herkenning van somatisatie in de huisartspraktijk: Een exploratie van het concept somatische fixatie. Leiden, Rijksuniversiteit Leiden [thesis]; 1992

6 Katon W, Kleinman A, Rosen G. Depression and somatization: A review: Part I. Am J Med 1982; 72: 127-135

7 Speckens AEM, Hemert AM van, Spinhoven P, Hawton KE, Bolk JH, Rooijmans HGM. Cognitive behavioural therapy for medically unexplained physical symptoms: A randomised controlled trial. Br Med J 1995; 311: 1328-1332

8 Verhaak PFM, Collijn D, Wijkel D, Cornelis-van der Feltz CM, Huijse FJ. Psychiatrisch consult in de huisartspraktijk: Somatiserende pariënten [Psychiatric consultation in general practice: Somatizing patients]. Medisch Contact 1994; 49: 1319-1321 


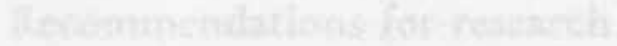

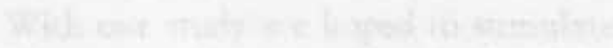

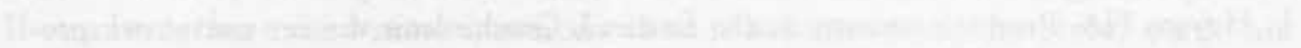

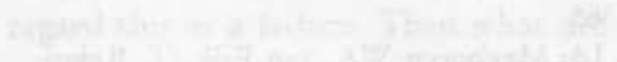

antant

क्र

(10020

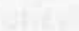

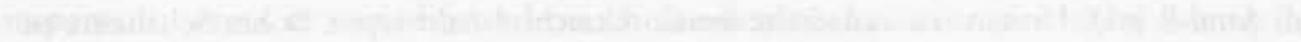
75:

The

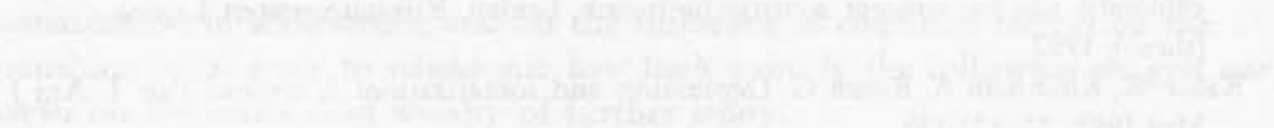

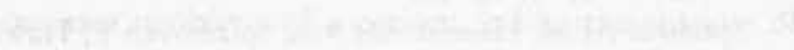




\section{Summary}

In chapter 1 the subject of the thesis is introduced: somatization. Somatization has become more visible with the growth of knowledge on health and disease of the human body. The phenomenon of somatization draws attention to what medical technology cannot do; bring cure to those who are ill, but do not have a diagnosable objective disease. In the Netherlands, the GP is in the most favourable position to care for somatizing patients. Somatization was an important issue in general practice research in the seventies. In the eighties, general practice has concentrated more on specific somatic complaints than on the general problem of somatization. The studies since 1980 on DSM-III somatization disorder (for the most part from a psychiatric point of view), however, raised questions about the much larger group of patients with milder forms of somatization.

The aim of our study was to gain understanding of the mechanisms that make somatizing patients emphasize the somatic aspects of their distress at certain moments. We concentrated on relations with depression, anxiety, stress and youth experiences. Key questions are:

1 What are the relations between somatization and depression, anxiety, unfavourable experiences in youth, major life events, chronic difficulties and social support? (chapters 5 and 6)

2 Do somatizing patients differ from non-somatizers in their reactions (with somatic and psychological complaints) to the physical and social context of a specific moment?

3 Do somatizing patients differ from non-somatizers in subjective well-being. health care utilization, specific health problems and physician-patient communication? (chapter 8)

The study was performed in an 'indicated population': frequent attenders of general practice with (a history of) recurrent or chronic abdominal, neck or back complaints.

In chapter 2 we describe a literature study on definitions of somatization suitable for research in general practice, and on operationalizations of these definitions. A definition of somatization for general practice research should be more comprehensive than the psychiatric definition of DSM-III-R somatization disorder (that is; have a lower threshold). A survey of the international literature was done by searching the Index Medicus. In 80 percent of articles somatization was defined as a psychiatric disorder: DSM-III-R somatization disorder. The remaining articles, 
mostly related to primary health care, assumed a continuum of somatization ranging from a normal psychologic mechanism to a psychiatric disorder. The definition of Lipowski is the most accepted one in the international literature: "a tendency to experience and express somatic complaints and symptoms that are not explained by pathologic findings, to attribute these complaints to somatic disease and to seek medical attention for them."

These so-called continuum definitions are more suitable for research in general practice. A more comprehensive version of the DSM-III-R somatization disorder criterion (the Somatic Symptom Index or SSI) appeared to be the best operationalization for use in general practice. The threshold of the SSI is 4 symptoms (for men) or 6 (for women) from a list of 35 frequently occurring vague somatic symptoms. For somatization disorder the threshold is 12 symptoms or 14 , respectively. Research into these milder forms of somatization can take advantage of the many studies carried out on somatization disorder, if the link between these milder forms of somatization and somatization disorder is clarified theoretically. Since on axis II of DSM-III personality traits (not meeting the threshold of a 'psychiatric disorder') can be coded apart from personality disorders, this link could be made if the somatization disorder would be moved from axis I (psychiatric disorders in the narrow sense) to this axis II. Empirical data suggested that somatization disorder fits well on axis II.

The contribution of Dutch general practice research was virtually absent in the international literature. Therefore, in chapter 3 we analyzed 19 volumes of 'Huisarts en Wetenschap' to explore whether Dutch general practice research offered an alternative for the SSI operationalization. We found the concepts 'nervous-functional complaints' (and, connected to this 'somatization'), 'somatic fixation' and 'problem behaviour'.

The 'somatic fixation' concept was difficult to apply in patient-centred research. 'Problem behaviour' appeared to be too broad a concept. The concepts 'nervous-functional complaints' and 'somatization' (as used in Huisarts en Wetenschap) were in keeping with the international literature.

In chapter 4 results are presented of the preliminary study on prevalence of somatization within the intended study population and on construct validity of the SSI. The SSI had shown good validity in open populations, that is; the SSI is related to variables the theoretical concept of somatization is supposed to be related to. However, a definition has to differentiate validly within a population of frequent attenders ('indicated population') to be a useful diagnostic instrument in general practice.

Eighty Dutch general practice patients were interviewed at home. They were selected on age (20-44 years), a history of back, neck or abdominal complaints, 


\section{Summary}

and on frequency of consultation; at least 12 consultations without compelling somatic reason for encounter in the previous three years.

Prevalence of somatization (according to the SSI) in this group was $45 \%$. Women had a two times higher risk of somatization. A relation with age was not found. Somatization was related to depressive complaints (relative risk 2.5) and probably also to anxiety. Somatizing patients consulted their general practitioner more often and had more health problems (especially psychological problems) than non-somatizers.

These results supported the validity of this definition. The distinction was emphasized between our definition of somatization and somatization defined as a symptom of psychiatric (e.g. depressive or anxiety) disorder.

The first question is answered in the following two chapters. Inclusion criteria for the main study were slightly more restrictive because of the results of the preliminary study: 15 consultations instead of 12 . In chapter 5 we concentrate on the influence of unfavourable youth experiences. The analyses of youth experience - somatization relations were supplemented with analyses of interrelations of somatization, depression and anxiety, and with analyses of relations between youth experiences on the one hand and depression and anxiety on the other.

For depression (ever depressive and/or dysthymic) and anxiety (panic, phobias and/or generalized anxiety) DSM-III-R criteria were used. Using a structured questionnaire we assessed illness experiences, deprivation of parental care, abuse (sexual/physical) and other life events before age 19. One hundred six patients were included. Prevalence of somatization in this group was $48 \%$.

The overlap between somatization, depression and anxiety was largely accounted for by 16 patients with a triple problem: somatization and depression and anxiety. Somatization was specifically related to deprivation, depression to other life events. Abuse (prevalence $16 \%$ ) independently predicted psychiatric problems in general (somatization or depression or anxiety). Early youth experiences (before age 12) were the most important.

The high prevalence of triple problems suggested a need to reconsider concepts like somatic anxiety and anxious depression. The specificity of deprivation-somatization and other life events-depression relations indicated that distinct causal mechanisms (in youth) contribute to development of these problems.

We had chosen to conceptualize somatization as a kind of personality trait (Lipowski-definition/SSI-operationalization). However, somatization can be conceptualized as a psychiatric disorder, a symptom of psychiatric disorder, and as somatic complaints too. We had data on three of these four (not on somatization as a symptom of psychiatric disorder) In chapter 6 we have tried to clarify interrelations of these concepts of somatization, relations with manifestations of 
depression and relations with stress (major life events, chronic difficulties and lack of social support). Relations with depression were important because depression too can be defined as a disorder, as a chronic condition resembling a personality trait (dysthymia), and as complaints.

Somatization (SSI) was associated with somatic complaints in the previous week. However, relations between somatization and lifetime depression/ dysthymia, as well as relations between somatic complaints and recent depressive complaints/episode, were stronger. Somatization was related to chronic difficulties and to lack of support from the parents. While support was an independent predictor of somatization, difficulties were not; deprivation in youth explained the bivariate relation. Patients with mild somatization (5-9 complaints) were distinct both from patients without somatization, and from patients with serious $(\geq 10)$ somatization. Somatic complaints generally were unrelated to support, difficulties and events.

We concluded that somatization operationalized according to the SSI is a stable characteristic of a person with origins in youth, that is relevant for present well-being. It is neither a psychiatric disorder, nor a symptom of one, nor can it be equated with somatic complaints. In its mild form it needs attention because of risks of dysthymia and medicalization. Serious somatization is related to frequent depressive episodes.

In chapter 7 we studied whether somatizing patients differed from non-somatizers in their reactions with somatic and psychological complaints to the physical and social context of a specific moment. The answer may give an impression of psychological mechanisms likely to be important in somatization. Context was defined as thoughts, activities, motivation, place, presence of others, perceived support, use of medication or alcohol, daily events and time of day.

Ninety-two patients kept a so-called 'Experience Sampling diary' for a week. They received a wristwatch that signalled them at unexpected moments, up to ten times a day. Each time they filled in a small questionnaire on complaints and contexts that pertained to the moment just before the signal. Complaints were divided in specific somatic complaints, tiredness, negative affectivity and positive affectivity. For each patient, a context-complaint reaction was defined as mean complaints in that context, minus mean complaints not in that context. In total 131 contexts were analyzed.

Somatizing patients felt slightly more tired and had specific somatic complaints somewhat more frequently; differences in contexts were not found. Patients clearly reacted to all domains of contexts. Yet, differences in contextcomplaint reactions between somatizing and non-somatizing patients were not found. With serious somatization or recent depression as criterion variable, however, we did find differences in context-complaint reactions. 
Mild somatization hardly influences daily life in an average week, we concluded. Our results fit a model of mild somatization as a personality trait that is evident only when the person is under stress or ill. More serious forms resemble a personality disorder in this model; maladaptive and inflexible, and thereby more visible in everyday life. Results suggested that the general practitioner may influence prognosis, favourably or unfavourably.

Follow-up data, and the interaction of the somatizing patient with the general practitioner are the subject of chapter 8 . We studied differences between somatizing and non-somatizing patients in subjective well-being, health care utilization, specific health problems and physician-patient communication. In addition, we studied general practitioners' recognition of somatization, and the course of complaints.

Eight and 16 months after the initial interview patients received a set of postal questionnaires (SCL-90, chronic difficulties, major life events, somatic complaints and health care utilization). After each consultation both patient and general practitioner filled in a short questionnaire on reasons for encounter, diagnostic conclusions, gravity of complaints and evaluation of the consultation. At the end of the 16-month follow-up period the general practitioner gave a summary of the medical records and his/her overall assessment on somatizing behaviour and function of complaints.

Somatizing patients reported higher SCL-90 scores, more major life events and more medication in the previous week. A difference in absenteeism or quality of life was not found. Somatizing patients had more diverse reasons for encounter and experienced their complaints as more troublesome than non-somatizers. They had a higher frequency of consultations without compelling somatic reason for encounter. The general practitioners rated somatizing patients about as high as non-somatizers in their overall assessment of difficult ('somatizing") behaviour. The relation between (SSI) somatization and somatization as judged by the general practitioner was not clear. Medicalization decreased in the course of the follow-up. Changes in psychological or somatic complaints were not found.

Differences between somatizing patients and non-somatizers were smaller than we had expected. Somatizing patients seem to function as well as non-somatizers, they (and/or their general practitioners) succeed in controlling medicalization and in maintaining a reasonably good doctor-patient relation, but they feel worse subjectively. Somatization according to the general practitioner seems to mean more 'difficult patient' than (SSI) somatization. The decrease in medicalization after participating in the study is promising for future intervention studies. 
In chapter 9 we have tried to join conclusions of earlier chapters together into a more or less coherent picture of 'the' somatizing patient. Our picture of the somatizing patient is one of a person in strained equilibrium. In his daily functioning (Experience Sampling-data, absenteeism, interaction with the general practitioner) the somatizing patient is almost indistinguishable from the nonsomatizer. However, he reports more symptoms, more stress and is vulnerable, as is evident from his youth experiences and risk of depression and dysthymia.

Some methodological aspects are discussed, particularly our reasons to carry out the study in an 'indicated population' of frequent attenders.

The link between the concept of somatic fixation and somatization as defined in this study is discussed. Probably, there is a large overlap empirically, that is; the definitions label about the same group of patients as somatically fixated / somatizing. In our view, however, somatic fixation is more a theory on a phenomenon (tendency to consult the general practitioner with somatic symptoms) than the phenomenon itself. Our criticism that the phenomenon somatic fixation is difficult to assess reliably, does not apply to the theory. In our view, current theoretical models can be fitted in the general theory of somatic fixation.

For practice we recommend not to overemphasize the importance of somatization, to pay attention to possible somatized depression or anxiety, and to conceptualize somatization as a personality trait. In addition we give some recommendations for further study. 


\section{Hoofdstuk 11}

\section{Samenvatting}

In hoofdstuk 1 wordt het onderwerp van dit proefschrift ingeleid. Met de groei van kennis over gezondheid en ziekte van het menselijk lichaam is somatisatie meer zichtbaar geworden. Het fenomeen 'somatisatie' vestigt de aandacht op wat de medische technologie niet kan: genezing brengen aan diegenen die ziek zijn, maar geen diagnostiseerbare objectieve ziekte hebben. In Nederland is de huisarts in de beste positie om voor somatiserende patiënten te zorgen. Somatisatie was een belangrijk onderwerp van huisartsgeneeskundig onderzoek in de jaren ' 70 . In de jaren ' 80 heeft de huisartsgeneeskunde zich echter meer geconcentreerd op specifieke somatische klachten dan op het algemene probleem somatisatie. Het (merendeels psychiatrische) onderzoek dat sinds 1980 is gedaan naar de kleine groep patiënten met DSM-III somatisatiestoornis roept vragen op over de veel grotere groep patiënten met mildere vormen van somatisatie.

Het doel van onze studie was inzicht te vergroten in de mechanismen waardoor somatiserende patiënten op bepaalde momenten de somatische aspecten van hun onwelbevinden benadrukken. Wij hebben ons gericht op relaties met depressie, angst, stress en jeugdervaringen. De belangrijkste onderzoeksvragen zijn: 1 Wat zijn de relaties tussen somatisatie en depressie, angst, belastende jeugdervaringen, ingrijpende levensgebeurtenissen, chronische moeilijkheden en sociale steun? (Hoofdstuk 5 en 6)

2 Verschillen somatiserende patiënten van niet-somatisanten in hun reacties (wat betreft lichamelijke klachten en stemming) op de fysieke en sociale context van een bepaald moment? (boofdstuk 7)

3 Verschillen somatiserende patiënten van niet-somatisanten in subjectief welbevinden, medische consumptie, specifieke gezondheidsproblemen en artspatiënt communicatie? (hoofdstuk 8)

Het onderzoek is verricht in een 'geïndiceerde populatie': patiënten die vaak de huisarts bezoeken en recidiverende of chronische buik- nek- of rugklachten hebben, dan wel hebben gehad.

In hoofdstuk 2 beschrijven wij een literatuurstudie naar definities van somatisatie geschikt voor huisartsgeneeskundig onderzoek, en naar operationalisaties van deze definities. Een definitie van somatisatie voor huisartsgeneeskundig onderzoek zou ruimer moeten zijn (dus een lagere drempel moeten hebben) dan de psychiatrische definitie van de DSM-III somatisatiestoornis. Een overzicht van de internationale literatuur is verkregen via een search in de Index Medicus. In $80 \%$ van de artike- 
len werd somatisatie gedefinieerd als een psychiatrische stoornis: de DSM-III somatisatiestoornis. In de overige artikelen, die veelal betrekking hadden op onderzoek in de eerstelijn, werd uitgegaan van een continuüm van somatisatie, van een normaal psychologisch mechanisme tot een psychiatrische stoornis.

Somatisatie volgens deze 'continuümdefinities' impliceert dus niet automatisch het etiket 'psychiatrische stoornis'. De definitie van Lipowski is internationaal het meest geaccepteerd: "Een neiging om somatische klachten en symptomen te ervaren en te uiten, die niet worden verklaard door pathologische bevindingen, om deze klachten toe te schrijven aan lichamelijke ziekte, en om medische hulp ervoor te vragen."

Deze continuümdefinities zijn meer geschikt voor huisartsgeneeskundig onderzoek. Een afgezwakte versie van het DSM-III criterium voor somatisatiestoornis (de Somatic Symptom Index of SSI) leek de beste operationalisatie voor huisartsgeneeskundig onderzoek. De SSI stelt als grens 4 klachten (voor mannen) of 6 (voor vrouwen) uit een lijst van 35 veel voorkomende vage klachten. Voor de somatisatiestoornis is de grens 12 , respectievelijk 14 klachten. Onderzoek naar deze lichtere vormen van somatisatie kan profiteren van het vele onderzoek dat is gedaan naar de somatisatiestoornis, als ook theoretisch het verband tussen deze lichtere vormen van somatisatie en de somatisatiestoornis wordt verduidelijkt. Aangezien op as II van de DSM-III naast persoonlijkheidsstoornissen ook persoonlijkheidstrekken (die niet voldoen aan het criterium 'psychiatrische stoornis') kunnen worden gecodeerd, zou dit verband kunnen worden gelegd als de somatisatiestoornis van as I (psychiatrische stoornissen in engere zin) naar deze as II zou worden verplaatst. Empirische gegevens wezen erop dat de somatisatiestoornis goed past op as II.

De bijdrage van het Nederlandse huisartsgeneeskundig onderzoek ontbrak vrijwel geheel in de internationale literatuur. In hoofdstuk 3 hebben wij daarom 19 jaargangen van Huisarts en Wetenschap doorzocht met de vraag of het Nederlands huisartsgeneeskundig onderzoek een beter alternatief bood voor de SSI. Wij vonden de begrippen 'nerveus-functionele klachten' (en in verband daarmee 'somatisatie'), 'somatische fixatie' en 'probleemgedrag'.

Het begrip 'somatische fixatie' was voor patiëntgebonden onderzoek moeilijk te operationaliseren. 'Probleemgedrag' leek een te ruim begrip. De begrippen 'nerveus-functionele klachten' en 'somatisatie' (zoals gebruikt in Huisarts en Wetenschap) sloten goed aan bij de internationale literatuur.

In hoofdstuk 4 worden de resultaten gepresenteerd van de voorstudie naar de prevalentie van somatisatie binnen de beoogde onderzoekspopulatie en naar de constructvaliditeit van de SSI. De constructvaliditeit van de SSI in open populaties was aangetoond, dat wil zeggen; de SSI hangt samen met variabelen die geacht 
worden samen te hangen met het theoretisch begrip somatisatie. Een operationalisatie van somatisatie moet echter ook binnen een populatie met hoge consultfrequentie ('geïndiceerde populatie') een valide onderscheid maken om een nuttig diagnostisch instrument in de huisartsgeneeskunde te kunnen zijn.

Tachtig patiënten uit de huisartspraktijk zijn thuis gë̈nterviewd. Zij waren geselecteerd op leeftijd (20-44 jaar), een voorgeschiedenis van buik-, nek- of rugklachten, en op consultfrequentie: tenminste 12 consulten zonder dwingende somatische reden van komst in de afgelopen drie jaar.

De prevalentie van somatisatie (volgens de SSI) in deze groep was $45 \%$. Vrouwen hadden een tweemaal hoger risico op somatisatie. Een relatie met de leeftijd werd niet gevonden. Somatisatie hing samen met depressieve klachten (relatief risico 2,5) en waarschijnlijk ook met angst. Somatiserende patiënten bezochten vaker de huisarts en hadden meer gezondheidsproblemen (in het bijzonder psychische problemen) dan niet-somatisanten.

Deze bevindingen ondersteunden de validiteit van de SSI. Het onderscheid werd benadrukt tussen deze definitie van somatisatie en somatisatie, gedefinieerd als een symptoom van een psychiatrische stoornis (bijvoorbeeld depressie of angststoornis).

In de volgende twee hoofdstukken wordt een antwoord gegeven op onze eerste vraag. De insluitcriteria voor het hoofdonderzoek waren iets aangescherpt op basis van de resultaten van de voorstudie: 15 consulten in plaats van 12 . In hoofdstuk 5 richten wij ons op de invloed van belastende jeugdervaringen. De analyses van verbanden tussen jeugdervaringen en somatisatie werden aangevuld met analyses van de onderlinge verbanden tussen somatisatie, depressie en angst, en met analyses van de verbanden van jeugdervaringen met depressie en angst.

Voor depressie (ooit depressieve episode of dysthymie) en angst (paniekstoornis, fobieën en/of gegeneraliseerde angststoornis) werden de DSM-III-R criteria gebruikt. Ziekte-ervaringen, gebrek aan ouderlijke zorg, mishandeling (sexueel/lichamelijk) en overige levensgebeurtenissen vóór het $19^{\mathrm{C}}$ jaar werden nagevraagd met een gestructureerd interview. Van 106 patiënten werden gegevens verkregen. De prevalentie van somatisatie in deze groep was $48 \%$.

De overlap van somatisatie, depressie en angst werd grotendeels verklaard door de 16 patiënten met een drievoudig probleem: somatisatie en depressie en angst. Somatisatie hing in het bijzonder samen met gebrek aan ouderlijke zorg, depressie met overige levensgebeurtenissen. Mishandeling (prevalentie $16 \%$ ) was een onafhankelijke voorspeller van psychische problemen in het algemeen (somatisatie of depressie of angst). Vroege jeugdervaringen (voor het twaalfde levensjaar) waren het meest belangrijk. 
De hoge prevalentie van drievoudige problemen suggereerde dat concepten als gesomatiseerde angst en angstige depressie opnieuw moeten worden bezien. De specificiteit van de relaties tussen gebrek aan ouderlijke zorg en somatisatie, en tussen overige levensgebeurtenissen en depressie, wees erop dat verschillende causale mechanismen (in de jeugd) bijdragen an het ontstaan van deze problemen.

Wij hebben gekozen om somatisatie op te vatten als een soort persoonlijkheidstrek (Lipowski-definitie/SSI-operationalisatie). Somatisatie kan echter ook worden opgevat als een psychiatrische stoornis (somatisatiestoornis), als een symptoom van een andere psychiatrische stoornis, of als lichamelijke klachten op zich. Wij hadden gegevens over drie van deze vier (niet over somatisatie als symptoom van een andere psychiatrische stoornis). In hoofdstuk 6 hebben wij geprobeerd om inzicht te verkrijgen in de onderlinge verbanden tussen deze opvattingen van somatisatie, in verbanden met verschillende vormen van depressie, en in verbanden met stress (ingrijpende levensgebeurtenissen, chronische moeilijkheden en gebrek aan sociale steun). Verbanden met depressie waren van belang omdat ook depressie kan worden gedefinieerd als een stoornis, als een chronische toestand die op een persoonlijkheidstrek lijkt (dysthymie), en als depressieve klachten op zich.

Somatisatie (SSI) hing samen met somatische klachten in de voorafgaande week. De verbanden tussen somatisatie en depressie (ooit) of dysthymie, en tussen somatische klachten en recente depressieve klachten of -episode waren echter sterker. Somatisatie hing samen met chronische moeilijkheden en (gebrek aan) steun van de ouders. Steun was een onafhankelijke voorspeller van somatisatie, moeilijkheden echter niet; het verband werd verklaard door gebrek aan ouderlijke zorg in de jeugd. Patiënten met lichte somatisatie (5-9 klachten) verschilden zowel van patiënten zonder somatisatie, als van patiënten met ernstige $(\geq 10)$ somatisatie. Somatische klachten hingen niet of nauwelijks samen met steun, moeilijkheden of levensgebeurtenissen.

Wij concludeerden dat somatisatie geoperationaliseerd volgens de SSI een stabiel kenmerk is van een persoon met een oorsprong in de jeugd, en dat somatisatie van belang is voor het huidig welbevinden. Het is geen psychiatrische stoornis, noch een symptoom van een stoornis, noch kan het worden gelijkgesteld aan somatische klachten. Voor lichte vormen van somatisatie is aandacht nodig vanwege de risico's op dysthymie en medicalisering. Ernstige somatisatie hangt samen met herhaalde depressieve episodes.

Hoofdstuk 7 gaat over de vraag of somatiserende patiënten verschillen van nietsomatisanten in hun reacties (met lichamelijke of psychische klachten) op de context van een bepaald moment. Het antwoord op deze vraag kan een indruk geven van psychologische mechanismen die mogelijk van belang zijn in somatisatie. Context werd gedefinieerd als gedachten, activiteiten, motivatie, plaats, 


\section{Samenvatting}

aanwezigheid van anderen, ervaren steun, gebruik van medicijnen of alcohol, dagelijkse levensgebeurtenissen en het tijdstip van de dag.

Een zogenaamd 'Experience Sampling dagboek' werd bijgehouden door 92 patiënten. $\mathrm{Zij}$ kregen een horloge dat op onverwachte momenten, tot tien keer per dag, een geluidssignaal gaf. Elke keer vulden zij een vragenlijstje in over klachten en de context, dat betrekking had op het moment vlak vóór het signaal. Klachten werden onderverdeeld in specifieke lichamelijke klachten, moeheid, negatieve affectiviteit en positieve affectiviteit. Per patiënt werd een context-klacht reactie gedefinieerd als het gemiddelde klachtniveau in die context, minus het gemiddeld klachtniveau wanneer hij/zij niet in die context was. In totaal werden 131 contexten geanalyseerd.

Somatiserende patiënten voelden zich iets meer vermoeid en hadden iets vaker lichamelijke klachten. Verschillen in contexten vonden wij niet. De patienten reageerden duidelijk op de contexten. Maar verschillen tussen somatiserende patiënten en niet-somatisanten in deze context-klacht reacties vonden wij niet. Met ernstige somatisatie of recente depressie als criteriumvariabele vonden we wèl verschillen in context-klacht reacties.

Onze conclusie was dat lichte somatisatie nauwelijks invloed heeft op het dagelijks leven in een gemiddelde week. Onze bevindingen passen in een model van lichte somatisatie als een persoonlijkheidstrek, die slechts tot uiting komt wanneer de persoon onder stress staat of ziek is. Ernstiger vormen lijken in dit model meer op een persoonlijkheidsstoornis; onaangepast en star, en daarmee meer zichtbaar in het gewone leven. De resultaten suggereren dat de huisarts invloed kan hebben op de prognose, ten goede of ten kwade.

De gegevens uit de follow-up en over de interactie van de somatiserende patiënt met de huisarts zijn het onderwerp van hoofdstuk 8 . Wij bestudeerden verschillen tussen somatiserende en niet-somatiserende patiënten in subjectief welbevinden, medische consumptie, specifieke gezondheidsproblemen en de arts-patiënt communicatie. Verder hebben wij gekeken naar herkenning van somatisatie door de huisarts en naar het beloop van de klachten.

Acht en 16 maanden na het initiële interview kregen de patiënten een aantal vragenlijsten toegestuurd (SCL-90, chronische moeilijkheden, ingrijpende levensgebeurtenissen, lichamelijke klachten en medische consumptie). Na ieder consult vulden de patiënt en de huisarts ieder een kort vragenlijstje in over redenen van komst, diagnose, ernst van de klachten en evaluatie van het consult. Aan het eind van de follow-up periode gaf de huisarts een samenvatting van de medische gegevens en zijn algemeen oordeel over somatiserend gedrag van de patiënt en over de functie van de klachten. 
Somatiserende patiënten hadden hogere SCL-90 scores, meer levensgebeurtenissen en gebruikten meer medicijnen in de voorafgaande week. Een verschil in ziekteverzuim of kwaliteit van leven werd niet gevonden. Somatiserende patiënten hadden meer diverse redenen van komst en ervoeren hun klachten als ernstiger dan niet-somatisanten. $\mathrm{Zij}$ hadden meer consulten zonder dwingende somatische reden van komst. In hun algemeen oordeel over moeilijk ('somatiserend') gedrag beoordeelden de huisartsen somatiserende patiënten ongeveer hetzelfde als nietsomatisanten. Het verband tussen (SSI) somatisatie en somatisatie naar het oordeel van de huisarts was niet duidelijk. Medicalisering nam af in de loop van de follow-up. Veranderingen in psychische of somatische klachten werden niet gevonden.

De verschillen tussen somatiserende patiënten en niet-somatisanten waren kleiner dan wij hadden verwacht. Somatiserende patiënten lijken even goed te functioneren als niet-somatisanten en zij (en/of hun huisartsen) slagen erin medicalisering te beperken en de arts-patiëntrelatie redelijk goed te houden. Somatiserende patiënten voelen zich echter slechter. Somatisatie naar het oordeel van de huisarts lijkt meer 'moeilijke patiënt' te betekenen dan (SSI) somatisatie. De afname van medicalisering na deelname aan de studie biedt perspectieven voor interventiestudies.

In hoofdstuk 9 hebben wij geprobeerd de conclusies van de eerdere hoofdstukken met elkaar in verband te brengen en een beeld te schetsen van 'de' somatiserende patiënt. Ons beeld van de somatiserende patiënt is dat van iemand in belast evenwicht. In zijn dagelijks functioneren (Experience Sampling-gegevens, ziekteverzuim, interactie met de huisarts) is hij nauwelijks te onderscheiden van de nietsomatisant. Maar hij rapporteert meer klachten, meer stress, en is kwetsbaar, zoals blijkt uit zijn jeugdervaringen en de prevalentie van depressie en dysthymie.

Enkele methodologische aspecten worden besproken, met name onze redenen om het onderzoek uit te voeren in een 'gë̈ndiceerde populatie' van patiënten met hoge consultfrequentie.

De relatie tussen het begrip somatische fixatie en somatisatie zoals gedefinieerd in dit onderzoek wordt besproken. Waarschijnlijk is er een grote overlap op empirisch niveau, dat wil zeggen; bestempelen beide definities ongeveer dezelfde groep patiënten als somatiserend / somatisch gefixeerd. Naar onze mening is somatische fixatie echter meer een theorie over een verschijnsel (neiging om met lichamelijk klachten naar de huisarts te gaan) dan het verschijnsel op zich. Onze kritiek dat het verschijnsel somatische fixatie moeilijk betrouwbaar te meten is, geldt uiteraard niet voor de theorie. Ons inziens kunnen tegenwoordige theoretische modellen goed binnen de algemene theorie van somatische fixatie worden ondergebracht. 


\section{Samenvatting}

Voor de praktijk bevelen wij aan het belang van somatisatie niet te overdrijven, te letten op mogelijke onderliggende depressie of angststoornis, en uit te gaan van een model van somatisatie als een persoonlijkheidstrek. Verder geven wij enige aanbevelingen voor verder onderzoek. 
Hoofdstuk 11

176 


\section{Dankwoord}

Velen hebben bijgedragen aan dit proefschrift. Ik wil allen daarvoor bedanken. In de eerste plaats gaat mijn dank uit naar de deelnemende patiënten. $\mathrm{Zij}_{\mathrm{ij}}$ hebben de tijd genomen voor twee lange gesprekken met ons, zich ingezet door een week lang onze Experience Sampling-vragenlijsten in te vullen, en ons hun vertrouwen geschonken door in te gaan op soms pijnlijke vragen. En dat voor een onderzoek dat niet ging over klachten waar zij (al dan niet op dat moment) mee zaten, maar over de manier waarop zij omgingen met klachten in het algemeen, of met hun dagelijks leven.

De deelnemende RNH-huisartsen van de Gezondheidscentra Heer, Hoensbroek Noord en Withuis, de groepspraktijken Eussen/Ypma/Stuurman, Eygelshoven, Govaert/Leclerc en Soomers en de huisartspraktijken Höppener en van der Ploeg wil ik bedanken voor hun inzet en enthousiasme. Het onderzoek heeft hen meer tijd gekost dan wij vooraf hadden voorgespiegeld. Zij hebben in een gezondheidszorgsituatie die weinig ruimte biedt voor andere prioriteiten, toch de tijd gevonden voor onze vragenlijsten. En dat deden zij terwijl andere onderzoeken in hun praktijk liepen, nog moesten worden afgerond, of op het punt stonden te beginnen. Ik heb begrepen dat zij bij tijde en wijle flink achter de vodden zijn gezeten door hun praktijkassistentes om alle lijsten in te vullen, maar dat doet niets af aan mijn dank. Wel wil ik deze praktijkassistentes speciaal hiervoor bedanken. Zij hebben ervoor gezorgd dat het onderzoek 'liep' in de praktijken en dat de vragen van de patiënten beantwoord werden, naast alle administratieve taken voor het onderzoek.

Ireen Proot, als onderzoeksassistente aan het project verbonden, heeft het merendeel van de interviews gedaan. Een groot deel van de praktische organisatie lag in haar handen (zij vormde ook de schakel tussen de praktijkassistentes en de projectgroep). Elke fase van het onderzoek droeg zij bij met haar zorgvuldig en kritisch commentaar. Ik dank haar voor haar inzet en voor de betrokkenheid bij de deelnemende patiënten en bij het onderwerp somatisatie. Nicole Gunther en Jeanine Kuypers hebben een deel van het interviewen van mij overgenomen, waarvoor dank.

De thuisbasis van het onderzoek was de sectie Sociale Psychiatrie en Psychiatrische Epidemiologie van de vakgroep Psychiatrie en Neuropsychologie Binnen het STEP-project vormden wij samen met onderzoeken naar angst en depressie het SAD cluster. Ik bewaar goede herinneringen aan het werkoverleg op de woensdagmorgen, en dank de mensen die mij daarin met raad en daad hebben bijgestaan: Leny Meertens, Chantal Dijkman, Germie van der Berg, Marcel Hilwig, Maaike Luxembourg en Diana Riksen. Felici Jeuken heeft in het kader van haar wetenschapsstage de gegevens over jeugdervaringen geanalyseerd en daar 
een heel mooi verslag van geschreven. Haar werk is de basis geweest voor hoofdstuk 5. Dika Luyendijk heeft als student-assistente de gegevens over de belangrijkste klacht van de patiënten gecodeerd. Ik had niet meer de tijd om haar werk mee te nemen in dit proefschrift, maar het komt nog wel.

Marten deVries en Philippe Delespaul hebben het Experience Sampling protocol ontwikkeld waarvan wij in hoofdstuk 7 gebruik hebben gemaakt. Ook de Experience Sampling vragenlijst was gebaseerd op hun werk. Verder hebben Nancy Nicholson en Marleen van Eck bijgedragen aan dit deel. Truda Driesen van Frida van Goethem hebben de grote hoeveelheid Experience Sampling gegevens ingevoerd in de computer. Gertie Wijnands en haar medewerkers deden de controle-invoer. Voor de invoer van de overige gegevens dank ik Elly Meij.

De vakgroep huisartsgeneeskunde fungeerde als thuisbasis wat betreft de uitvoering van onderzoek in de huisartspraktijk en epidemiologische methoden en technieken. De belangrijkste bijdrage van mijn collega's van huisartsgeneeskunde echter lag op het inhoudelijke vlak; als resultaten van dit onderzoek interessant zijn voor huisartsen, en bruikbaar is in de huisartspraktijk, dan is dat voor een groot deel te danken aan de discussies in de researchgroep en inhoudelijke bespreking en aan het commentaar van mijn (ex-)kamergenoten: Michiel Cornel, Jan-Willem de Jonge, Victor Kaiser, Jelle Stoffers en George Wolfs.

$\mathrm{Om}$ het onderzoek in de $\mathrm{RNH}$-praktijken te kunnen uitvoeren was toestemming nodig van de RNH-toetsingscommissie, naast André Knottnerus bestaande uit Charles Limonard, Martijn van Nunen, Job Metsemakers en GeertJan van Schendel. Ik dank hen voor het in mij gestelde vertrouwen. De RNHgegevens waren nodig om de patiënten te kunnen selecteren en zijn inhoudelijk geanalyseerd in hoofdstuk 4.

Het begon allemaal met een idee van Marten deVries voor een huisartsonderzoeker in opleiding. Daarna hadden Herro kraan, André Knottnerus en Edward Steur voldoende vertrouwen in mij om me in staat te stellen het onderzoeksvoorstel uit te werken dat tot dit proefschrift heeft geleid. André en Herro dank ik voor de maier waarop zij hun projectleiderschap hebben ingevuld: conscientieus, betrokken en geduldig. Ik heb veel van hen geleerd. Dat geldt ook voor Frans van der Horst, met zijn aanstekelijk enthousiasme. Verder had ik hier graag They Lemmens willen bedanken. They overleed voordat de dataverzameling van start ging. $\mathrm{Zijn}$ grote ervaring als praktiserend huisarts en visie op somatisatie hebben me veel geholpen.

Mijn collega's van de sectie Sociale Psychiatrie en Psychiatrische Epidemiologie, en die van de vierde verdieping in het bijzonder, en van de vakgroep Huisartsgeneeskunde bedank ik voor hun belangstelling, de gezelligheid bij de koffie en voor hun morele steun. Werken aan een proefschrift schijnt een eenzame bezigheid te zijn, maar dat heb ik nooit gemerkt. 
Jan van Dongen en later Frank Tummers gaven als huisarts-gastheer mij de ruimte om in hun praktijk mijn ideeën over de omgang met somatiserende patiënten verder te ontwikkelen. $\mathrm{Zij}$ makten het mij mogelijk veel tijd en energie in het onderzoek te steken. Ik ben hen dankbaar daarvoor.

Toen ik op het laatst in tijdnood kwam, hebben Frans-Jan Hulsmans, Pascale Heuts en Beppie Hellemons de hoofdstukken 2 en 3 voor me vertaald. Bob Wilkinson heeft de meeste hoofdstukken gecorrigeerd op het engels. En Margreet Jansen hielp met de lay-out.

Van mijn thuisfront kreeg ik kritisch commentaar over de excuusfunctie van een dankwoord. Ik zal daarom mijn dank op een andere manier uiten. Maar mijn paranimfen, Frans-Jan Hulsmans en Hanna Wierts wil ik hier toch even noemen. 


\section{Curriculum Vitae}

Piet Portegijs was born on march $30^{\text {th }} 1958$ in 't Zand (province of Northern Holland), the Netherlands. He grew up on the small farm of his father as one of the eldests of six children. From 1970 till 1976 he received his secondary education at the Johannes College in Den Helder. He studied medicine at the University of Limburg (which recently changed her name in 'Universiteit Maastricht') from 1976 till 1983.

During his vocational training (Department of General Practice of the University of Limburg, 1985-1986) he worked as GP trainee in the practice of Tom Nieuwenhuis in Heerlen. Before that he worked as scientific assistant for evaluation of the GP vocational training programme, for the Maastricht Institute for Health Ethics, and for the experimental GP research training of the University of Limburg. After his vocational training he entered the one-year GP research training, combining this with part-time work as a GP. As a sequel to the small study that was performed as part of this training at the Department of Social Psychiatry, he wrote under the guidance of Herro Kraan and André Knottnerus the study proposal for the present study. He received a grant from the Netherlands Organization for Scientific Research Council for Medical Research as part of the Incentive Fund Programme for General Practice Research to work on the study (1989-1994). The study was performed in collaboration of the Departments of Social Psychiatry and General Practice. From 1990 till 1994 he combined working on the study with part-time work as a GP in the practices of Jan van Dongen (America, Limburg) and Frank Tummers (Tegelen, Limburg). Since 1995 he combines research work with undergraduate teaching. He lives together with Anita Botterweck (who preferred not to be mentioned in the 'dankwoord'). 


\title{
Somatization in frequent attenders of general practice: Determinants, psychiatric problems, consequences for everyday life and health care utilization
}

\author{
Piet J. M. Portegijs
}

Illness without disease, or somatization, is a difficult problem within a primarily somatically oriented health care system. The term somatization covers a range of phenomena, from a situationally determined reaction that most of us have had to a chronic, disabling psychiatric disorder with low prevalence. In this thesis somatization is defined somewhere in between, as a personality trait. These patients are the most important within the health care system. The thesis deals with an exploratory study on somatization in frequent attenders of general practice. Results thus suggest whether the somatization concept distinguishes meaningfully witbin this 'indicated population'.

Somatization was strongly related to deprivation of parental care in youth. Somatizing patients reported more somatic complaints in the previous week and more stress than nonsomatizing frequent attenders. Somatization was clearly related to lifetime depressive disorder and dysthymia (chronic, mild depression), but not directly to anxiery disorders. Somatizing patients were very similar to non-somatizers in their reactions (with somatic complaints or mood) to situations and events of everyday life. Somatization was not visible in specific reasons for encounter, nor in the evaluation of the physician-patient communication. However, somatizing patients consulted more frequently and used more medication.

From the stidy emerges a picture of the typical somatizing patient as being in strained equilibrium; he or she does not differ from the non-somatizer in his or her daily functioning, but feels worse subjectively and has increased risks of depression or dysthỵmia.

The study was carried out at the Section of Social Psychiatry and Psychiatric Epidemiology (Department of Psychiatry and Neuropsychology) and at the Departiment of General Practice of the Universiteit Maastricht. Piet Portegijs is general practitioner and combines research with undergraduate teaching. 